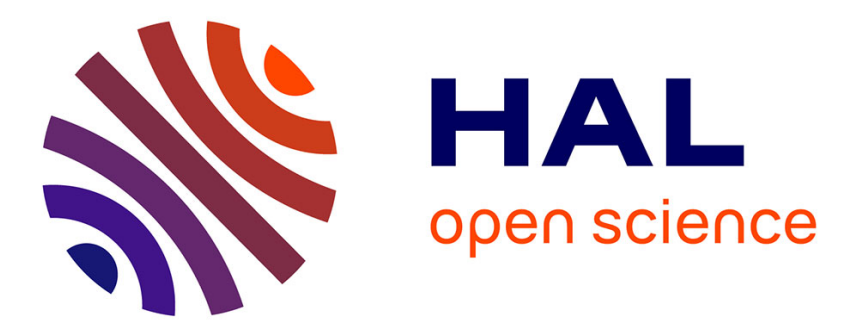

\title{
A consistency test for $\alpha$-functions of cubic equations of state
}

Yohann Le Guennec, Silvia Lasala, Romain Privat, Jean-Noël Jaubert

\section{To cite this version:}

Yohann Le Guennec, Silvia Lasala, Romain Privat, Jean-Noël Jaubert. A consistency test for $\alpha$-functions of cubic equations of state. Fluid Phase Equilibria, 2016, 427, pp.513-538. 10.1016/j.fluid.2016.07.026 . hal-01413873

\section{HAL Id: hal-01413873 https://hal.science/hal-01413873}

Submitted on 25 Jan 2017

HAL is a multi-disciplinary open access archive for the deposit and dissemination of scientific research documents, whether they are published or not. The documents may come from teaching and research institutions in France or abroad, or from public or private research centers.
L'archive ouverte pluridisciplinaire HAL, est destinée au dépôt et à la diffusion de documents scientifiques de niveau recherche, publiés ou non, émanant des établissements d'enseignement et de recherche français ou étrangers, des laboratoires publics ou privés.

$$
\text { Copyright }
$$




\title{
A consistency test for $\alpha$-functions of cubic equations of state
}

\author{
Yohann LE GUENNEC, Silvia LASALA, Romain PRIVAT and Jean-Noël JAUBERT ${ }^{(*)}$ \\ Université de Lorraine, École Nationale Supérieure des Industries Chimiques, \\ Laboratoire Réactions et Génie des Procédés (UMR CNRS 7274) \\ 1 rue Grandville, 54000 Nancy, France.
}

\section{E-mail: jean-noel.jaubert@univ-lorraine.fr}

$\left(^{*}\right)$ author to whom the correspondence should be addressed.

\section{Highlights}

1) A consistency test for $\alpha$-functions is derived.

2) $\alpha$-functions must be positive, decreasing, convex with negative third derivative.

3) VLE data solely shape the $\alpha$-function in the subcritical domain, not beyond.

4) $\alpha$-functions should pass this test to safely extrapolate to the supercritical domain.

5) No $\alpha$-function from the literature passes the proposed consistency test.

\begin{abstract}
This study highlights that $\alpha$-functions used in cubic equations of state must be of class $C^{2}$ i.e. that their first $(\mathrm{d} \alpha / \mathrm{dT})$ and second $\left(\mathrm{d}^{2} \alpha / \mathrm{dT}^{2}\right)$ derivatives must exist and must be continuous, positive $(\alpha>0)$, monotonically decreasing $(\mathrm{d} \alpha / \mathrm{dT}<0)$, convex $\left(\mathrm{d}^{2} \alpha / \mathrm{dT}^{2}>0\right)$ and also verify $\mathrm{d}^{3} \alpha / \mathrm{dT}^{3}<0$, for any value of the temperature T. Our proposed "consistency test for $\alpha$ functions" gathers all these conditions. The non-respect of one of them can entail low-accuracy prediction of binary phase diagrams involving at least one supercritical compound (this statement is illustrated through the case-studies of the $\mathrm{CO}_{2}$-argon and $\mathrm{CO}_{2}$-decane systems) as well as improper variations of pure-component supercritical properties $\left(h\right.$ and $\left.c_{P}\right)$ with respect to the temperature. Finally, an extensive study of the mostly used $\alpha$-functions described in the open literature is performed and shows that all of them fail this test. Some component-dependent $\alpha$-functions may however pass this test but only if mathematical constraints are added to their parameters.
\end{abstract}

A consistency test for $\alpha$-functions of cubic equations of state 


\section{Graphical abstract}

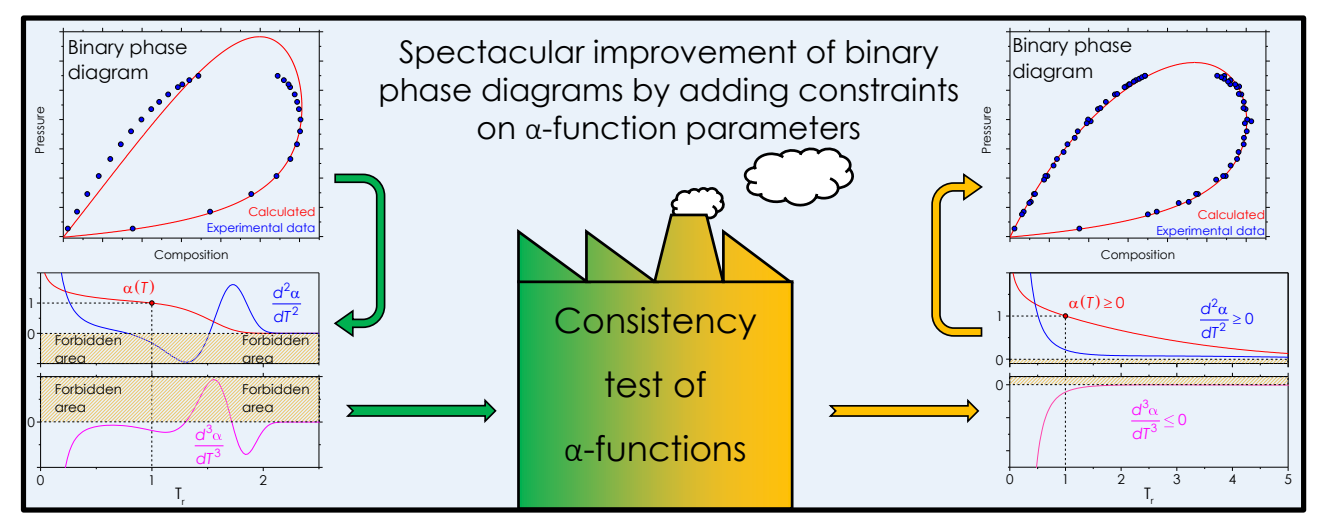

\section{Keywords}

Alpha-function; Equation of state; Consistency test; Soave; Twu

\section{Introduction}

Numerous modifications to the Van der Waals cubic equation of state (CEoS) have been presented over the years [1], with the aim of representing with increasingly accuracy the properties of complex systems. As a matter of facts, most of these improvements do not incorporate a substantial difference in the functional combination of attractive and repulsive forces, with respect to the original formulation introduced by Van der Waals. As a rare exception, let us mention the Cubic-Plus-Association model (CPA) [2], which combines the Soave-Redlich-Kwong attractive and repulsive terms [3] with an association term introduced by Wertheim [4]. Indeed, analogously to the Van der Waals expression of the pressure equation [5], a generic CEoS may be written as the sum of a repulsive and an attractive term:

$$
\mathrm{P}=\mathrm{P}_{\text {rep }}+\mathrm{P}_{\text {att }}
$$

Although the analytical expressions of the repulsive and attractive terms proposed in literature do not correctly quantify the actual repulsive and attractive contributions to pressure, their sum results in a quantitative representation of fluid properties being sufficiently accurate to make their combination the "cornerstone of the generalized Van der Waals theory" [6].

Since the Van der Waals proposal, even the most successful two-parameter CEoS still expresses their attractive and repulsive terms by introducing a parameter $a$ which is a measure of the attractive forces ("energy parameter") between molecules, and a parameter $b$ which is a 
measure of the size ("intrinsic volume" or "co-volume") of the molecules. It results the general formulation of a two-parameter CEoS:

$$
P(T, v)=\frac{R T}{v-b}+\frac{-a(T)}{\left(v-r_{1} b\right)\left(v-r_{2} b\right)}
$$

where $r_{1}$ and $r_{2}$ are two universal constants which depend on the selected CEoS.

The most successful theoretically-based modification to the Van der Waals CEoS consisted in the recognition by Clausius in 1879 [7] of the temperature-dependency of the energy parameter. In 1949, Redlich and Kwong [8] proposed the first temperature-dependent formulation which resulted to be sufficiently accurate to gain popularity in the industry. Starting from this outcome, many researches have been focused on the improvement of the functional form of this term, which soon proved to strongly affect the modelling capability of a CEoS in fluid equilibrium calculations. The attractive term of any CEoS can be written as:

$$
\mathrm{a}(\mathrm{T})=\mathrm{a}_{\mathrm{c}} \cdot \alpha(\mathrm{T})
$$

i.e. as the product of the value of the attractive term at the critical temperature $\left(a_{c}\right)$ multiplied by a so-called $\alpha$-function. Such $\alpha$-functions have a strong impact on the accuracy of CEoS and must be selected with caution. Not only the properties of pure compounds in the supercritical region are highly affected by the mathematical expression of the $\alpha$-function but also the vaporliquid equilibrium calculations of multicomponent systems. From our experience, when applied to mixtures, the accuracy of CEoS is equally affected by the choice of the mixing rules and by the expression of the $\alpha$-function.

The first aim of this paper is thus to present the requirements that an $\alpha$-function should absolutely fulfil in order to guarantee safe predictions of the vapor-liquid equilibrium and of derived thermodynamic properties at all temperatures. Emphasis will be made on the incapacity of $\alpha$-functions regressed on subcritical properties to correctly extrapolate in the supercritical temperature domain without addition of supplementary constraints during the regression procedure. Such constraints ensure, among others, the proper curvature of the $\alpha$-function. Similarly to the consistency tests developed to certify the quality of experimental vapor-liquid equilibrium data, it is proposed to develop a consistency test for $\alpha$-functions, i.e., to derive a list of consistent constraints applicable to any $\alpha$-function. Such a test aims at identifying which $\alpha$-functions are (or not) thermodynamically consistent and should (or not) be used. In this paper, this consistency test will be applied to twelve $\alpha$-functions issued from the literature. 


\section{Definition, historical background and general classification of the $\alpha$-functions}

\subsection{Definition of the $\alpha$-function}

As for the original Van der Waals equation of state, the critical attractive parameter $\left(a_{c}\right)$, the covolume (b) and the critical molar volume $\left(\mathrm{v}_{\mathrm{c}}\right)$ of any CEoS can be determined by applying the so-called critical constraints:

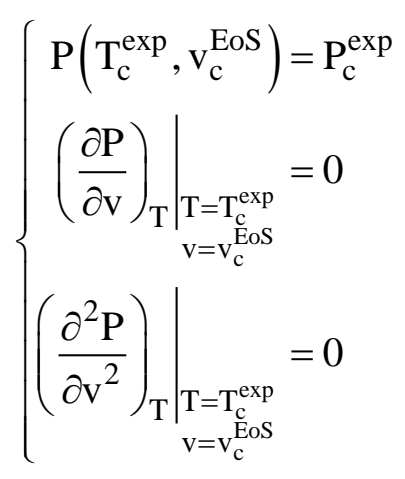

where $\mathrm{T}_{\mathrm{c}}^{\exp }$ and $\mathrm{P}_{\mathrm{c}}^{\mathrm{exp}}$ are the experimental critical temperature and pressure and where the critical molar volume $\left(v_{c}^{E o S}\right)$ is calculated by solving the CEoS under the conditions $T=T_{c}^{\exp }$ and $\mathrm{P}=\mathrm{P}_{\mathrm{c}}^{\exp }$. The resulting critical energy parameter $\left(\mathrm{a}_{\mathrm{c}}\right)$ and covolume $(\mathrm{b})$ are usually expressed in terms of the CEoS-dependent coefficients $\Omega_{\mathrm{a}}$ and $\Omega_{\mathrm{b}}$ :

$$
\left\{\begin{array}{l}
a_{c}=\Omega_{a} \frac{R^{2}\left(T_{c}^{\exp }\right)^{2}}{P_{c}^{\exp }} \\
b=\Omega_{b} \frac{R_{c}^{\exp }}{P_{c}^{\exp }}
\end{array}\right.
$$

While a covolume is necessarily temperature-independent [9], the energy parameter a $(\mathrm{T})$ is written as the product of its value at the critical point, $a_{c}$, and of a temperature-dependent $\alpha$ function:

$$
\mathrm{a}(\mathrm{T})=\mathrm{a}_{\mathrm{c}} \cdot \alpha(\mathrm{T})
$$

Doing so, it follows that $\alpha(\mathrm{T})$ is a non-dimensional factor which becomes unity at the critical temperature

$$
\alpha\left(\mathrm{T}_{\mathrm{c}}\right)=1
$$


Therefore, $\alpha$-function should be considered as a deviation factor of the energy parameter of a $\mathrm{CEOS}$ to its value at the critical temperature.

\subsection{Historical background and general classification of the $\alpha$-functions}

One of the most influential contributions in the prediction of vapor pressures of non-polar and slightly polar pure compounds has been the introduction in 1972 of the Soave $\alpha$-function [3]. Over the years, further modifications have been introduced to this functional form, mainly aimed at improving the correlation of vapor pressures. Higher accuracy was achieved by the addition of more parameters [10], [11] but as stated by Poling et al. [12], most of the $\alpha$-functions presented in literature have been developed without evaluating their predictive capability in the supercritical domain. Indeed, the Soave $\alpha$-function diverges at very high temperature, leading to unrealistic calculations of thermodynamic properties. Therefore, $\alpha$-functions inspired by the Soave formulation, called polynomial $\alpha$-functions as they are polynomials of the square-root of the reduced temperature, should not be used at high reduced temperature. To overcome this limitation, some authors proposed exponential $\alpha$-functions [13-17] which are positive and decreasing functions on the whole temperature range.

Aware of the benefits of using a polynomial $\alpha$-function in the subcritical temperature domain and using an exponential $\alpha$-function in the supercritical temperature domain, some authors proposed piecewise $\alpha$-functions with different mathematical expressions for the $\alpha$-function depending on whether the temperature is above or below the critical temperature, leading to possible discontinuities of the $\alpha$-function derivatives at the critical temperature. Although this approach seems to be a good compromise between the complexity of the $\alpha$-function expression and the accuracy of results, it was objected by Coquelet et al. [18] that continuity of the first and second derivatives of the $\alpha$-function at the critical temperature must be enforced. If not, calculated residual enthalpies and heat capacities show discontinuities at the critical temperature. This abnormal behavior of the piecewise $\alpha$-functions was also highlighted by Boston et al. [19], Twu et al. [16,17] when they respectively proposed their own $\alpha$-functions and deeply analyzed by Neau et al. [20,21].

As reported by Valderrama [1], numerous $\alpha$-functions can be found in the literature and are compared in some recent papers [22,23]. Enumerating all the existing $\alpha$-functions is not of practical interest as only a dozen of them are used in the commercial process simulation software. Therefore, a general classification of the $\alpha$-functions based on their mathematical form (polynomial or exponential) and on the unicity of their formulation (T-overall formulation

A consistency test for $\alpha$-functions of cubic equations of state 
or piecewise) is presented in Table 1 . Moreover, we found desirable to distinguish two kinds of $\alpha$-functions: component-dependent $\alpha$-functions and generalized ones. Parameters of component dependent $\alpha$-functions have to be regressed, component by component, on experimental data while coefficients of generalized $\alpha$-functions are determined with correlations needing the acentric factor $(\omega)$ as input parameter. Therefore, generalized $\alpha$ functions can be applied to pure compounds for which no experimental vapor-liquid equilibrium data, except $\omega$, are known. This advantage is counterbalanced by a less accurate prediction of the thermodynamic properties.

In the rest of the article, emphasis will be made on two $\alpha$-functions having a T-overall formulation: the model proposed by Soave (1972) (from now on, called Soave) and the one introduced by Twu (1991) (from now on, called Twu91). Their expressions are reported below.

- The Soave $\alpha$-function [3]

$$
\begin{cases}\alpha\left(T_{r}\right)=\left[1+m(\omega)\left(1-\sqrt{T_{r}}\right)\right]^{2} & \\ m(\omega)=0.480+1.574 \omega-0.176 \omega^{2} & \text { for the Redlich-Kwong CEoS } \\ m(\omega)=0.37464+1.54226 \omega-0.26992 \omega^{2} & \text { for the Peng-Robinson CEoS }\end{cases}
$$

This $\alpha$-function is polynomial, generalized and it has a T-overall formulation. Having regard to its simplicity and to the accuracy of results obtained by using it, this $\alpha$-function should be regarded as a reference before deriving any new $\alpha$-function. These reasons justify, in fact, its widespread popularity.

- The Twu91 $\alpha$-function [15]

$$
\alpha\left(\mathrm{T}_{\mathrm{r}}\right)=\mathrm{T}_{\mathrm{r}}^{\mathrm{N}(\mathrm{M}-1)} \exp \left[\mathrm{L}\left(1-\mathrm{T}_{\mathrm{r}}^{\mathrm{MN}}\right)\right]
$$

This $\alpha$-function is exponential, component-specific and it has a T-overall formulation. Parameters L, M and $\mathrm{N}$ have to be optimized, component by component, over experimental data so that better accuracy is expected in comparison to the Soave $\alpha$-function. 


\section{Component-dependent $\alpha$-functions}

\begin{tabular}{|c|c|c|}
\hline & $\begin{array}{c}\text { T-overall formulation } \\
\text { (unique temperature formulation) }\end{array}$ & Piecewise \\
\hline \multirow[t]{2}{*}{ Polynomial } & $\begin{array}{l}\text { Soave (1984) [24] } \\
\alpha=1+\left(1-\mathrm{T}_{\mathrm{r}}\right)\left(\mathrm{a}+\frac{\mathrm{b}}{\mathrm{T}_{\mathrm{r}}}\right)\end{array}$ & $\begin{array}{l}\text { Stryjek-Vera }[11] \\
\alpha=\left[1+\kappa\left(1-\sqrt{T_{\mathrm{r}}}\right)\right]^{2} \\
\kappa=\kappa_{0}+\kappa_{1}\left(1+\sqrt{\mathrm{T}_{\mathrm{r}}}\right)\left(0.7-\mathrm{T}_{\mathrm{r}}\right) \\
\kappa_{0}=0.378893+1.4897153 \omega-0.17131848 \omega^{2}+0.0196554 \omega^{3} \\
\left\{\begin{array}{l}\kappa_{1}\left(\mathrm{~T} \leq 0.7 \mathrm{~T}_{\mathrm{c}}\right) \neq 0 \\
\kappa_{1}\left(\mathrm{~T}>0.7 \mathrm{~T}_{\mathrm{c}}\right)=0\end{array}\right.\end{array}$ \\
\hline & $\begin{array}{l}\text { Gibbons-Laughton [25] } \\
\alpha=1+\mathrm{X}\left(\mathrm{T}_{\mathrm{r}}-1\right)+\mathrm{Y}\left(\sqrt{\mathrm{T}_{\mathrm{r}}}-1\right)\end{array}$ & $\begin{array}{l}\text { Mathias-Copeman }[10] \\
\alpha_{\text {SUB }}=\alpha\left(T_{r} \leq 1\right)=\left[\begin{array}{l}1+c_{1}\left(1-\sqrt{T_{r}}\right)+c_{2}\left(1-\sqrt{T_{r}}\right)^{2} \\
+c_{3}\left(1-\sqrt{T_{r}}\right)^{3}\end{array}\right]^{2} \\
\alpha_{\text {SUP }}=\alpha\left(T_{r} \geq 1\right)=\left[1+m\left(1-\sqrt{T_{r}}\right)\right]^{2}\end{array}$ \\
\hline \multirow{3}{*}{ Exponential } & $\begin{array}{l}\text { Twu (1988) [14] } \\
\alpha=\mathrm{T}_{\mathrm{r}}^{2(\mathrm{M}-1)} \exp \left[\mathrm{L}\left(1-\mathrm{T}_{\mathrm{r}}^{2 \mathrm{M}}\right)\right]\end{array}$ & \multirow{3}{*}{- Not any - } \\
\hline & $\begin{array}{l}\text { Twu (1991) [15] } \\
\alpha=\mathrm{T}_{\mathrm{r}}^{\delta} \exp \left[\mathrm{L}\left(1-\mathrm{T}_{\mathrm{r}}^{\gamma}\right)\right]\end{array}$ & \\
\hline & $\begin{array}{l}\text { Trebble-Bishnoi [26] } \\
\alpha=\exp \left[\mathrm{L}\left(1-\mathrm{T}_{\mathrm{r}}\right)\right]\end{array}$ & \\
\hline \multirow[b]{2}{*}{$\begin{array}{c}\text { Polynomial \& } \\
\text { Exponential }\end{array}$} & \multirow[t]{2}{*}{$\begin{array}{l}\text { Melhem-Saini-Goodwin [27] } \\
\alpha=\exp \left[\mathrm{m}\left(1-\mathrm{T}_{\mathrm{r}}\right)+\mathrm{n}\left(1-\sqrt{\mathrm{T}_{\mathrm{r}}}\right)^{2}\right]\end{array}$} & $\begin{array}{l}\text { Boston-Mathias [19] } \\
\qquad \begin{array}{l}\alpha_{\text {SUB }}=\alpha\left(\mathrm{T}_{\mathrm{r}} \leq 1\right)=\alpha_{\text {SOAVE }}=\left[1+\mathrm{m}\left(1-\sqrt{\mathrm{T}_{\mathrm{r}}}\right)\right]^{2} \\
\alpha_{\mathrm{SUP}}=\alpha\left(\mathrm{T}_{\mathrm{r}}>1\right)=\exp \left[\mathrm{L}\left(1-\mathrm{T}_{\mathrm{r}}^{\gamma}\right)\right]\end{array} \\
\text { with }\left\{\begin{array}{l}\mathrm{L}=\frac{2 \mathrm{~m}}{1+\mathrm{m}} \\
\gamma=1+\frac{\mathrm{m}}{2}\end{array}\right.\end{array}$ \\
\hline & & $\begin{array}{l}\text { Mathias [28] } \\
\qquad \begin{array}{l}\alpha_{\text {SUB }}=\alpha\left(\mathrm{T}_{\mathrm{r}} \leq 1\right)=\left[\begin{array}{l}1+\mathrm{m}(\omega)\left(1-\sqrt{\mathrm{T}_{\mathrm{r}}}\right) \\
-\mathrm{p}\left(1-\mathrm{T}_{\mathrm{r}}\right)\left(0.7-\mathrm{T}_{\mathrm{r}}\right)\end{array}\right]^{2} \\
\alpha_{\text {SUP }}=\alpha\left(\mathrm{T}_{\mathrm{r}}>1\right)=\left[\exp \left[\mathrm{L}\left(1-\mathrm{T}_{\mathrm{r}}^{\gamma}\right)\right]\right]^{2}\end{array} \\
\text { with }\left\{\begin{array}{l}\mathrm{L}=1+\frac{\mathrm{m}}{2}+0.3 \mathrm{p} \\
\gamma=\frac{\mathrm{L}-1}{\mathrm{~L}}\end{array}\right.\end{array}$ \\
\hline
\end{tabular}




\begin{tabular}{|c|c|c|}
\hline \multicolumn{3}{|c|}{ Generalized $\alpha$-functions } \\
\hline & $\begin{array}{c}\text { T-overall formulation } \\
\text { (unique temperature formulation) }\end{array}$ & Piecewise \\
\hline Polynomial & $\begin{array}{l}\text { Soave }(1972)[3] \\
\left\{\begin{array}{l}\alpha=\left[1+\mathrm{m}(\omega)\left(1-\sqrt{\mathrm{T}_{\mathrm{r}}}\right)\right]^{2} \\
\mathrm{~m}_{\mathrm{RK}}(\omega)=0.480+1.574 \omega-0.176 \omega^{2} \\
\mathrm{~m}_{\mathrm{PR}}(\omega)=0.37464+1.54226 \omega-0.26992 \omega^{2}\end{array}\right.\end{array}$ & - Not any - \\
\hline Exponential & $\begin{array}{l}\text { Trebble-Bishnoi [29] } \\
\alpha=\exp \left[\mathrm{L}\left(1-\mathrm{T}_{\mathrm{r}}\right)\right] \\
\text { For alkanes, water and carbon dioxide: } \\
\text { if } \omega \leq 0.4: \mathrm{L}=0.418+1.58 \omega-0.580 \omega^{2} \\
\text { if } \omega \geq 0.4: \mathrm{L}=0.212+2.20 \omega-0.831 \omega^{2}\end{array}$ & 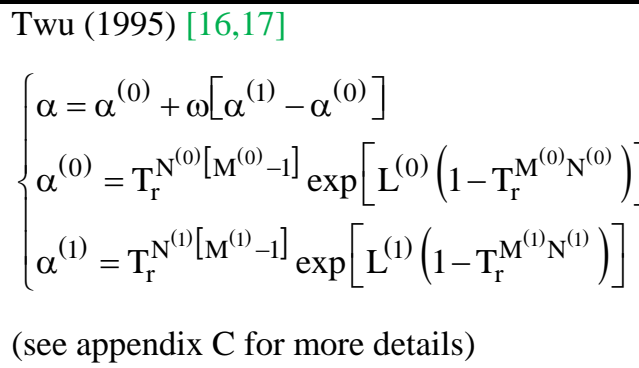 \\
\hline
\end{tabular}

Table 1. Classification of $\alpha$-functions commonly found in process simulation software.

Component-dependent $\alpha$-functions are usually parameterized over vapor-liquid equilibrium data, which are also the most reported data in the literature. Therefore, most of the $\alpha$-functions will have a similar behavior in the subcritical temperature domain. However, the literature lacks of specific, theoretically-based guidelines to derive an $\alpha$-function that could guarantee consistent predictions, also in the supercritical temperature domain, of thermodynamic properties related to the $\alpha$-function itself and to its derivatives. With that respect, the purpose of the next section is to present requirements that a proper $\alpha$-function should fulfil.

\section{Requirements for a consistent $\alpha$-function}

Firstly, to avoid non-physical positive values of the attractive term, $\alpha$-functions should be positive and thus lead to a decrease of the pressure of the system when the attraction between molecules increases. As stated by Deiters [30], a negative $\alpha$-function "only results from compensating an insufficient repulsion term" and should be regarded as a consequence of a maladjusted model but not as a theoretical valid behavior.

Secondly, $\alpha$-functions should be constant at the infinite temperature limit. This constant can be positive or zero. Colina et al. [31] give proof that the limiting value of $\alpha$ at the infinite temperature limit would be equal to zero, by assuming that (i) "at infinite temperature, the cubic EoS reduces to a hard-body EoS, with residual internal energy identically zero at all densities" 
and (ii) the Van der Waals repulsive term $\mathrm{RT} /(\mathrm{v}-\mathrm{b})$ correctly represents hard-body repulsions. However, Abbott and Prausnitz [32] and Sandler [33] leave some uncertainty on whether the $\alpha$-function at infinite temperature should assume a zero rather than a positive finite value. Since no unquestionable theoretical evidences have been found on this issue, we do not conclude about the constant value of the $\alpha$-function at infinite temperature.

Thirdly, as temperature decreases, the average molecular kinetic energy is reduced, resulting in a system where molecules are particularly prone to interacting, upon collision. This explains why the CEoS energy parameter should become increasingly important when temperature decreases. In other words, $\alpha$ has to be a decreasing function of temperature, its first derivative has not only to be negative but has also to cancel out at the infinite temperature limit to ensure a finite $\alpha$-value. It should be noticed that, if an $\alpha$-function is both positive and decreasing, it will automatically admit a finite value at the infinite temperature limit.

The last point is that not only the $\alpha$-function but also its first and second derivatives with respect to the temperature have to be continuous functions of temperature in order to avoid discontinuities in the calculated state functions. As highlighted in Eq.(10), $\alpha$ indeed appears in the mathematical expression of the fugacity and the residual molar enthalpy, the first derivative of $\alpha$ appears in the mathematical expression of the residual molar enthalpy and entropy and the second derivative of $\alpha$ appears in the mathematical expression of the residual heat capacity at constant volume.

$$
\begin{aligned}
& \int \ln f(T, v)=v\left[\frac{1}{v-b}-\frac{a_{c} \boldsymbol{\alpha}(T)}{R T\left(v-r_{1} b\right)\left(v-r_{2} b\right)}\right]-1-\ln \left(\frac{v-b}{R T}\right) \\
& +\frac{\mathrm{a}_{\mathrm{c}} \boldsymbol{\alpha}(\mathbf{T})}{\mathrm{RTb}\left(\mathrm{r}_{1}-\mathrm{r}_{2}\right)} \ln \left(\frac{\mathrm{v}-\mathrm{r}_{1} \mathrm{~b}}{\mathrm{v}-\mathrm{r}_{2} \mathrm{~b}}\right) \\
& \left\{\mathrm{s}^{\mathrm{res}}(\mathrm{T}, \mathrm{v})=\mathrm{R} \ln \left(\frac{\mathrm{v}-\mathrm{b}}{\mathrm{v}}\right)-\frac{\mathrm{a}_{\mathrm{c}}}{\mathrm{b}\left(\mathrm{r}_{1}-\mathrm{r}_{2}\right)} \frac{\mathbf{d} \boldsymbol{\alpha}(\mathbf{T})}{\mathbf{d T}} \ln \left(\frac{\mathrm{v}-\mathrm{r}_{1} \mathrm{~b}}{\mathrm{v}-\mathrm{r}_{2} \mathrm{~b}}\right)\right. \\
& \mathrm{h}^{\mathrm{res}}(\mathrm{T}, \mathrm{v})=\frac{\mathrm{RTb}}{\mathrm{v}-\mathrm{b}}-\frac{\mathrm{a}_{\mathrm{c}} \boldsymbol{\alpha}(\mathbf{T}) \mathrm{v}}{\left(\mathrm{v}-\mathrm{r}_{1} \mathrm{~b}\right)\left(\mathrm{v}-\mathrm{r}_{2} \mathrm{~b}\right)}+\frac{\mathrm{a}_{\mathrm{c}}}{\mathrm{b}\left(\mathrm{r}_{1}-\mathrm{r}_{2}\right)}\left[\boldsymbol{\alpha}(\mathbf{T})-\mathrm{T} \frac{\mathbf{d} \boldsymbol{\alpha}(\mathbf{T})}{\mathbf{d T}}\right] \ln \left(\frac{\mathrm{v}-\mathrm{r}_{1} \mathrm{~b}}{\mathrm{v}-\mathrm{r}_{2} \mathrm{~b}}\right) \\
& \mathrm{c}_{\mathrm{v}}^{\mathrm{res}}(\mathrm{T}, \mathrm{v})=\frac{-\mathrm{Ta}_{\mathrm{c}}}{\mathrm{b}\left(\mathrm{r}_{1}-\mathrm{r}_{2}\right)} \frac{\mathbf{d}^{2} \boldsymbol{\alpha}(\mathbf{T})}{\mathbf{d T}^{2}} \ln \left(\frac{\mathrm{v}-\mathrm{r}_{1} \mathrm{~b}}{\mathrm{v}-\mathrm{r}_{2} \mathrm{~b}}\right)
\end{aligned}
$$

We can summarize our observations by: 


$$
\text { For all T: }\left\{\begin{array}{l}
\alpha(T) \geq 0 \text { and continuous } \\
\frac{d \alpha}{d T} \leq 0 \text { and continuous } \\
\frac{d^{2} \alpha}{d T^{2}} \text { continuous }
\end{array}\right.
$$

These conditions are often cited in the literature as sufficient conditions for consistent predictions of thermodynamic properties but: are they really sufficient? In the next section, we are going to answer this key question through a case study: the calculation of the isothermal phase diagram of the system $\mathrm{CO}_{2}$-argon at $253.1 \mathrm{~K}$, with the Peng-Robinson CEoS, associated with two $\alpha$ functions that satisfy criteria in (11). Before presenting calculation results over this system, it is worth pointing out that it is a complex mixture to be modelled since it exhibits a type III phase behavior in the classification scheme of Van Konynenburg and Scott [34].

\section{Case-study: prediction of the $\mathrm{CO}_{2}$-argon binary phase diagram}

The $\mathrm{CO}_{2}$-argon binary system is considered as a key system for $\mathrm{CO}_{2}$-Capture and Storage (CCS) applications [35]. It is desired to predict the phase diagram of this system at $253.1 \mathrm{~K}$ with the Peng-Robinson CEoS and highly efficient mixing rules which combine the expression by Huron and Vidal [36] with the residual part of the Wilson activity-coefficient model [37]. The two parameters of the Wilson model were regressed in order to minimize the following objective function which takes into account the deviations between calculated and experimental molar fractions of $\mathrm{CO}_{2}$ in the liquid (x) and gas (y) phases:

$$
F_{o b j, 1}=\sum_{i=1}^{N_{\exp }}\left(\frac{x_{i}^{\exp }-x_{i}^{\text {calc }}}{\sigma_{x_{i}}^{\exp }}\right)^{2}+\sum_{i=1}^{N_{\exp }}\left(\frac{y_{i}^{\exp }-y_{i}^{\text {calc }}}{\sigma_{y_{i}}^{\exp }}\right)^{2}
$$

where $\sigma_{\Gamma_{\mathrm{i}}}^{\exp }$ is the experimental standard deviation associated to the $\mathrm{i}^{\text {th }}$ data point of property $\Gamma$. In order to test the influence of the selected $\alpha$-function on the resulting calculations, two different $\alpha$-functions, that are the Soave and the Twu91 $\alpha$-functions, were successively considered for both pure carbon dioxide and argon. The m-parameter of the Soave $\alpha$-function was calculated by applying Eq. (8), while the three parameters L, M and N of the Twu91 $\alpha$ function were determined by minimizing the objective function expressed by Eq. (13), which takes into account the deviations between calculated and pseudo-experimental vapor pressures $\left(\mathrm{P}^{\mathrm{sat}}\right)$, enthalpies of vaporization $\left(\Delta_{\mathrm{vap}} \mathrm{H}\right)$ and saturated liquid heat capacities $\left(\mathrm{c}_{\mathrm{P}, \mathrm{L}}^{\mathrm{sat}}\right)$ : 


$$
\begin{aligned}
\mathrm{F}_{\text {obj }, 2}=\sum_{\mathrm{i}=1}^{50}\left|\frac{\mathrm{P}_{\mathrm{EoS}}^{\mathrm{sat}}\left(\mathrm{P}, \mathrm{T}_{\mathrm{i}}\right)-\mathrm{P}_{\mathrm{DIPPR}}^{\mathrm{sat}}\left(\mathrm{T}_{\mathrm{i}}\right)}{\mathrm{P}_{\mathrm{DIPPR}}^{\mathrm{sat}}\left(\mathrm{T}_{\mathrm{i}}\right)}\right| & +\sum_{\mathrm{i}=1}^{50}\left|\frac{\Delta_{\mathrm{vap}} \mathrm{H}_{\mathrm{EoS}}\left(\mathrm{P}, \mathrm{T}_{\mathrm{i}}\right)-\Delta_{\mathrm{vap}} \mathrm{H}_{\mathrm{DIPPR}}\left(\mathrm{T}_{\mathrm{i}}\right)}{\Delta_{\mathrm{vap}} \mathrm{H}_{\mathrm{DIPPR}}\left(\mathrm{T}_{\mathrm{i}}\right)}\right| \\
& +\sum_{\mathrm{i}=1}^{50}\left|\frac{\mathrm{c}_{\mathrm{P}, \mathrm{L}, \mathrm{EoS}}^{\mathrm{sat}}\left(\mathrm{P}, \mathrm{T}_{\mathrm{i}}\right)-\mathrm{c}_{\mathrm{P}, \mathrm{L}, \mathrm{DIPPR}}^{\mathrm{sat}}\left(\mathrm{T}_{\mathrm{i}}\right)}{\mathrm{c}_{\mathrm{P}, \mathrm{L}, \mathrm{DIPPR}}^{\mathrm{sat}}\left(\mathrm{T}_{\mathrm{i}}\right)}\right|
\end{aligned}
$$

The pseudo-experimental $\mathrm{P}^{\mathrm{sat}}, \Delta_{\mathrm{vap}} \mathrm{H}$ and $\mathrm{c}_{\mathrm{P}, \mathrm{L}}^{\mathrm{sat}}$ data were extracted from the correlations available in the DIPPR database: for each property, 50 equidistant data points were generated in the temperature validity range of the correlations. Following this regression procedure, optimal parameters have been obtained for the Twu91 $\alpha$-function. Those are reported in Table 2.

\begin{tabular}{|c|c|c|}
\hline & $\mathrm{CO}_{2}$ & Argon \\
\hline $\mathrm{L}$ & 0.040 & 0.027 \\
\hline $\mathrm{M}$ & 0.943 & 0.968 \\
\hline $\mathrm{N}$ & 8.538 & 8.213 \\
\hline
\end{tabular}

Table 2. Twu91 $\alpha$-function parameters of $\mathrm{CO}_{2}$ and argon obtained by minimizing Eq. (13).

A significant difference between the two calculated phase diagrams of the $\mathrm{CO}_{2}$-argon system is observable in Figure 1. To better analyze the cause of such a difference, it is worth recalling that the two phase diagrams were modeled using the same CEoS and the same mixing rules; they thus only differ in the choice of the $\alpha$-function. 


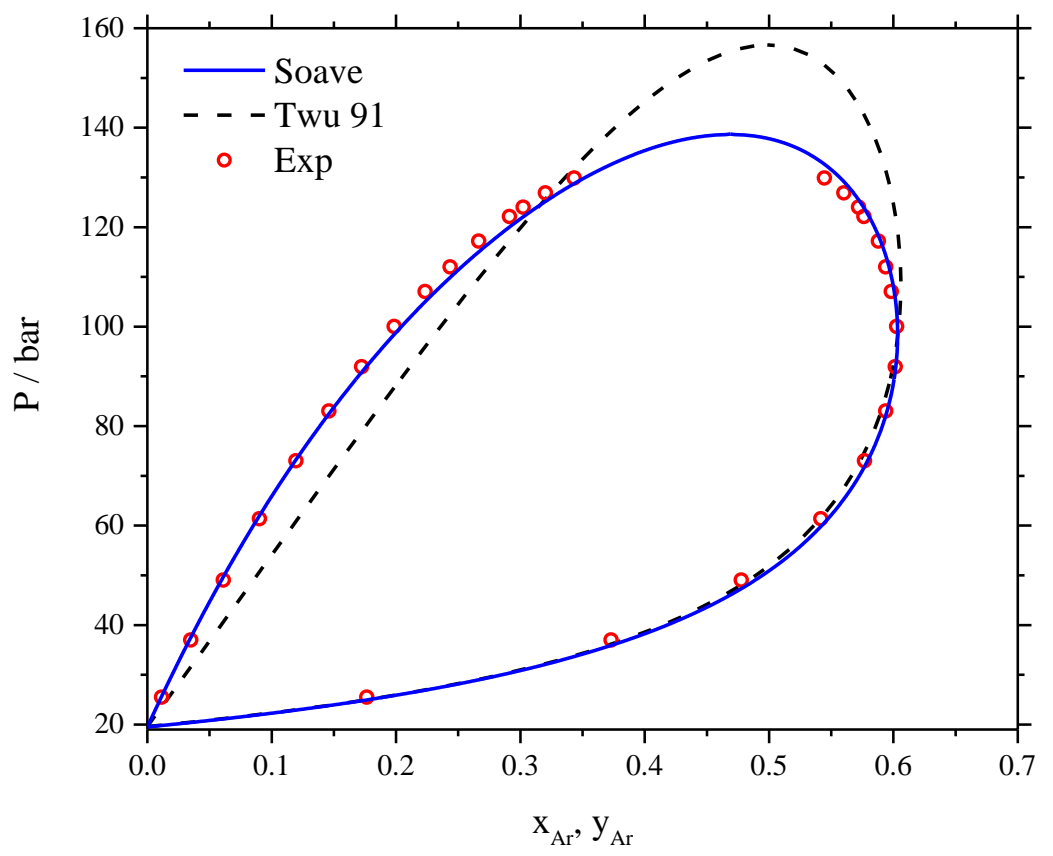

Figure 1. Binary phase diagram of the $\mathrm{CO}_{2}$-Ar system at $253.1 \mathrm{~K}$ calculated with the PengRobinson CEoS and two different $\alpha$-functions parameterized on subcritical vapor-liquid equilibrium data.

When the Soave $\alpha$-function is used for both compounds, a nearly perfect prediction of the phase diagram is achieved (the continuous curve is extremely close to the experimental data points). On the other hand, very poor results are obtained with the Twu91 $\alpha$-function. By having a look at the dashed curve in Figure 1, it could be erroneously concluded that the Peng-Robinson EoS is totally unable to correlate the $\mathrm{CO}_{2}$-argon system and that it over predicts the binary critical pressure and the solubility of argon in $\mathrm{CO}_{2}$. It is undeniably surprising to observe that the generalized Soave $\alpha$-function, which does not contain any adjustable parameter, performs better than the component-dependent Twu91 $\alpha$-function that involves three adjustable parameters per component. In order to better understand the origin of the significant difference between the two calculated phase diagrams, it is necessary to analyze more closely each of the two $\alpha$ functions (Soave and Twu91) which were designed to accurately reproduce pure component vapor-liquid equilibrium data. To this aim, $\alpha$-curves of $\mathrm{CO}_{2}$ and argon are reported in Figure 2 and Figure 3. The two figures highlight that, in the temperature range where the parameters were fitted (let us say between $0.4 \mathrm{~T}_{\mathfrak{c}}$ and $\mathrm{T}_{\mathrm{c}}$ ), the Soave and Twu $91 \alpha$-functions are superimposed for both pure components. 


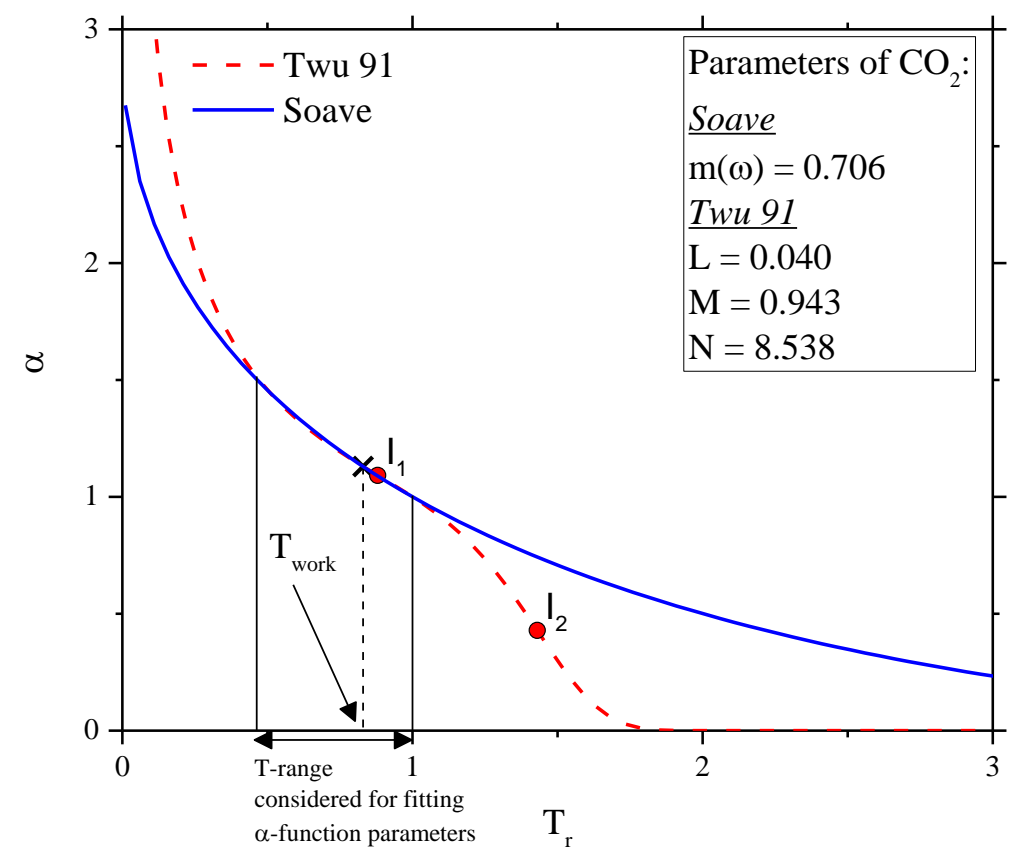

Figure 2. $\alpha$-curves of $\mathrm{CO}_{2}$ parameterized on subcritical vapor-liquid equilibrium data.

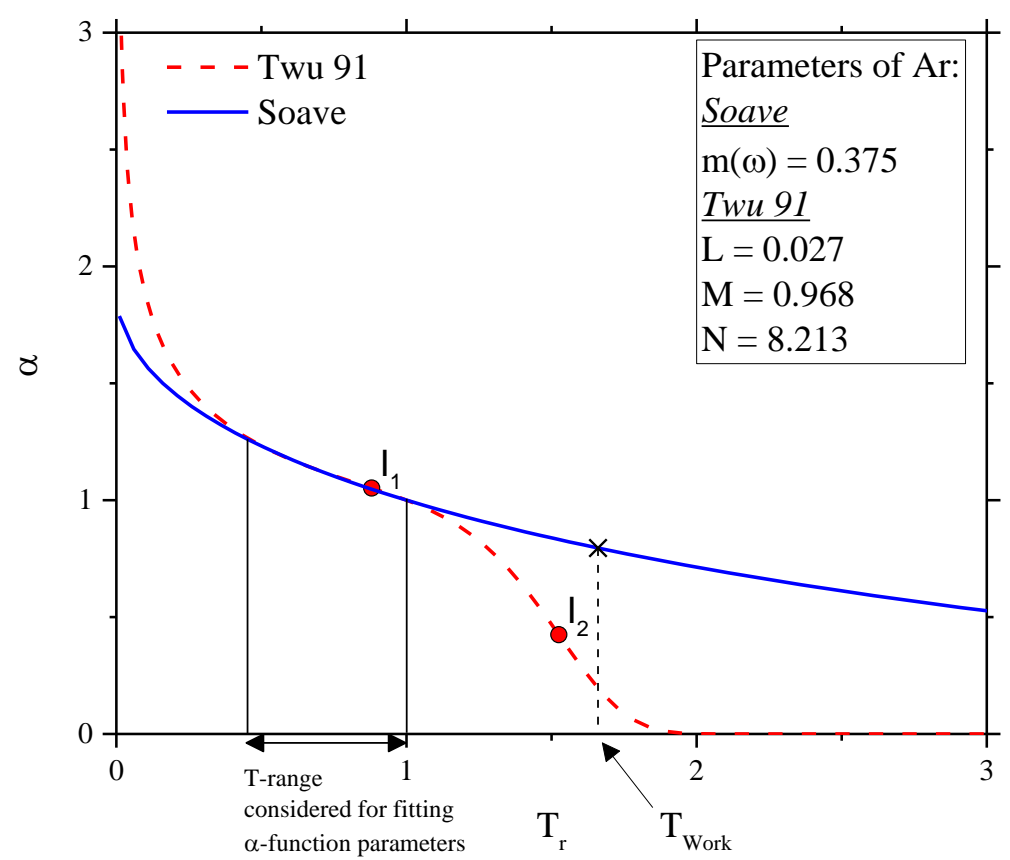

Figure 3. $\alpha$-curves of argon parameterized on subcritical vapor-liquid equilibrium data.

At the working temperature of $253.1 \mathrm{~K}$, pure $\mathrm{CO}_{2}$ is subcritical $\left(\mathrm{T}_{\mathrm{c}}=304.21 \mathrm{~K}\right)$ while pure argon is supercritical $\left(\mathrm{T}_{\mathrm{c}}=150.86 \mathrm{~K}\right)$. Since for $\mathrm{CO}_{2}$ the working temperature is in the range where the parameters were fitted, it is not surprising to observe (see X symbol in Figure 2) that, 
at this temperature, the two $\alpha$-functions return the same value. On the other hand, at $253.1 \mathrm{~K}$, argon is supercritical $\left(\mathrm{T}_{\mathrm{r}}=1.7\right)$, that is at a temperature completely outside the range where the parameters were fitted. At this temperature, the two $\alpha$-functions take totally different values ( $\alpha_{\text {Soave }} \approx 0.8$ and $\alpha_{\mathrm{Twu}} \approx 0.2$ ), as shown in Figure 3. At this step it is thus possible to conclude that the mismatch in $\alpha$-values for argon is the unique responsible for the poor correlation of the $\mathrm{CO}_{2}$-argon vapor-liquid equilibrium data with the Twu91 $\alpha$-function at $253.1 \mathrm{~K}$. Such a difference between $\alpha$-function values in the supercritical domain, for both $\mathrm{CO}_{2}$ and argon, appears to be caused by the presence of two inflection points along the Twu91 $\alpha$-curve. As highlighted by Figure 2 and Figure 3, Twu91 $\alpha$-functions of argon and $\mathrm{CO}_{2}$ go from convex to concave to convex with a steep and quick decrease in the concave part of the $\alpha$-curve. On the other hand, the Soave $\alpha$-function is strictly convex on the whole temperature range with a significantly slower decrease in the supercritical domain. Figure 2 and Figure 3 thus give rise to two questions which are addressed in the next section: are the two inflection points observed on the Twu91 $\alpha$-curve the actual responsible for the poor correlation of the binary vapor-liquid equilibrium data and, above all, are such inflection points thermodynamically consistent?

\section{Are inflection points on $\alpha$-curves thermodynamically consistent?}

To begin, let us recall that at an inflection point, the curvature of a function changes sign and hence its second derivative vanishes:

$$
\left.\frac{\mathrm{d}^{2} \alpha}{\mathrm{dT}_{\mathrm{r}}^{2}}\right|_{\mathrm{T}_{\mathrm{r}, \text { inflection point }}}=0
$$

Among all the thermodynamic properties that can be derived from a CEoS, the residual heat capacity at constant volume is directly proportional to the second derivative of the $\alpha$-function:

$$
c_{v}^{\text {res }}(T, v)=\frac{T a_{c}}{b\left(r_{1}-r_{2}\right)} \frac{d^{2} \alpha}{d T^{2}} \ln \left(\frac{v-r_{2} b}{v-r_{1} b}\right)
$$

The $c_{v}$ coefficient is given by:

$$
\mathrm{c}_{\mathrm{v}}(\mathrm{T}, \mathrm{v})=\mathrm{c}_{\mathrm{v}}^{\bullet}(\mathrm{T})+\mathrm{c}_{\mathrm{v}}^{\mathrm{res}}(\mathrm{T}, \mathrm{v})
$$

with $\mathrm{c}_{\mathrm{v}}^{\bullet}$ the heat capacity at constant volume of the perfect gas. As a direct consequence, if an $\alpha$-curve exhibits an inflection points at temperature $T^{*}$, the second derivative of $\alpha$ with respect to the temperature vanishes (see Eq.(14)) at $\mathrm{T}^{*}, \mathrm{c}_{\mathrm{v}}^{\mathrm{res}}$ cancels out and, thus, $\mathrm{c}_{\mathrm{v}}$ takes the value 
of that of the perfect gas, $\mathrm{c}_{\mathrm{v}}^{\bullet}$ (see Eq.(16)), uniquely dependent on temperature. It is thus possible to write that, at $\mathrm{T}^{*}$ :

$$
\mathrm{c}_{\mathrm{v}}\left(\mathrm{T}^{*}, \mathrm{v}\right)=\mathrm{c}_{\mathrm{v}}^{\bullet}\left(\mathrm{T}^{*}\right)
$$

and whatever the molar volume is (i.e. irrespectively of the pressure), $c_{v}$ is the same (that of the perfect gas). Since, at the temperature $T^{*}, c_{v}$ results to be pressure independent, all the isobaric curves in $\mathrm{a}_{\mathrm{v}}-\mathrm{T}$ plane are going to intersect at such a temperature. For illustration purpose, the change of $\mathrm{c}_{\mathrm{v}}$ with respect to $\mathrm{T}$, calculated for pure $\mathrm{CO}_{2}$ with the Twu91 $\alpha$ function (see Table 2 for values of L, M and N), is shown in Figure 4 within the pressure range 50-150 bar. As expected, at the two reduced temperatures $\left(T_{r, 1}^{*}\right.$ and $\left.T_{r, 2}^{*}\right)$ where the $\alpha$-curve exhibits an inflection point (i.e. where the second derivative vanishes) all the isobars ( $\mathrm{P} / \mathrm{bar}=$ $50,100,150)$ in the $\left(c_{v}, T\right)$ plane intersect. Experimental evidences about this peculiar behavior have never been observed and therefore we are convinced of its unphysical foundation. Consequently, the presence of inflection points on $\alpha$-curves should be regarded as thermodynamically inconsistent and should, thus, be avoided. In other words, the second derivative of $\alpha$-functions should never cancel out.

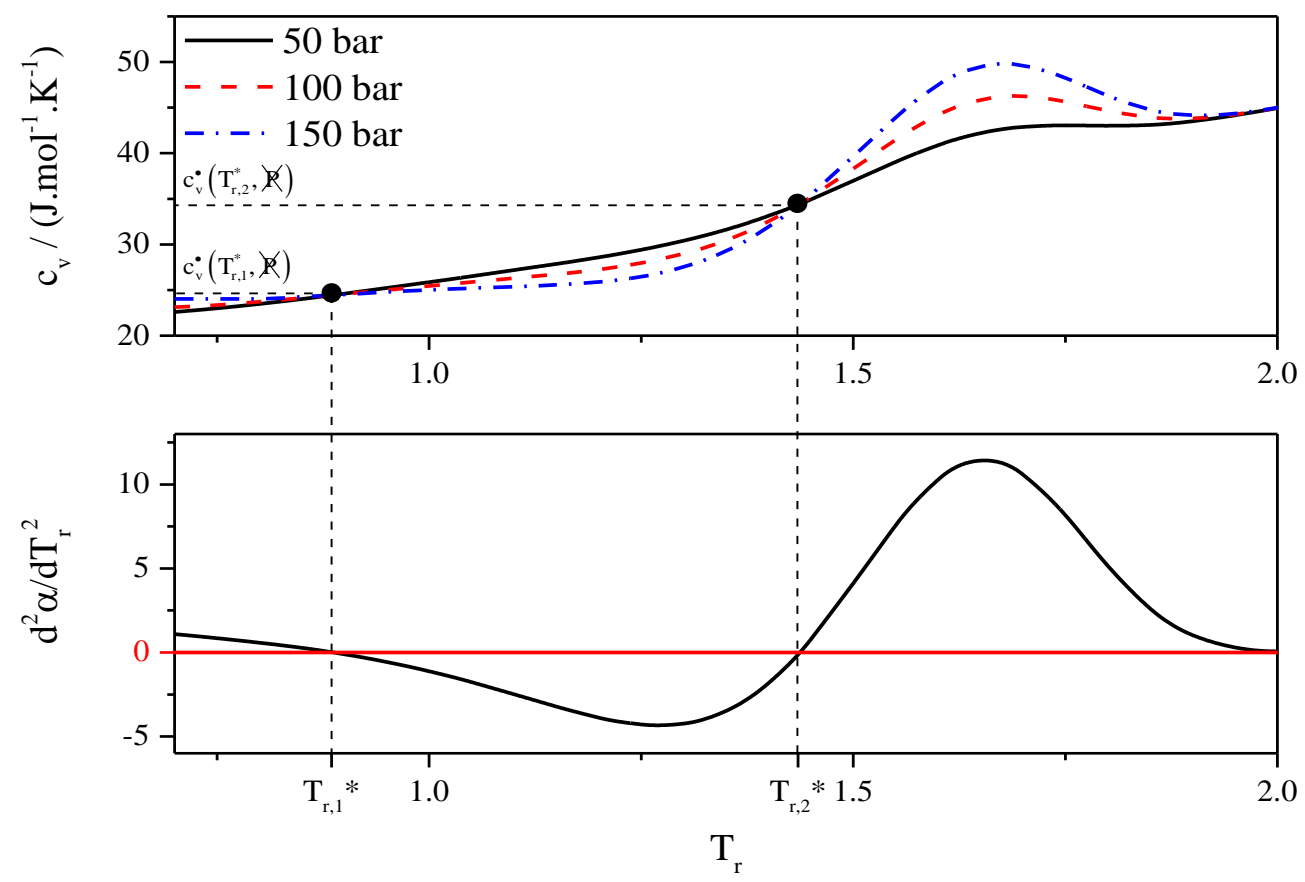

Figure 4. Illustration of the unphysical isobars crossing when the second derivative of an $\alpha$ function cancels - case of $\mathrm{CO}_{2}$. 
To avoid inconsistent inflection points on the $\alpha$-curve we must impose the convexity of the $\alpha$ function, for any temperature value:

$$
\frac{\mathrm{d}^{2} \alpha}{\mathrm{dT}^{2}} \geq 0 \text { for all } \mathrm{T}
$$

That being said, parameters of the Twu91 $\alpha$-function of $\mathrm{CO}_{2}$ and $\operatorname{argon}$ have thus been reregressed in this section by imposing the constraint $\mathrm{d}^{2} \alpha / \mathrm{dT}^{2}>0$ on the second derivative (the mathematical aspects are derived in Appendix A). Corresponding values for the $\mathrm{L}, \mathrm{M}$ and $\mathrm{N}$ parameters are reported in Table 3.

\begin{tabular}{|c|c|c|}
\hline & $\mathrm{CO}_{2}$ & Argon \\
\hline $\mathrm{L}$ & 0.091 & 0.072 \\
\hline $\mathrm{M}$ & 0.890 & 0.919 \\
\hline $\mathrm{N}$ & 3.805 & 2.667 \\
\hline
\end{tabular}

Table 3. Parameters regressed for the Twu91 $\alpha$-function when convexity of the $\alpha$-curve is enforced.

$\alpha$-curves obtained with and without the imposition of the convexity of the corresponding $\alpha$ function (Eq. (18)), are reported in Figure 5 and Figure 6. The second derivative of the convex $\alpha$-function is also reported, to enable the reader to attest that, as imposed, it is always positive. 


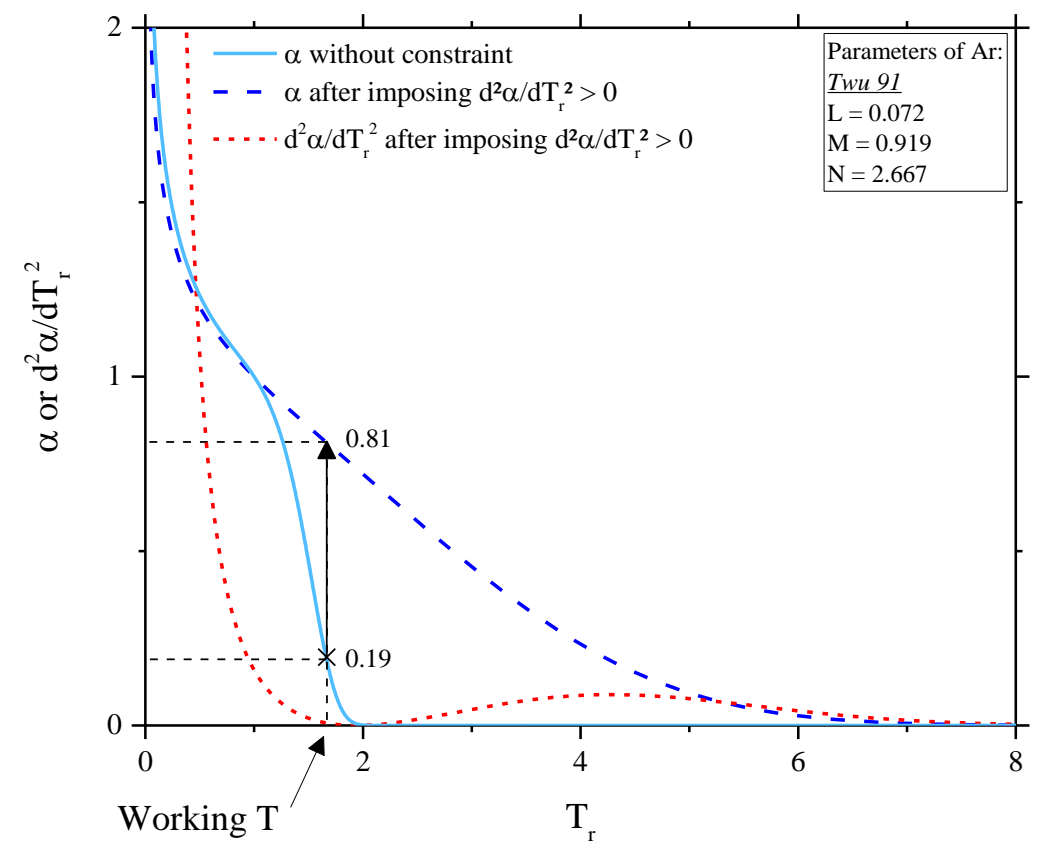

Figure 5. $\alpha$-function of pure argon and its second derivative when the convexity constraint is enforced.

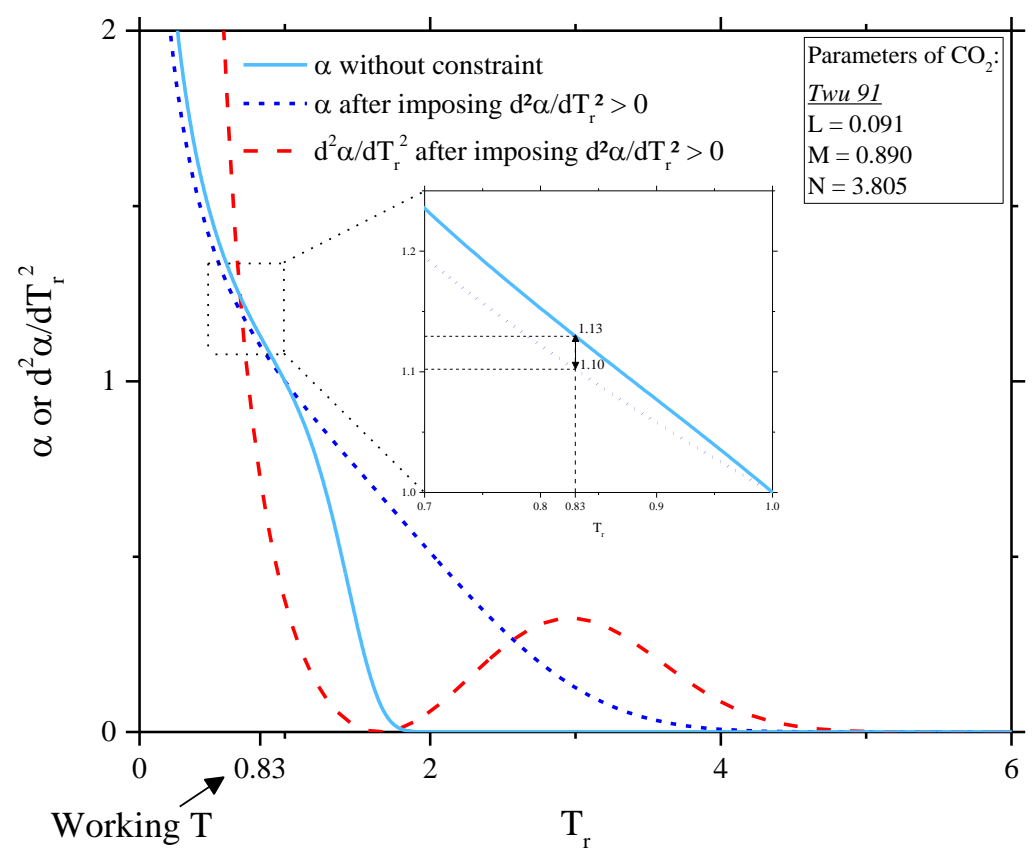

Figure 6. $\alpha$-function of pure $\mathrm{CO}_{2}$ and its second derivative when the convexity constraint is enforced.

As highlighted by Figure 5 at the working temperature of $253.1 \mathrm{~K}$, the value of the non-convex $\alpha$-function of argon (being supercritical in this condition) is 0.19 . Differently, Twu91 L, M and 
$\mathrm{N}$ parameters optimized under the imposition of the convexity constraint lead to an $\alpha$-function value of 0.81 , at the same temperature of $253.1 \mathrm{~K}$. On the other hand, at $253.1 \mathrm{~K} \alpha$-value of $\mathrm{CO}_{2}$, (being subcritical at that temperature), is only slightly affected by the addition of the convexity constraint (see Figure 6); it raises from 1.10 to 1.13 .

Moreover, it should be noticed, from both Figure 5 and Figure 6, that major changes on $\alpha$ curves, deriving from the imposition of constraint in Eq. (18), lie in the supercritical domain, leaving almost unchanged the subcritical part of it. This is a straightforward consequence of the fact that, as mentioned above, only subcritical data were used in the optimization procedure. It is also possible to conclude that different sets of parameters leading to the same objective function value, i.e. leading to the same $\alpha$-function values in the subcritical domain, are obtained when Eq. (13) is minimized. Such sets of parameters however lead to totally different behaviors in the supercritical region.

Furthermore, Figure 7 reports the comparison between experimental VLE data and phase diagrams calculated by means of the PR-EoS either combined with the Soave $\alpha$-function (as previously shown in Figure 1) or with the re-parameterized Twu91 model (L, M, N parameters collected in Table 3). Comparing Figure 1 and Figure 7, that only differ in the VLE calculations performed with the Twu91 model, it is possible to attest that the imposition of the condition $\mathrm{d}^{2} \alpha / \mathrm{dT}^{2}>0$ to Twu91 parameters (Figure 7) results in a spectacular improvement of the accuracy of such a model. Figure 7 also highlights that a similar accuracy of prediction is achieved using either the Twu91 $\alpha$-function with the convexity constraint or the Soave $\alpha$ function. 


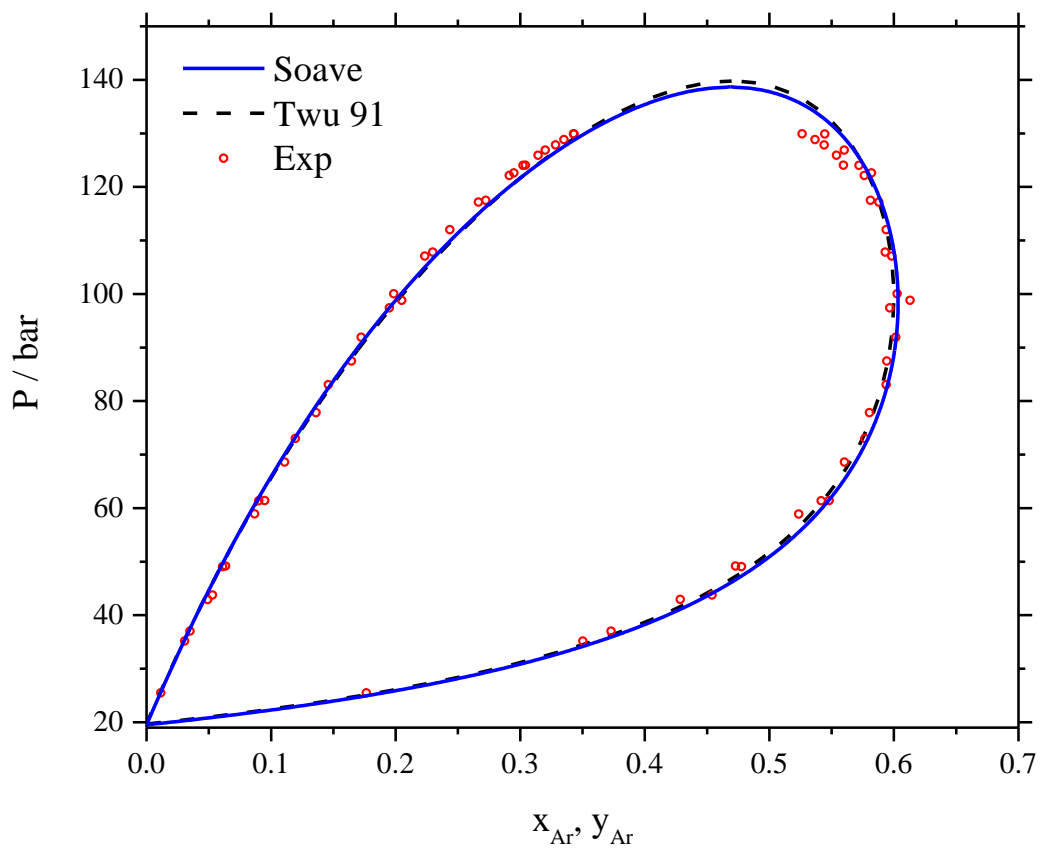

Figure 7. Binary phase diagram of the $\mathrm{CO}_{2}-\mathrm{Ar}$ system at $253.1 \mathrm{~K}$ when the convexity constraint is enforced $\left(d^{2} \alpha / d T^{2}>0\right)$.

A satisfactory prediction of the binary phase diagram being now achieved by the imposition of $\mathrm{d}^{2} \alpha / \mathrm{dT}^{2}>0$, our following priority concern is the investigation of the necessity of adding new constraints to properly predict state functions, such as enthalpies and heat capacities, also in the supercritical domain.

\section{Relevance of the parameters obtained by imposing $d^{2} \alpha / d T^{2}>0$ to predict state functions in the supercritical domain}

Pseudo-experimental enthalpy $(\mathrm{h})$ and heat capacity $\left(\mathrm{c}_{\mathrm{P}}\right)$ were generated for pure $\mathrm{CO}_{2}$ and pure argon in the supercritical domain, in particular for reduced temperatures ranging from 1.2 to 5. The reference Span-Wagner equation [38] was used in this work to estimate properties of $\mathrm{CO}_{2}$ at 10, 59.7, 109, 159 and 209 bar, while the Tegeler-Span-Wagner reference equation [39] was used for argon at 10, 42, 74, 106 and 138 bar. Figure 8 shows the comparison between properties calculated with these reference models and their values determined with the PengRobinson EoS combined with the Twu91 $\alpha$-function (see Table 3 for values of L, M, and N). As it can be seen from Figure 8c and Figure 8d, molar enthalpies ( h ) are well represented by the newly regressed $\alpha$-functions for both $\mathrm{CO}_{2}$ and Ar: not only the numerical values are 
accurately predicted but also the change of $\mathrm{h}$ with respect to the temperature is properly reproduced. Totally different conclusions apply for the $\mathrm{c}_{\mathrm{P}}$. The Peng-Robinson EoS with the currently evaluated $\alpha$-function predicts a "wave shape" while the application of reference equations results in a weak change of the $c_{P}$ with respect to temperature (a minimum is only observed). Such unexpected behavior is particularly visible in Figure $\mathbf{8 b}$, relative to $\mathrm{CO}_{2}$. By comparing Figure 6 and Figure $8 b$, it is noticeable that both $\mathrm{d}^{2} \alpha / \mathrm{dT}^{2}$ and $\mathrm{c}_{\mathrm{P}}$ curves exhibit the same "wave shape" in a similar temperature range. It is thus expected that the $c_{P}$ curve would exhibit a more realistic trend by removing the "wave shape" on the $\mathrm{d}^{2} \alpha / \mathrm{dT}^{2}$ curve. To do that, it is enough to eliminate (see Figure 6) the increasing part of such a function. In other words, it is expected that the imposition of condition $d^{3} \alpha / \mathrm{dT}^{3}<0$ would result in $c_{P}$ variations with temperature, calculated with the PR EoS, being similar to those obtained with the reference equations. 

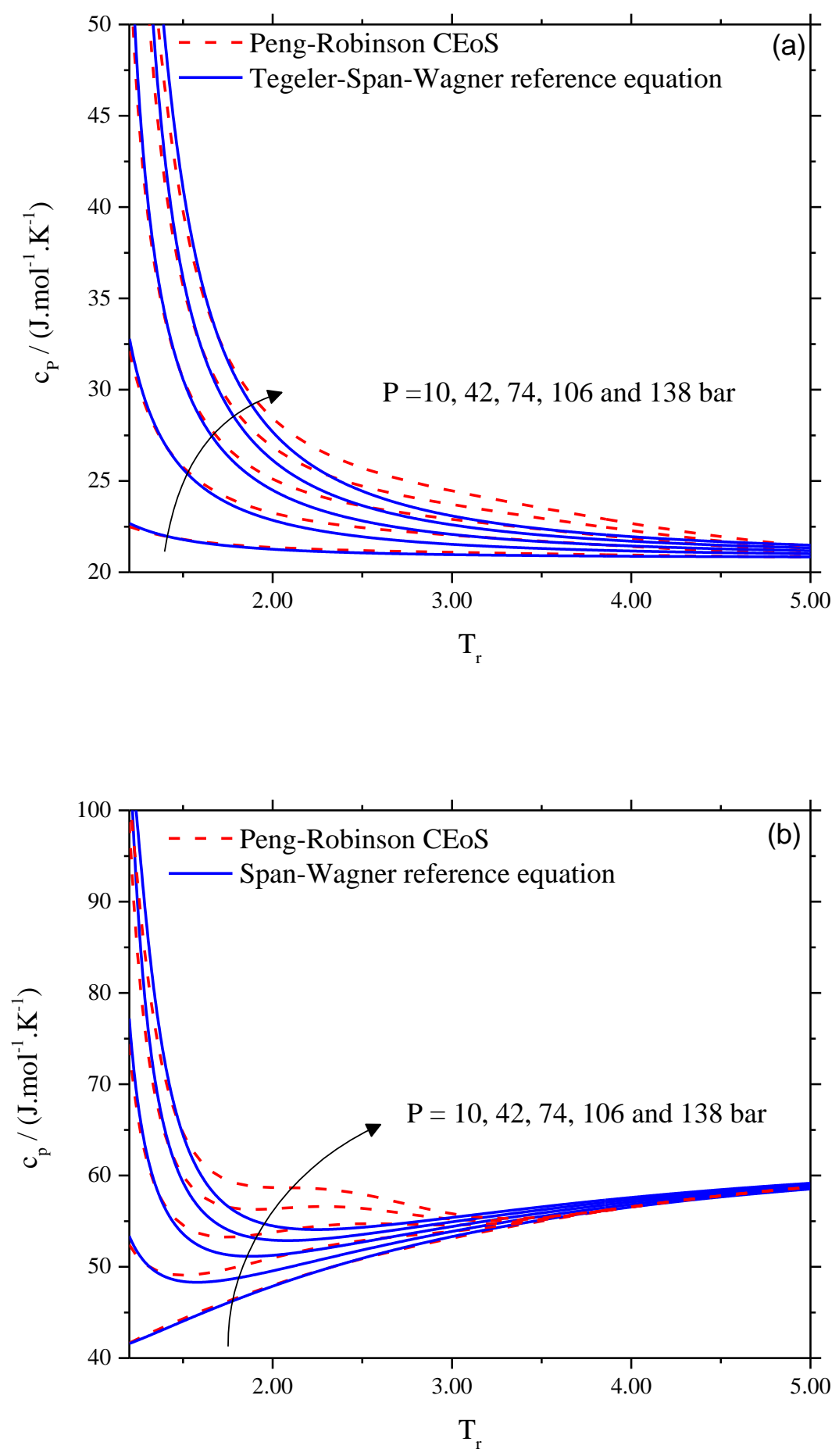

A consistency test for $\alpha$-functions of cubic equations of state 

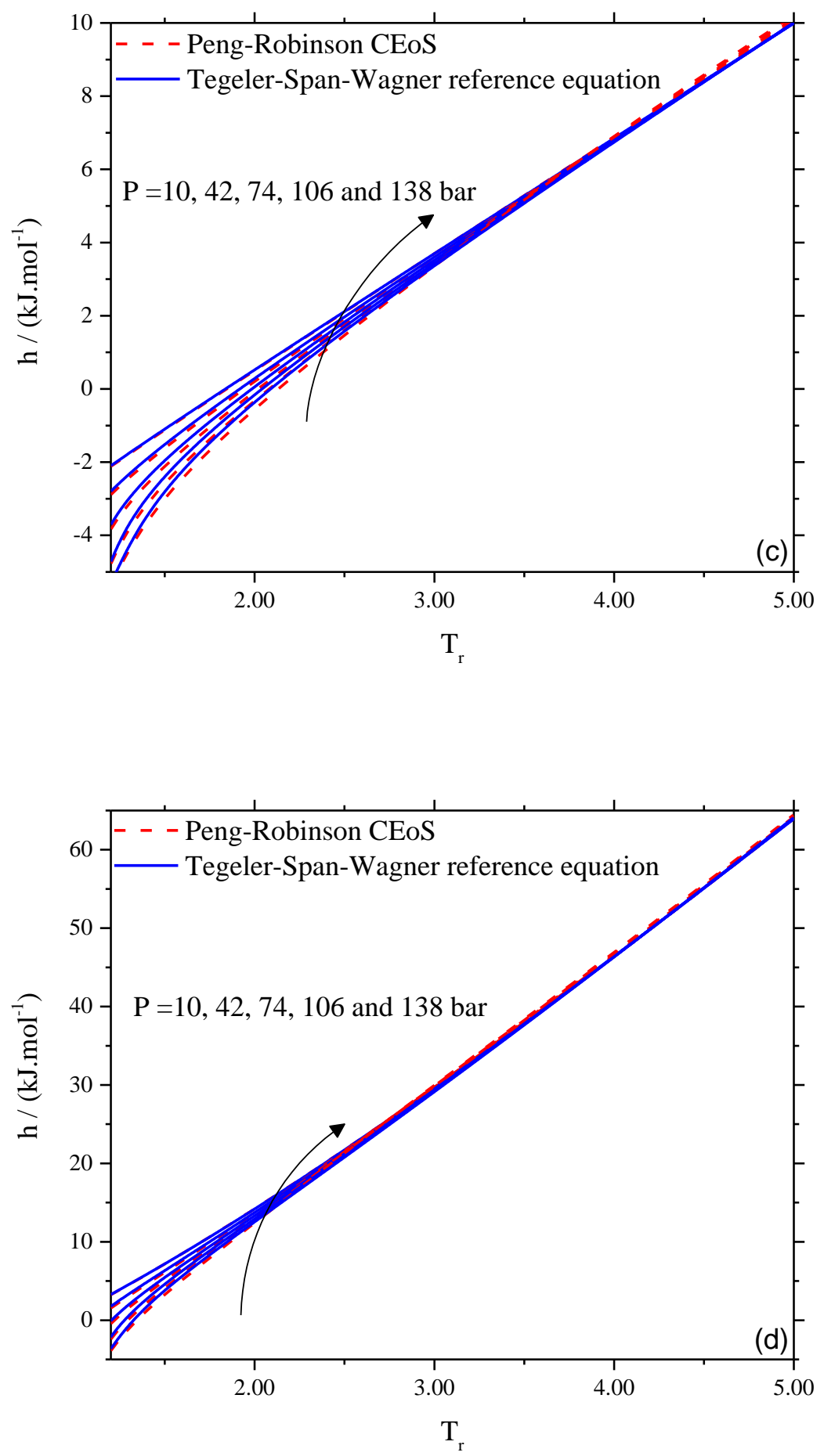

Figure 8. Prediction of supercritical $c_{\mathrm{P}}$ of $\operatorname{argon}(\mathrm{a})$ and $\mathrm{CO}_{2}(\mathrm{~b})$ and prediction of supercritical $\mathrm{h}$ of $\operatorname{argon}(\mathrm{c})$ and $\mathrm{CO}_{2}(\mathrm{~d})$ when convexity constraint $\left(\mathrm{d}^{2} \alpha / \mathrm{dT}^{2}>0\right)$ only is applied. 
To check this hypothesis, the parameters of the Twu91 $\alpha$-function of $\mathrm{CO}_{2}$ and argon have been thus re-optimized under the simultaneous imposition of $\mathrm{d}^{2} \alpha / \mathrm{dT}^{2}>0$ and $\mathrm{d}^{3} \alpha / \mathrm{dT}^{3}<0$. Optimal values of parameters are reported in Table 4.

\begin{tabular}{|c|c|c|}
\hline & $\mathrm{CO}_{2}$ & Argon \\
\hline $\mathrm{L}$ & 0.091 & 0.072 \\
\hline $\mathrm{M}$ & 0.890 & 0.919 \\
\hline $\mathrm{N}$ & 3.805 & 2.667 \\
\hline
\end{tabular}

Table 4. Parameters regressed for the Twu91 $\alpha$-function when both the convexity of the $\alpha$ curve $\left(\mathrm{d}^{2} \alpha / \mathrm{dT}^{2}>0\right)$ and the negativity of the third derivative of the $\alpha$-function

$$
\left(\mathrm{d}^{3} \alpha / \mathrm{dT}^{3}<0\right) \text { are enforced. }
$$

$\alpha$-functions that result from the use of these parameters (Table 4) are represented in Figure 9 and Figure 10. These figures also report the second derivatives, calculated with respect to temperature, relative to these $\alpha$-functions. A major change in the shape of the $\alpha$-curve which results from the use of this new set of constraints concerns the rate at which $\alpha$-functions decrease to zero. It can be seen that the use of parameters reported in Table 3 (optimized over the unique constraint $d^{2} \alpha / d T^{2}>0$ ) results in $\alpha$-functions that equal zero at a reduced temperature $T_{\mathrm{r}} \sim 4$, while the application of parameters optimized under the simultaneous imposition of $\mathrm{d}^{2} \alpha / \mathrm{dT}^{2}>0$ and $\mathrm{d}^{3} \alpha / \mathrm{dT}^{3}<0$ generates $\alpha$-functions that equal zero at higher reduced temperatures, $\mathrm{T}_{\mathrm{r}}>8$. Therefore, for such functions, the attractive term of the CEoS used for the calculations still plays a relevant role at high temperature.

Supercritical $\mathrm{h}$ and $\mathrm{c}_{\mathrm{P}}$ of $\mathrm{CO}_{2}$ and argon are represented in Figure 11. For both compounds, the quality of prediction of $\mathrm{h}$ is similar to the one previously obtained when the third derivative of the $\alpha$-functions could be positive. On the other hand, this new set of parameters not only guarantees more accurate $c_{P}$ values but also correct trends of $c_{P}$-variations with temperature, with respect to results obtained from reference models.

It is legitimate now to wonder what was the prize to pay to get such a large improvement of the state functions in the supercritical domain. Were subcritical properties damaged? To answer 
this question, deviations on $\mathrm{P}^{\mathrm{sat}}, \Delta_{\mathrm{vap}} \mathrm{H}$ and $\mathrm{c}_{\mathrm{P}, \mathrm{L}}^{\mathrm{sat}}$ for both compounds have been calculated and reported in Table 5. The content of this table enables the comparison between results obtained with the addition of the constraint on the third derivative of the $\alpha$-function to the results obtained when only the convexity constraint was enforced. As highlighted by Table 5, this huge improvement on the prediction of the supercritical properties is marginally counterbalanced by a small accuracy decrease of $c_{P, L}^{\text {sat }}$ of $\mathrm{CO}_{2}$ and argon. Moreover, it is worth noting that $\mathrm{P}^{\text {sat }}$ of $\mathrm{CO}_{2}$ is better predicted when the negativity constraint on the third derivative of the $\alpha$-function is set and that $\Delta_{\mathrm{vap}} \mathrm{H}$ is calculated with the same accuracy in both cases.

Finally, the $\mathrm{CO}_{2}$-argon binary phase diagram is represented in Figure 12. Impressive results are obtained by the application of the full set of constraints $\left(\mathrm{d}^{2} \alpha / \mathrm{dT}^{2}>0\right.$ and $\left.\mathrm{d}^{3} \alpha / \mathrm{dT}^{3}<0\right)$, even slightly better than when only the convexity constraint is enforced. As shown by Figure 12, the resulting optimal Twu91 formulation is characterized by an accuracy similar to that of the Soave $\alpha$-function.

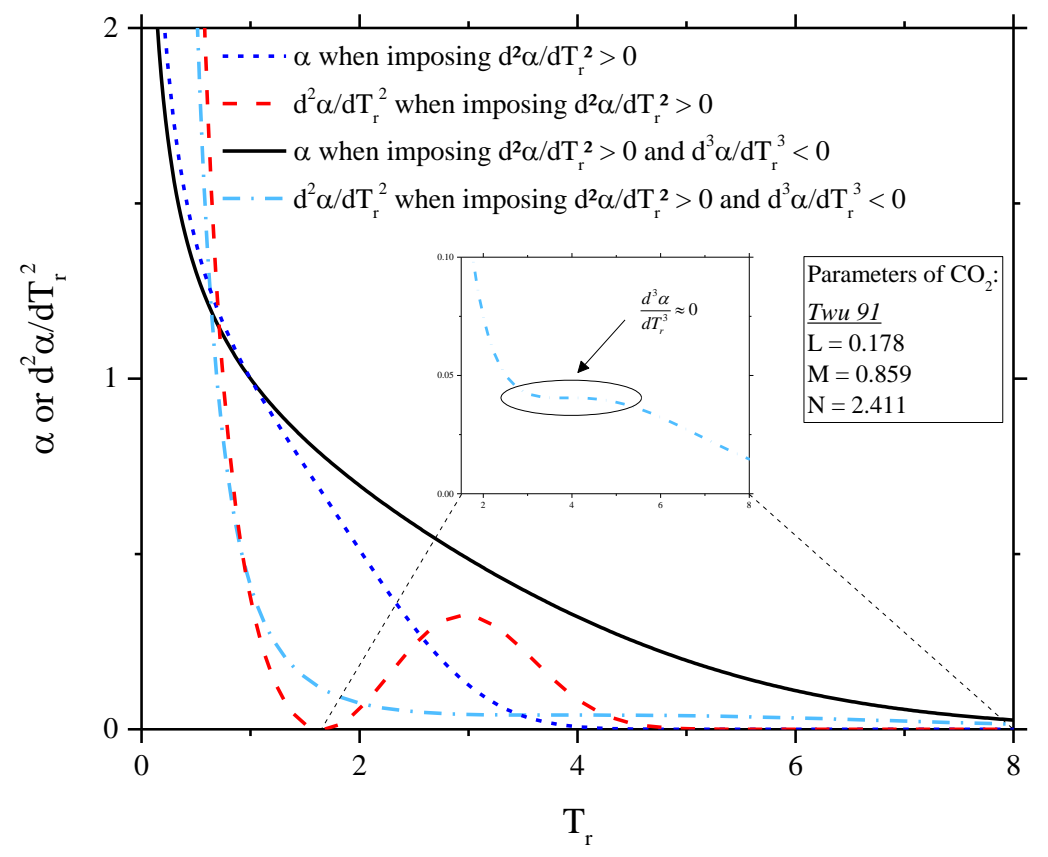

Figure 9. $\alpha$-function of $\mathrm{CO}_{2}$ and it second derivative when constraints $\mathrm{d}^{2} \alpha / \mathrm{dT}^{2}>0$ and $\mathrm{d}^{3} \alpha / \mathrm{dT}^{3}<0$ are simultaneously applied. 


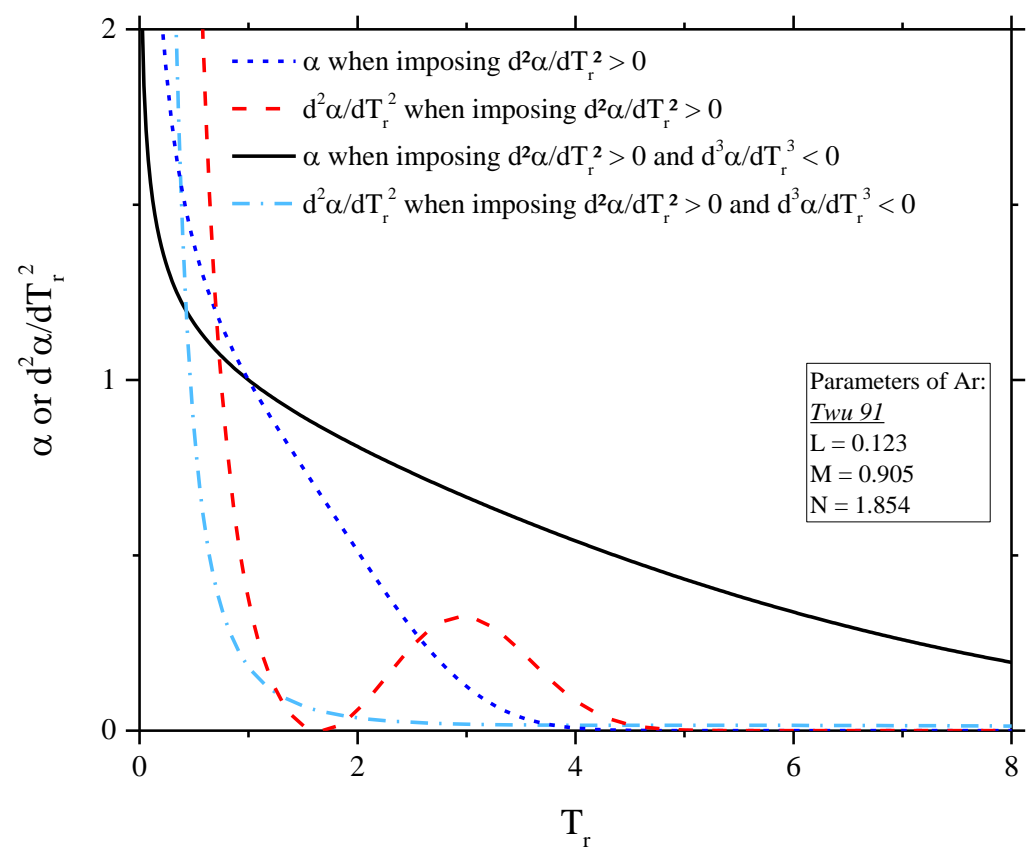

Figure 10. $\alpha$-function of argon and it second derivative when constraints $d^{2} \alpha / d^{2}>0$ and $\mathrm{d}^{3} \alpha / \mathrm{dT}^{3}<0$ are simultaneously applied. 

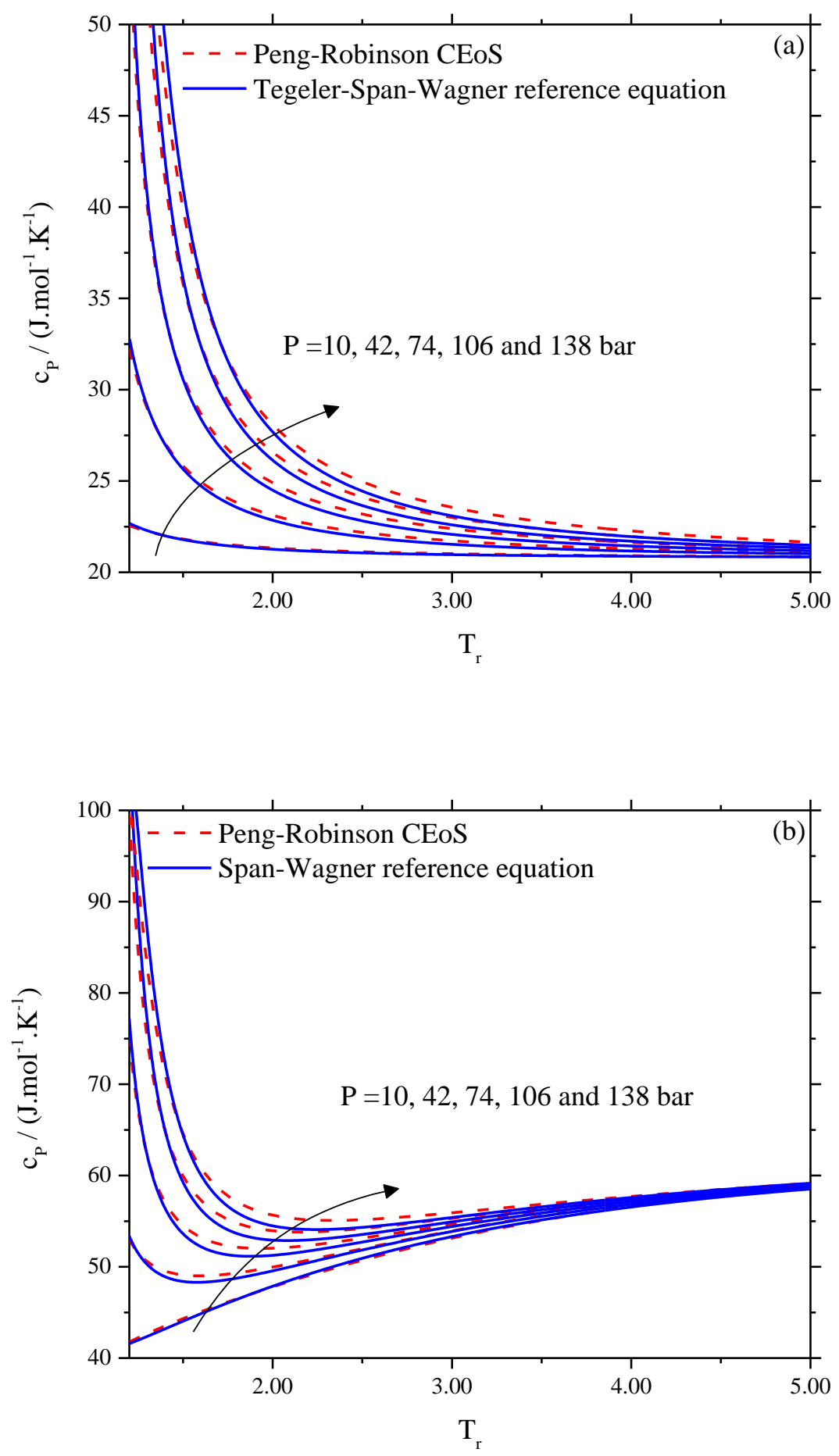

A consistency test for $\alpha$-functions of cubic equations of state 

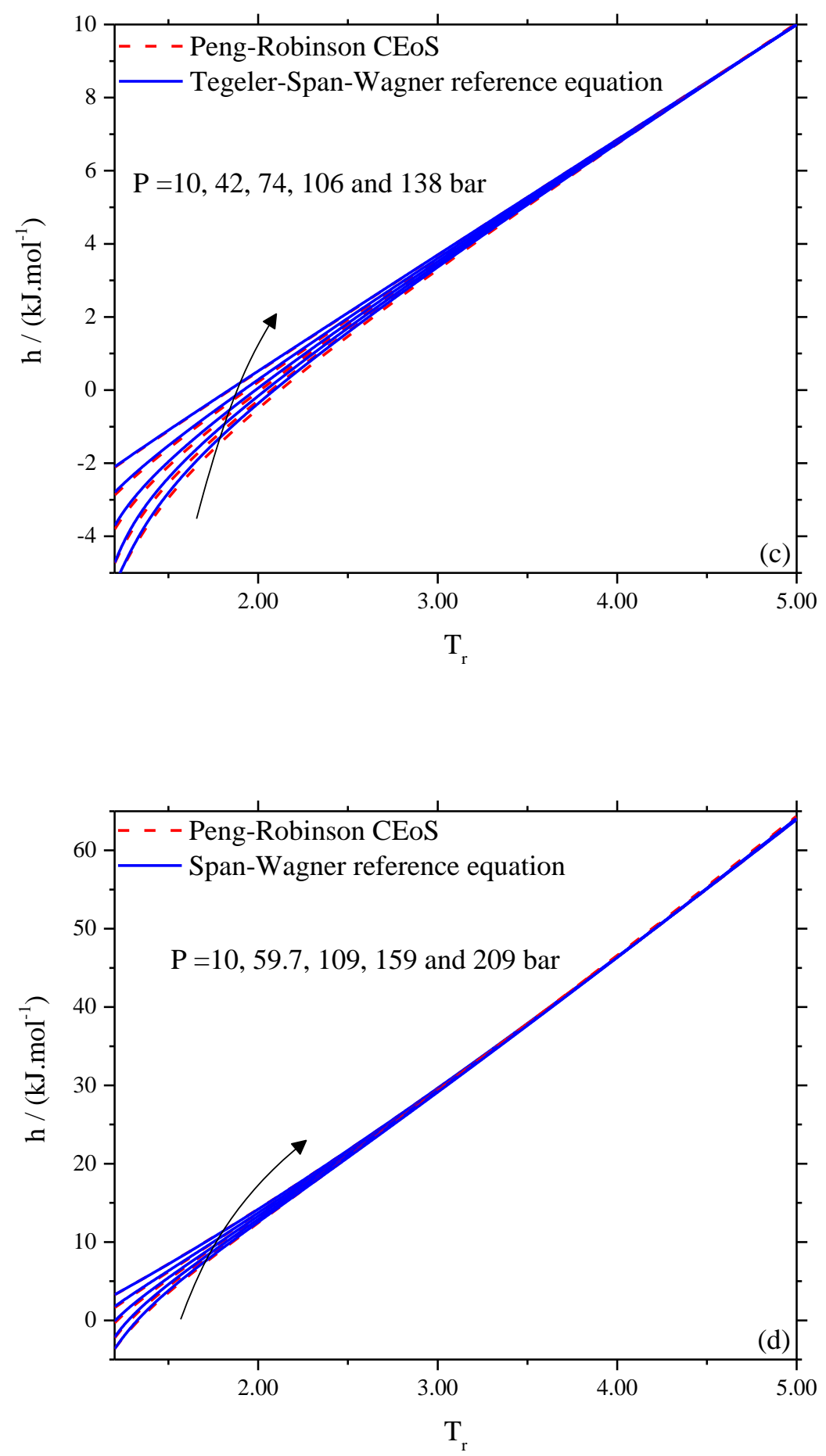

Figure 11. Prediction of supercritical $c_{\mathrm{P}}$ of $\operatorname{argon}(\mathrm{a})$ and $\mathrm{CO}_{2}(\mathrm{~b})$ and prediction of supercritical $\mathrm{h}$ of argon (c) and $\mathrm{CO}_{2}(\mathrm{~d})$ when constraints $\mathrm{d}^{2} \alpha / \mathrm{dT}^{2}>0$ and $\mathrm{d}^{3} \alpha / \mathrm{dT}^{3}<0$ are both applied. 


\begin{tabular}{|c|c|c|c|c|}
\hline \multirow{3}{*}{ Argon } & Constraints applied & Error $\mathrm{P}^{\text {sat }}$ & Error $\Delta_{\mathrm{vap}} \mathrm{H}$ & Error $\mathrm{c}_{\mathrm{p}, \mathrm{L}}^{\mathrm{sat}}$ \\
\hline & $\frac{\mathrm{d}^{2} \alpha}{\mathrm{dT}_{\mathrm{r}}^{2}} \geq 0$ & $0.27 \%$ & $2.16 \%$ & $3.95 \%$ \\
\cline { 2 - 5 } & $\frac{\mathrm{d}^{2} \alpha}{\mathrm{dT}_{\mathrm{r}}^{2}} \geq 0$ and $\frac{\mathrm{d}^{3} \alpha}{\mathrm{dT}_{\mathrm{r}}^{3}} \leq 0$ & $0.28 \%$ & $2.30 \%$ & $4.74 \%$ \\
\hline \multirow{2}{*}{$\mathrm{CO}_{2}$} & $\frac{\mathrm{d}^{2} \alpha}{\mathrm{dT}_{\mathrm{r}}^{2}} \geq 0$ & $0.56 \%$ & $0.92 \%$ & $5.52 \%$ \\
\cline { 2 - 5 } & $\frac{\mathrm{d}^{2} \alpha}{\mathrm{dT}_{\mathrm{r}}^{2}} \geq 0$ and $\frac{\mathrm{d}^{3} \alpha}{\mathrm{dT}_{\mathrm{r}}^{3}} \leq 0$ & $0.29 \%$ & $1.01 \%$ & $6.99 \%$ \\
\hline
\end{tabular}

Table 5. Comparison of the errors calculated on subcritical properties for $\mathrm{CO}_{2}$ and argon when only a constraint on the second derivative of the $\alpha$-function is applied and when the constraint on the third derivative is added to the previous one.

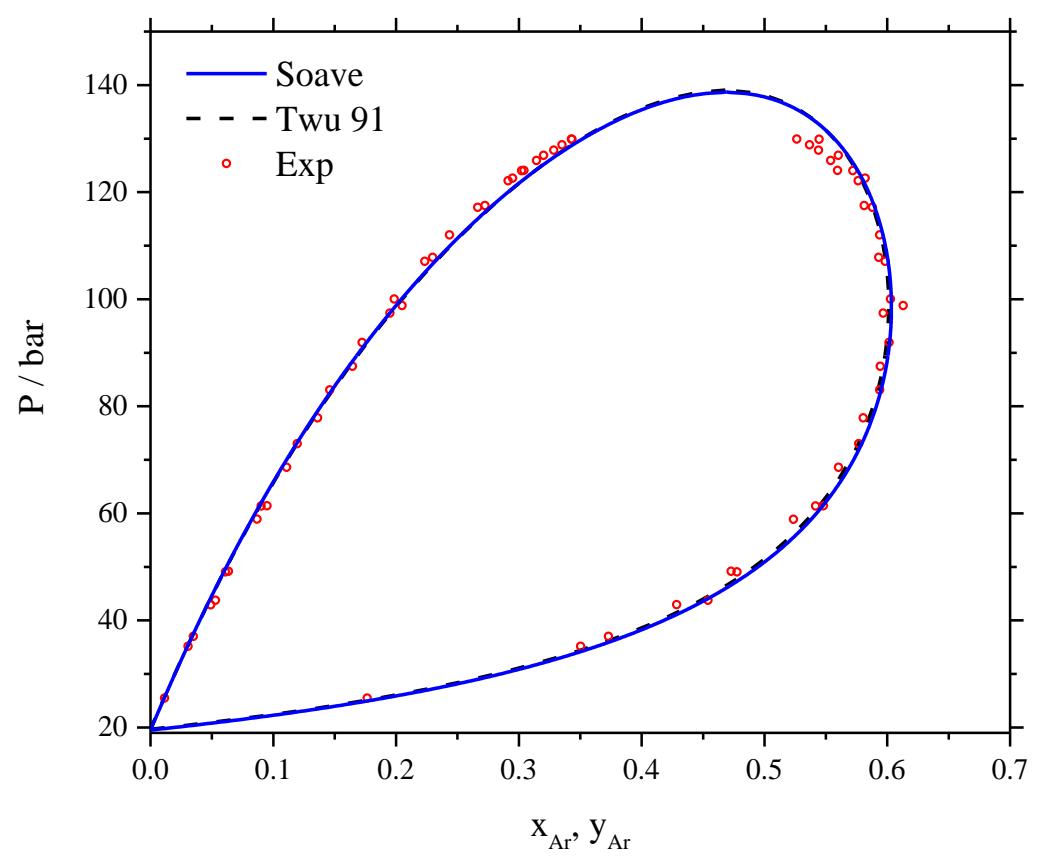

Figure 12. Binary phase diagram of the $\mathrm{CO}_{2}$-argon system at $253.1 \mathrm{~K}$ when constraints $\mathrm{d}^{2} \alpha / \mathrm{dT}^{2}>0$ and $\mathrm{d}^{3} \alpha / \mathrm{dT}^{3}<0$ are simultaneously applied.

In conclusion, the addition of a new negativity constraint on the third derivative of the $\alpha$ function (i) leads to a thermodynamically consistent $\alpha$-function on the whole temperature range, avoiding non-physical $c_{P}$ changes with respect to temperature, (ii) allows for a good prediction of subcritical properties used in the regression procedure and (iii) correctly extrapolates to the 
supercritical domain. We can thus claim that a proper $\alpha$-function must satisfy all the following constraints:

For all $\mathrm{T}:\left\{\begin{array}{lll||}\alpha \geq 0 & \text { and } & \alpha(\mathrm{T}) \text { continuous } \\ \frac{\mathrm{d} \alpha}{\mathrm{dT}} \leq 0 & \text { and } & \frac{\mathrm{d} \alpha}{\mathrm{dT}} \text { continuous } \\ \frac{\mathrm{d}^{2} \alpha}{\mathrm{dT}_{\mathrm{r}}^{2}} \geq 0 & \text { and } & \frac{\mathrm{d}^{2} \alpha}{\mathrm{dT}_{\mathrm{r}}^{2}} \text { continuous } \\ \frac{\mathrm{d}^{3} \alpha}{\mathrm{dT}_{\mathrm{r}}^{3}} \leq 0 & & \\ \hline\end{array}\right.$

The set of conditions reported in Eq. (19) establishes what we decided to call a "consistency test for an $\alpha$-function". In other words, if one of these constraints is not satisfied, the EoS will possibly return - depending on the temperature and pressure domain - inaccurate or unexpected values.

At this step, it could be argued that our derivations rely on the unique analysis of the $\mathrm{Ar}+\mathrm{CO}_{2}$ binary system which contains two molecules having the same size. In order to convince the reader that our conclusions are general, the size-asymmetric $\mathrm{CO}_{2}+n$-decane system is studied in the next section.

\section{Study of a size-asymmetric binary mixture with classical mixing-rules: case of the $\mathrm{CO}_{2}+\mathrm{n}-\mathrm{C}_{10}$ System}

In this section, our objective is to test the influence of the selected $\alpha$-function on the correlation of the properties of the $\mathrm{CO}_{2}+\mathrm{n}$-decane size-asymmetric binary system with the PR EoS. As was previously made, three $\alpha$-functions will be compared: the soave $\alpha$-function, an inconsistent Twu91 $\alpha$-function (which fails the proposed consistency test) and a consistent-Twu91 $\alpha$ function (which passes the proposed consistency test). To treat this system, classical mixing rules are preferred over complex mixing rules for two reasons: (i) excellent accuracy of prediction is achieved for this system by only regressing a $\mathrm{k}_{\mathrm{ij}}$ over experimental phase equilibrium data and (ii) discussion will be facilitated when it will come to compare different optimal $\mathrm{k}_{\mathrm{ij}}$ values. Their expressions are reported below: 


$$
\left\{\begin{array}{l}
a(T, x)=\sum_{i=1}^{N} \sum_{j=1}^{N} x_{i} x_{j} \sqrt{a_{i}(T) a_{j}(T)}\left(1-k_{i j}\right) \\
b(x)=\sum_{i=1}^{N} x_{i} b_{i}
\end{array}\right.
$$

In a first step, the isothermal $(P, x, y)$ phase diagram was calculated at $520 \mathrm{~K}$ with the 3 different $\alpha$-functions. For $\mathrm{CO}_{2}$, the parameters are those determined in the previous sections (see Table 2 and Table 4) and the plots of the inconsistent and consistent Twu91 $\alpha$-functions are shown in Figure 2 and Figure 9 respectively. For $n-C_{10}$, the three parameters of the Twu91 $\alpha$-function are those which minimize Eq. (13). They were determined twice: (i) without any specific constraints and (ii) by simultaneously imposing $\mathrm{d}^{2} \alpha / \mathrm{dT}^{2}>0$ and $\mathrm{d}^{3} \alpha / \mathrm{dT}^{3}<0$ in order to get a consistent $\alpha$-function. At $520 \mathrm{~K}, \mathrm{CO}_{2}$ is supercritical $\left(\mathrm{T}_{\mathrm{r}, \mathrm{CO}_{2}}=1.71\right)$ and as highlighted by Figure 2 and Figure 9, at such a temperature, the inconsistent and consistent Twu91 $\alpha$ functions have very different values. On the other hand, $n-C_{10}$ is subcritical $\left(T_{r, n-C_{10}}=0.84\right)$ so that the two Twu91 $\alpha$-functions, the parameters of which were fitted in this temperature range, have very similar values. Calculations of the phase diagrams at $520 \mathrm{~K}$ are reported in Figure 13. In this figure, no difference can be seen between the red full curve (Soave $\alpha$ function) and the blue dashed curve (consistent Twu91 $\alpha$-function): they are superimposed even in the vicinity of the critical pressure. Fitted $\mathrm{k}_{\mathrm{ij}}$ values to be used with the Soave and the consistent Twu91 $\alpha$-functions are also very close with respective values of 0.14 and 0.11 which correspond to expected values of this parameter. Figure 13 also highlights that the green dashed curve corresponding to the inconsistent Twu91 $\alpha$-function does not correlate badly the experimental data points although it over predicts the critical pressure. However, the major drawback with the use of this inconsistent $\alpha$-function is the value of the optimal $k_{i j}$ which was found to be equal to -2.43 , far beyond an acceptable value. This abnormal $\mathrm{k}_{\mathrm{ij}}$ value can be explained by the role this parameter plays when the inconsistent Twu91 $\alpha$-function is used. Indeed, in this case, the $\mathrm{k}_{\mathrm{ij}}$ endorses the role of a corrective term which restores the quality of prediction of the CEoS by counterbalancing the wrongly estimated $\alpha$-value of $\mathrm{CO}_{2}$ at $520 \mathrm{~K}$. At this step, one could believe that it is not necessary to regress the $\alpha$-function parameters by imposing the constraints listed in Eq. (19) as long as the $\mathrm{k}_{\mathrm{ij}}$, or any other parameter from any 
mixing rule, can compensate the defects of the $\alpha$-function. This reasoning is however not admissible because, as previously demonstrated, heat capacities and enthalpies of $\mathrm{CO}_{2}$ at 520 $\mathrm{K}$ will be extremely poorly predicted if the $\alpha$-function does not pass the proposed consistency test. Therefore, a too large $\mathrm{k}_{\mathrm{ij}}$ value is not only an unordinary value but also a warning against poorly regressed $\alpha$-function parameters that might lead to inaccurate predictions of supercritical properties of pure compounds.

In the next few lines, in order to convince the reader of the absolute necessity of using a consistent $\alpha$-function in their calculations, the mixing enthalpies $\left(h^{\mathrm{M}}\right)$ of the $\mathrm{CO}_{2}+\mathrm{n}-\mathrm{C}_{10}$ system are predicted with the three considered $\alpha$-functions (Soave, consistent and inconsistent Twu91). Calculations are performed at 125 bar and at $470.11 \mathrm{~K}$ and $573.11 \mathrm{~K}$ and the results are reported in Figure 14 and Figure 15. At 470.11 K and 125 bar (Figure 14), the inconsistent Twu91 $\alpha$ function (that corresponds to $\mathrm{k}_{\mathrm{ij}}=-2.43$ ) over predicts by a factor 100 the experimental mixing enthalpies and wrongly predicts a one-phase system whatever the composition is. On the other hand, coupling a $\mathrm{k}_{\mathrm{ij}}$ of 0.11 with the consistent Twu91 $\alpha$-function or a $\mathrm{k}_{\mathrm{ij}}$ of 0.14 with the Soave $\alpha$-function leads to an accurate prediction of $\mathrm{h}^{\mathrm{M}}$. It is believed that the consistent Twu91 $\alpha$-function performs better than the Soave $\alpha$-function (see Figure 14b) because its parameters were not only regressed on vapor pressures but also on vaporization enthalpies and heat capacities (Soave solely parameterized his $\alpha$-function with the objective of reproducing the experimental vapor pressures). At $573.11 \mathrm{~K}$ and 125 bar (Figure 15) a non-existing VLE is predicted and poor results are obtained for the mixing enthalpies when a $\mathrm{k}_{\mathrm{ij}}$ of -2.34 is coupled with the inconsistent Twu91 $\alpha$-function while the two others $\alpha$-functions allow for an excellent adequacy between the experimental points and the predicted curves.

In conclusion, we can state that the constraints defined by Eq. (19) apply whatever the binary system. This section also pointed out that the classical Van der Waals mixing rules, involving a $\mathrm{k}_{\mathrm{ij}}$, do not permit to overcome the limitations of a poorly regressed $\alpha$-function. Indeed, when a very large $\mathrm{k}_{\mathrm{ij}}$ is calculated to balance the deficiencies of a non-consistent $\alpha$-function, not so bad VLE correlation can be achieved but extremely poor predictions of the derived properties (here illustrated with the mixing enthalpies) is performed. 


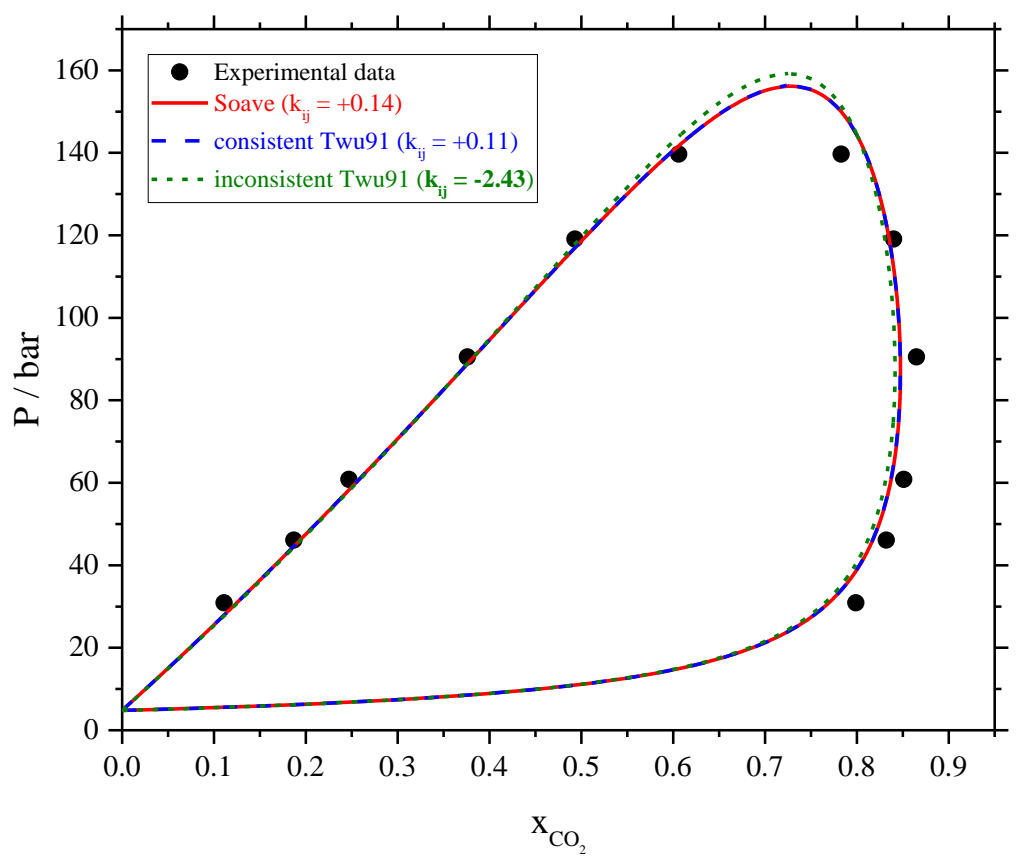

Figure 13. Prediction of the $\mathrm{CO}_{2}-\mathrm{n}-\mathrm{C}_{10}$ phase diagram at $520 \mathrm{~K}$ with different $\alpha$-functions and classical mixing rules. Red full curve is calculated with the Soave $\alpha$-function while blue and green dashed curves are calculated with the Twu91 $\alpha$-function. Parameters of the $\alpha$-function used to calculate the green curve do not satisfy the consistency test while parameters of the blue curve do.
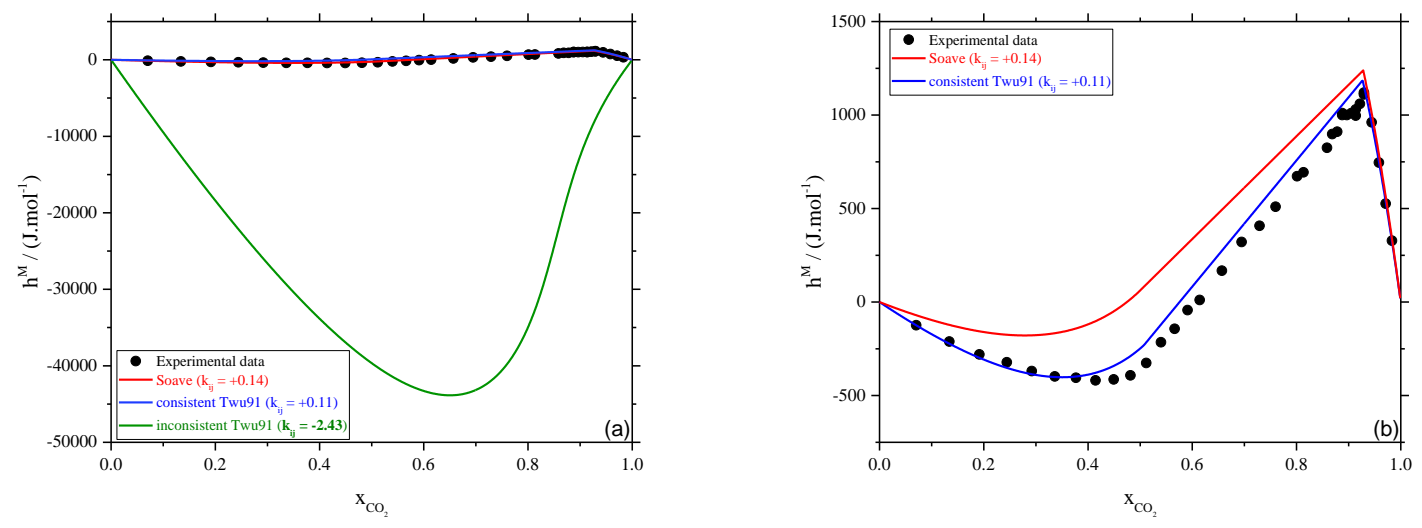

Figure 14. Calculation of the mixing enthalpies of the $\mathrm{CO}_{2}-\mathrm{n}-\mathrm{C}_{10}$ system at $470.11 \mathrm{~K}$ and 125 bar. 


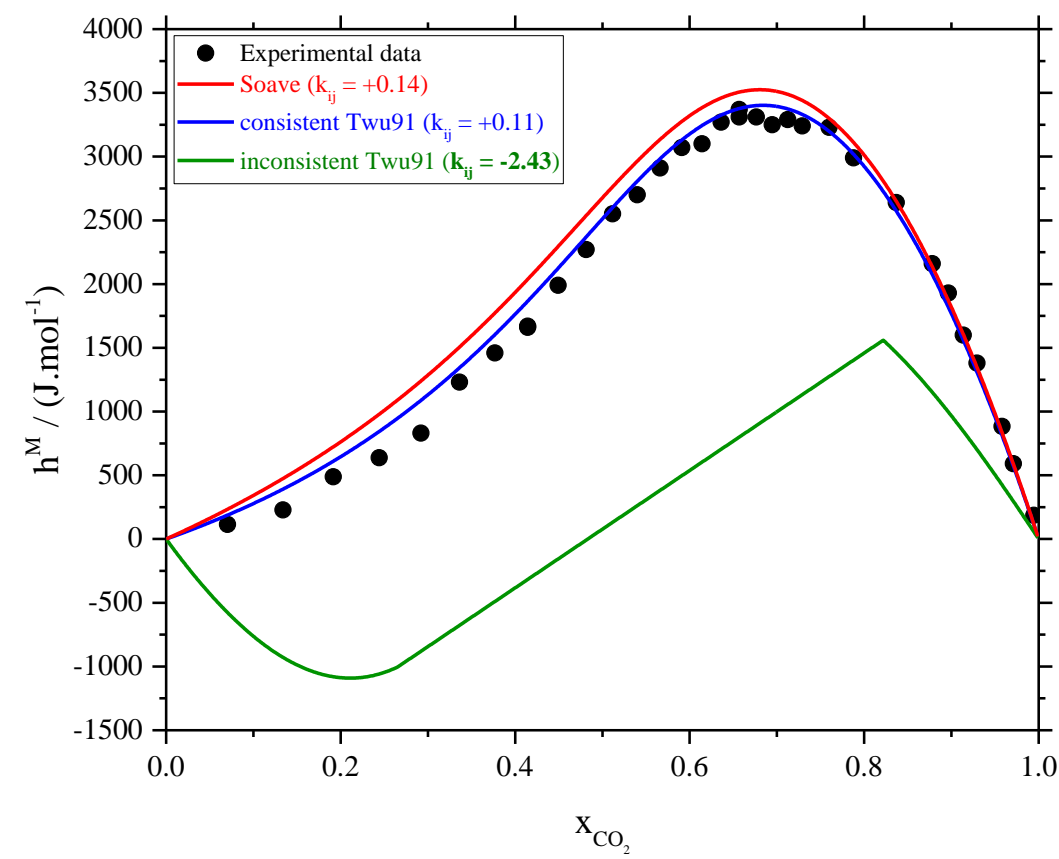

Figure 15. Calculation of the mixing enthalpies of the $\mathrm{CO}_{2}-\mathrm{n}-\mathrm{C}_{10}$ system at $573.11 \mathrm{~K}$ and 125 bar.

Although it is claimed that the consistency test developed in this paper apply whatever the component, a special attention should be paid to the so-called "quantic fluids" like $\mathrm{He}$ and $\mathrm{H}_{2}$. This is the aim of the next section. 


\section{The special case of quantic fluids $\left(\mathrm{H}_{2}\right.$ and $\mathrm{He}$ )}

$\mathrm{He}_{\mathrm{e}}$ and $\mathrm{H}_{2}$, the critical temperatures of which are $5.20 \mathrm{~K}$ and $33.15 \mathrm{~K}$ respectively, are qualified of quantic fluids as their low temperature physical behaviors can only be represented if quantum effects are taken into account in the modelling procedure. Consequently, they must be treated apart from other classical fluids. As an example, Gasem et al. [40] and Mahmoodi et al. [22] noticed that when $\alpha$-functions of $\mathrm{H}_{2}$ and $\mathrm{He}$ are both regressed on vapor pressures, they exhibit an increasing $(\mathrm{d} \alpha / \mathrm{dT}>0)$ and concave portion $\left(\mathrm{d}^{2} \alpha / \mathrm{dT}^{2}<0\right)$ followed, at least for $\mathrm{H}_{2}$, by a decreasing $(\mathrm{d} \alpha / \mathrm{dT}<0)$ and convex portion $\left(\mathrm{d}^{2} \alpha / \mathrm{dT}^{2}>0\right)$ in the supercritical domain.

Working with quantic fluids and in order to determine the proper shape (convex or concave) of $\alpha$-functions in the subcritical temperature range, let us recall that $\mathrm{c}_{\mathrm{v}}^{\text {res }}$ and the second derivative of the $\alpha$-function have always the same sign. We indeed can write:

$$
c_{\mathrm{v}}^{\mathrm{res}}(\mathrm{T}, \mathrm{v})=\underbrace{\frac{\mathrm{Ta}_{\mathrm{c}}}{\mathrm{b}\left(\mathrm{r}_{1}-\mathrm{r}_{2}\right)} \ln \left(\frac{\mathrm{v}-\mathrm{r}_{2} \mathrm{~b}}{\mathrm{v}-\mathrm{r}_{1} \mathrm{~b}}\right)}_{>0} \times \frac{\mathrm{d}^{2} \alpha}{\mathrm{dT}^{2}}
$$

Along the vaporization curve, i.e. when the pure component is in VLE, the 2 phases have the same temperature i.e. the same $\mathrm{d}^{2} \alpha / \mathrm{dT}^{2}$ value and both the liquid and vapor phases $c_{\mathrm{v}}^{\text {res }}$ calculated from a CEoS have the same sign (the sign of the second derivative of the $\alpha$-function). Extracted from the NIST database, the quantity $\mathrm{c}_{\mathrm{v}}^{\mathrm{res}}$ of $\mathrm{He}$ and $\mathrm{H}_{2}$ for both the liquid and vapor phases are shown in Figure 16 and Figure 17.

One can see that for $\mathrm{H}_{2}$ at a temperature lower than $28.5 \mathrm{~K}$, experimental $\mathrm{c}_{\mathrm{v}}^{\text {res }}$ of the liquid phase is negative while it is positive for the vapor phase. Therefore, at these low temperatures, where fluids are quantic, the second derivative of the $\alpha$-function should be both positive and negative. This contradiction leads us to affirm that the same $\alpha$-function cannot represent simultaneously the liquid and vapor phases. In other words, these fluids do not follow the 3parameter law of corresponding states in the low temperature range. It is also possible to conclude that $\mathrm{c}_{\mathrm{v}}^{\text {res }}$ data in the subcritical temperature range are not relevant data to fit the parameters of $\alpha$-functions. 
Although the quantum effects cannot be described by a 2-parameter CEoS, it would be valuable to accurately represent the behavior of $\mathrm{He}$ and $\mathrm{H}_{2}$ in some specific temperature ranges due to their use in some chemical process plants. First, it must be noticed that in most applications, the operating temperature is far above the respective critical temperatures of these two compounds. Therefore, focusing on the subcritical temperature range is not relevant. Secondly, it is expected that at reasonably high temperatures the $\alpha$-function of each of these pure compounds behaves like a classical fluid, i.e. it satisfies, all the criteria defined by Eq.(19).

In order to verify whether or not $\alpha$-functions of $\mathrm{He}$ and $\mathrm{H}_{2}$ at sufficiently high temperatures behave conventionally, a regression of the Twu91 parameters was performed on both subcritical $\left[\mathrm{P}^{\text {sat }}(\mathrm{T})\right.$ and $\left.\Delta_{\mathrm{vap}} \mathrm{H}(\mathrm{T})\right]$ and supercritical $\left[\mathrm{c}_{\mathrm{v}}^{\text {res }}(\mathrm{T}, \mathrm{P})\right.$ and $\left.\mathrm{h}^{\text {res }}(\mathrm{T}, \mathrm{P})\right]$ data. The same weight was given to all the properties. Subcritical $\mathrm{c}_{\mathrm{v}}^{\text {res }}$ were excluded from the regression procedure since values for the liquid and vapor phases are conflicting. The supercritical experimental data were generated using the NIST database at pressures of 10, 100 and 1000 bar, for temperatures varying between 150 and $750 \mathrm{~K}$ with a step of $50 \mathrm{~K}$. For comparison purpose, regression of the $\alpha$-function parameters was also performed on (i) only subcritical data and (ii) only supercritical data. Results of these calculations are reported in Figure 18 and Figure 19 and numerical values of the MAPE are reported in Table 6.

Results shown in Figure 18 and Figure 19 are in accordance with previous literature studies as almost all $\alpha$-functions are increasing functions of temperature in the low temperature range. The single exception is the $\alpha$-curve of $\mathrm{H}_{2}$ with parameters regressed on supercritical data which is a monotonically decreasing, convex function of temperature. This result is highly reassuring as at temperatures above $150 \mathrm{~K}$ (the smallest temperature of the experimental supercritical data) we expect the fluid not to behave as a "quantic fluid" anymore, i.e. to respect the constraints defined by Eq. (19). The following conclusions can be drawn from Table 7, Figure 18 and Figure 19:

- When the L, M and $\mathrm{N}$ parameters are only regressed on subcritical data, excellent representation of the subcritical properties is achieved although an increasing $\alpha$-function is calculated on this temperature range, demonstrating the unusual behavior of fluids in “quantic state". Meanwhile, supercritical properties are poorly represented (see Table 8). As seen in Figure 18, in the case of $\mathrm{He}$, the $\alpha$-function goes to zero at a temperature of $40 \mathrm{~K}$ (red dashed curve) and, thus, is unable to accurately extrapolate at higher temperatures making this $\alpha$-function unsuitable for most of the actual processes involving this molecule. 
- When the $\alpha$-function parameters are regressed on both subcritical and supercritical properties, a slight accuracy decrease of prediction is observed for the subcritical properties while supercritical ones are largely improved. This enhancement is caused by the shape of the $\alpha$-function at high temperature, which is adjusted to represent the residual heat capacities and enthalpies. This improvement is obvious when attention is paid to the change of the $\mathrm{He}$ $\alpha$-function with respect to the case when only subcritical data were regressed. Now the $\alpha$ function is very different from zero at temperatures above $150 \mathrm{~K}$, dividing by two the error over heat capacities while leaving almost unchanged the other properties. An excellent improvement of the supercritical properties is also achieved when considering $\mathrm{H}_{2}$.

- Finally, regression on solely supercritical properties is not desirable as errors on saturated pressures and vaporization enthalpies skyrocket while the benefit on the prediction accuracy of supercritical properties is not significant. More generally, one can observe that on the temperature range for which experimental data were generated and used in the regression procedure, the $\alpha$-function is a strictly decreasing, convex function of temperature. A graphical representation of the third derivative would show that it is negative. This confirms that molecules which behave as "quantic fluids" in the low temperature range do not keep this unusual tendency at higher temperature and that the consistency test, defined by Eq.(19) , is satisfied.

In conclusion, $\alpha$-functions of quantic fluids:

- Exhibit a bell shape (increasing and concave functions) below $40-50 \mathrm{~K}$.

- Become decreasing, convex and with a negative third derivative at temperatures higher than $50 \mathrm{~K}$ (i.e. they satisfy Eq. (19)).

- Should be regressed on both subcritical and supercritical data to achieve satisfying representation accuracy of the thermodynamic properties on the whole temperature range. 


\begin{tabular}{|c|c|c|c|c|c|}
\hline \multirow{5}{*}{} & & \multicolumn{3}{|c|}{ MAPE (\%) } \\
\hline \multirow{7}{*}{$\begin{array}{c}\text { Type of data } \\
\text { used in the } \\
\text { regression } \\
\text { procedure }\end{array}$} & $\mathrm{P}^{\text {sat }}$ & $\Delta_{\mathrm{vap}} \mathrm{H}$ & $\begin{array}{c}\text { Supercritical } \\
\mathrm{h}^{\text {res }}\end{array}$ & $\begin{array}{c}\text { Supercritical } \\
\mathrm{c}_{\mathrm{v}}^{\text {res }}\end{array}$ \\
\hline \multirow{3}{*}{ He } & Subcritical & 0.001 & 3.68 & 20.79 & 100.00 \\
\cline { 2 - 6 } & Supercritical & 141.44 & 78.29 & 21.30 & 24.17 \\
\cline { 2 - 6 } & Both & 1.75 & 7.00 & 18.09 & 42.77 \\
\hline \multirow{3}{*}{$\mathbf{H}_{2}$} & Subcritical & 0.02 & 3.17 & 54.52 & 58.91 \\
\cline { 2 - 6 } & Supercritical & 38.23 & 50.23 & 4.90 & 44.22 \\
\cline { 2 - 6 } & Both & 2.16 & 4.66 & 6.08 & 56.27 \\
\hline
\end{tabular}

Table 6. MAPE calculated for $\mathrm{He}$ and $\mathrm{H}_{2}$ with respect to the type of data used in the regression procedure of the Twu91 $\alpha$-function parameters (subcritical, supercritical or both).

After this debate on the particular behavior of quantic fluids, the next section aims at discussing which $\alpha$-functions, published in the open literature, pass the proposed consistency test (see Eq. (19)). 


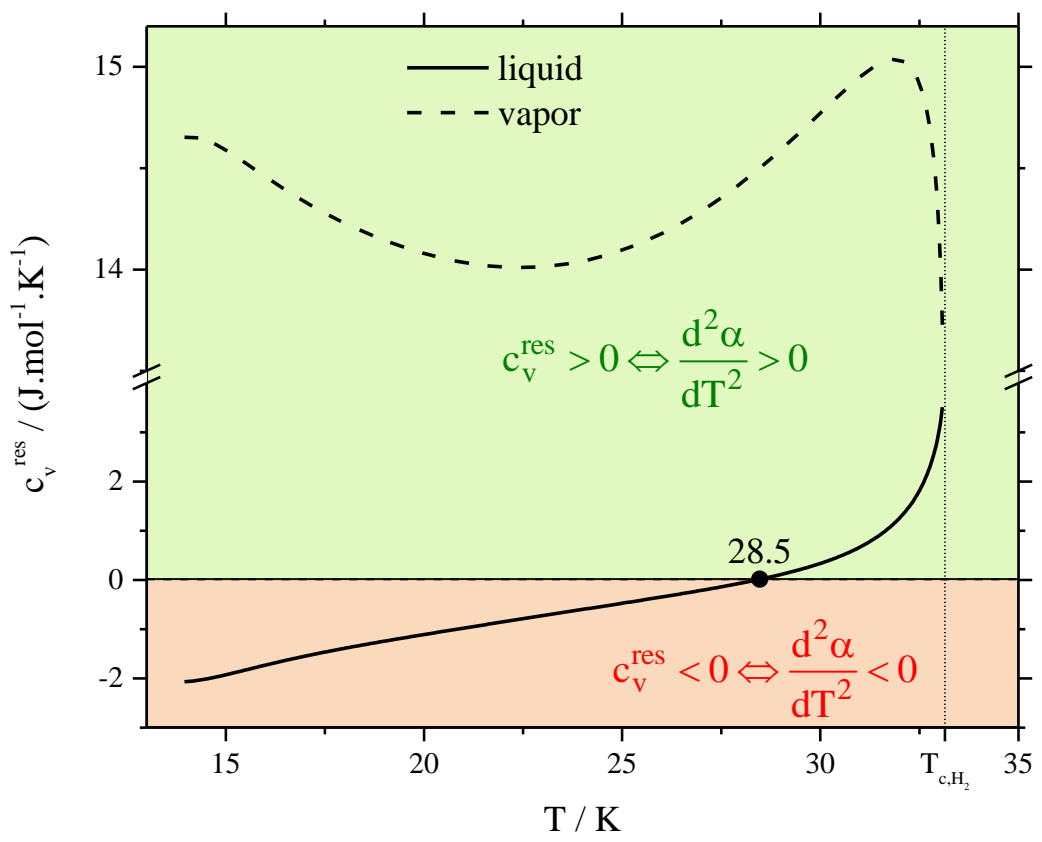

Figure 16. Residual heat capacities of vapor and liquid phases of saturated $\mathrm{H}_{2}$.

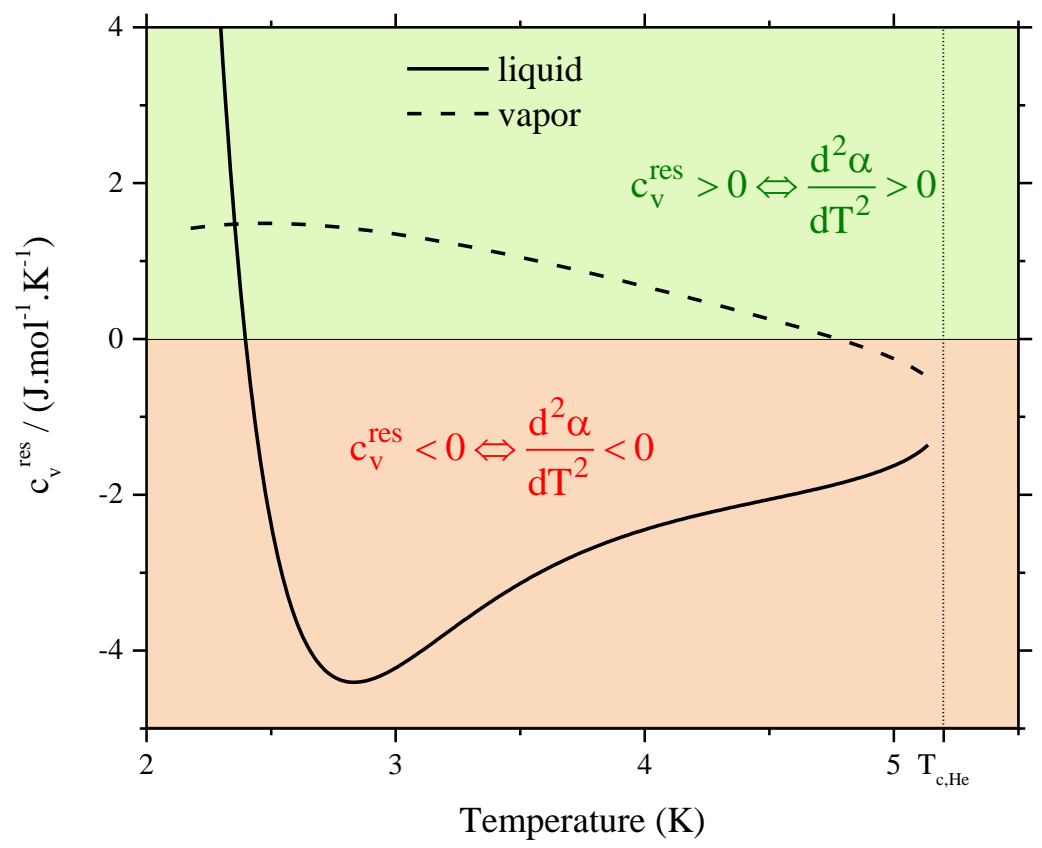

Figure 17. Residual heat capacities of vapor and liquid phases of saturated He. 


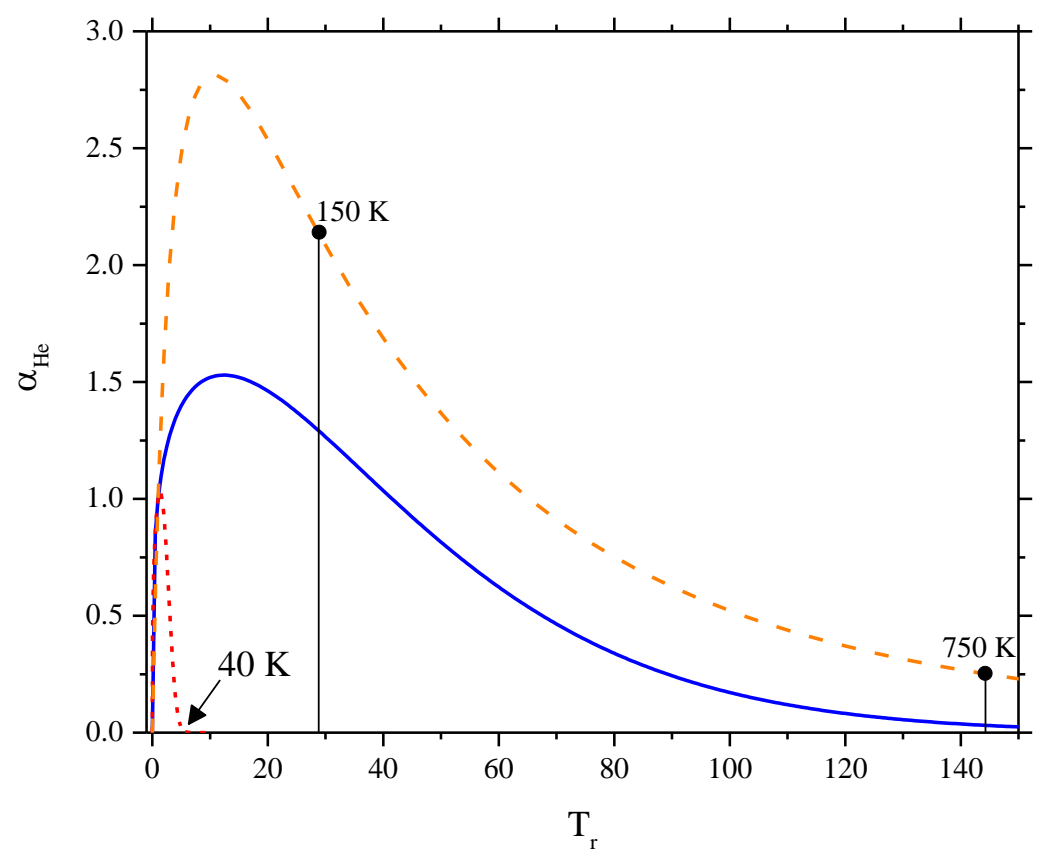

Figure 18. Optimized $\alpha$-functions of He. Small dashed curve is regressed on subcritical data, large dashed curve is regressed on supercritical data, full curve is regressed on both subcritical and supercritical data.

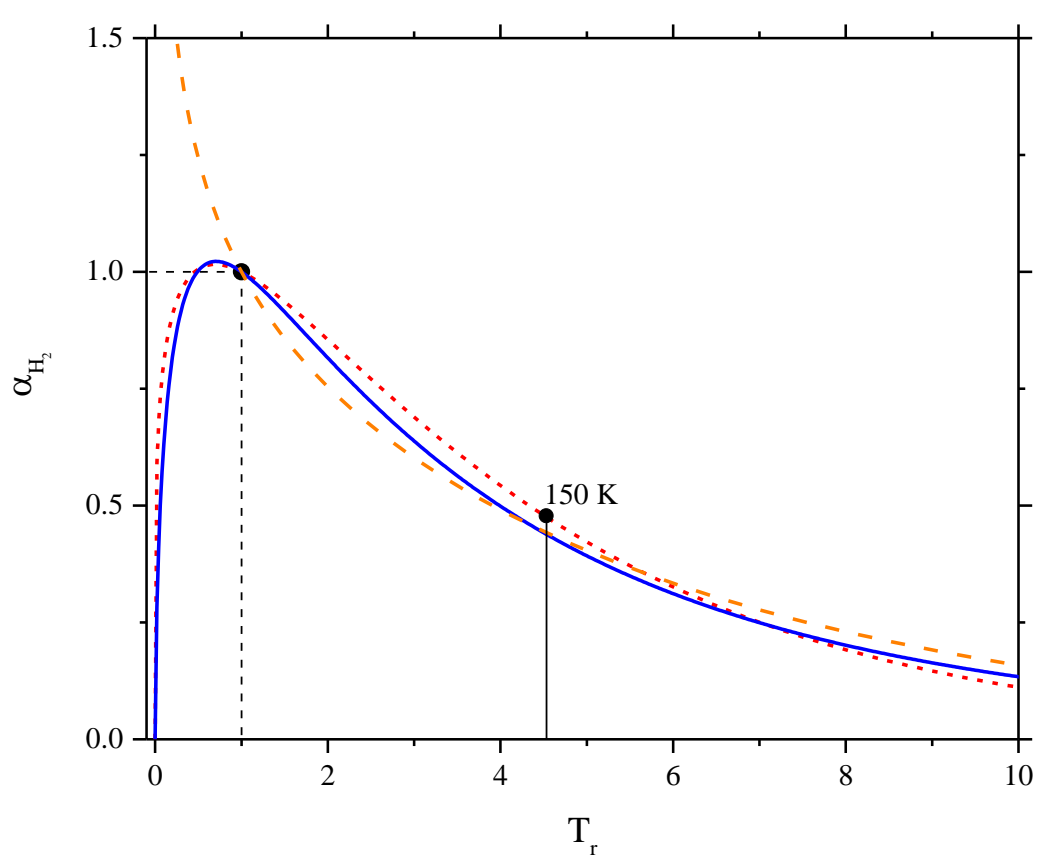

Figure 19. Optimized $\alpha$-functions of $\mathrm{H}_{2}$. Small dashed curve is regressed on subcritical data, large dashed curve is regressed on supercritical data, full curve is regressed on both subcritical and supercritical data.

A consistency test for $\alpha$-functions of cubic equations of state 


\section{Do current $\alpha$-functions available in the open literature pass the proposed consistency test?}

Mathematical conditions on the $\alpha$-function and its successive derivatives aimed at ensuring consistent and accurate calculations of thermodynamic properties in both subcritical and supercritical domains have been identified along the previous part of this paper (see Eq. (19)). This section evaluates which of the mostly used $\alpha$-functions of the literature fulfil all these conditions. Mathematical derivations are detailed in Appendices A to L and only main results are reported in Table 7.

The twelve selected $\alpha$-functions are those which are generally available in process simulation software. We selected:

1- Soave 1972

2- Soave 1984

3- Gibbons-Laughton

4- Stryjek-Vera

5- Mathias-Copeman

6- Mathias

7- Twu 1995

8- Boston-Mathias

9- Trebble-Bishnoi

10- Melhem-Saini-Goodwin

11- Twu 1988

12- Twu 1991

As highlighted in Table 7, eight over twelve of these well-known $\alpha$-functions (Soave 1972, Soave 1984, Gibbons-Laughton, Stryjek-Vera, Boston-Mathias, Mathias-Copeman, Mathias, Twu 1995) fail the proposed consistency test whatever the values of the parameters are. The four remaining $\alpha$-functions (Trebble-Bishnoi, Melhem-Saini-Goodwin, Twu 1988, Twu 1991) pass the test but only if constraints (sometimes drastic) are added to the parameters.

We can thus conclude that, presently, it is impossible to find an $\alpha$-function which passes our consistency test for any values of the parameters.

A consistency test for $\alpha$-functions of cubic equations of state 
From a practical point of view:

1- All $\alpha$-functions which derive from the Soave $\alpha$-function, the so-called "polynomial $\alpha$ functions", are not monotonically decreasing functions of temperature; therefore, special caution should be taken when those are applied to light supercritical compounds at reduced temperatures above the temperature at which the minimum of these $\alpha$-functions occurs.

2- The higher the number of adjustable parameters in $\alpha$-functions, the harder the optimization procedure will be since more constraints on the parameters will have to be added, to ensure that the function passes the consistency test. Two-parameter $\alpha$-functions appear as a good trade-off between complexity and flexibility of the $\alpha$-function formulation.

3- Piecewise $\alpha$-functions should at least have 2 parameters in the subcritical and supercritical temperature domains. Application of the continuity constraint of the first and second derivatives of an $\alpha$-function permits to establish relations between subcritical and supercritical parameters. As a consequence, thermodynamic properties, such as $\mathrm{h}$ and $\mathrm{c}_{\mathrm{v}}$, would be kept continuous at the critical temperature.

4- It should be noticed that, among the two generalized $\alpha$-functions studied in this paper (Soave and Twu 1995), none of them satisfies all the constraints of the proposed consistency test. For molecules with an acentric factor out of the range $[0 ; 1]$ or for the prediction of heat capacities just above the critical temperature, the Soave $\alpha$-function should be preferred.

\section{Conclusion}

- The main conclusion of this article is that $\alpha$-functions must:

1. Be of class $C^{2}$, i.e., their first $(\mathrm{d} \alpha / \mathrm{dT})$ and second $\left(\mathrm{d}^{2} \alpha / \mathrm{dT}^{2}\right)$ derivatives must exist and must be continuous for any temperature value,

2. Be positive for any temperature value $(\alpha(T) \geq 0)$,

3. Be monotonically decreasing for any temperature value $(\mathrm{d} \alpha / \mathrm{dT} \leq 0)$,

4. Be convex for any temperature value $\left(\mathrm{d}^{2} \alpha / \mathrm{dT}^{2} \geq 0\right)$,

5. Also verify $d^{3} \alpha / d T^{3} \leq 0$ for any temperature value.

All these requirements are absolutely necessary to get accurate and physically meaningful behaviors in both the subcritical and supercritical domains. Other key conclusions follow.

- The role of the $\alpha$-function is at least as important as the role of mixing rules. As highlighted with the $\mathrm{CO}_{2}$-argon binary system, even with the most elaborated mixing rules, an

A consistency test for $\alpha$-functions of cubic equations of state 
inconsistent $\alpha$-function will always lead to poor results if at least one component is supercritical. The reverse is also true: a consistent $\alpha$-function coupled with unsuitable mixing rules cannot lead to accurate results.

- When the parameters of component-specific $\alpha$-functions are fitted in order to pass our consistency test [Eq. (19)], pure component properties in the supercritical region are highly improved without deteriorating the accuracy of the calculated subcritical properties.

- The parameter-optimization procedure, aimed at determining the parameters of a given $\alpha$ function by minimizing the deviations between calculated and experimental vapor-liquid equilibrium data, can generate many sets of parameters leading to similar objective function values (meaning that the same behavior is observed when temperature is below the critical temperature of the pure compound) but inducing totally different behaviors in the supercritical domain. The constraints proposed in this paper make it possible to select the best set of parameters. It is believed that similar constraints should be developed for SAFTtype EoS [41]. It is indeed well-known that the fitting of the three parameters $m, \sigma$ and $\epsilon$ on saturation pressures and liquid densities leads to many triplets of solutions for which the objective function is the same.

- None of the $\alpha$-functions currently published in the open literature passes the proposed consistency test. Researches in this area thus need to be intensified.

\section{Acknowledgment}

The French Petroleum Company TOTAL and more particularly Dr. Pierre DUCHETSUCHAUX, Dr. Laurent AVAULLÉE and Freddy GARCIA (experts in thermodynamics) are gratefully acknowledged for sponsoring this research. 


\begin{tabular}{|c|c|c|c|c|c|c|c|}
\hline \multicolumn{2}{|r|}{$\alpha$-function } & $\begin{array}{l}\text { Class } \\
\mathrm{C}^{2}(*)\end{array}$ & $\alpha \geq 0$ & $\frac{\mathrm{d} \alpha}{\mathrm{dT}} \leq 0$ & $\frac{\mathrm{d}^{2} \alpha}{\mathrm{dT}_{\mathrm{r}}^{2}} \geq 0$ & $\frac{\mathrm{d}^{3} \alpha}{\mathrm{dT}_{\mathrm{r}}^{3}} \leq 0$ & Condition(s) \\
\hline $\begin{array}{c}\text { Soave (1972) } \\
{[3]}\end{array}$ & $\left\{\begin{array}{l}\alpha=\left[1+\mathrm{m}(\omega)\left(1-\sqrt{\mathrm{T}_{\mathrm{r}}}\right)\right]^{2} \\
\mathrm{~m}_{\mathrm{RK}}(\omega)=0.480+1.574 \omega-0.176 \omega^{2} \\
\mathrm{~m}_{\mathrm{PR}}(\omega)=0.37464+1.54226 \omega-0.26992 \omega^{2}\end{array}\right.$ & 曰 & $\square$ & 冈 & $\nabla$ & $\nabla$ & $\mathrm{m}(1+\mathrm{m}) \geq 0$ \\
\hline \multirow{4}{*}{$\begin{array}{c}\text { Soave (1984) } \\
{[24]}\end{array}$} & \multirow{4}{*}{$\alpha=1+\left(1-T_{r}\right)\left(a+\frac{b}{T_{r}}\right)$} & \multirow{4}{*}{$\nabla$} & \multicolumn{2}{|c|}{$a \geq 0$} & \multirow{4}{*}{ च } & \multirow{4}{*}{$\nabla$} & \multirow{4}{*}{$b>0$} \\
\hline & & & 凶 & $\nabla$ & & & \\
\hline & & & \multicolumn{2}{|c|}{$\mathrm{a} \leq 0$} & & & \\
\hline & & & च & 冈 & & & \\
\hline $\begin{array}{l}\text { Gibbons- } \\
\text { Laughton } \\
{[25]}\end{array}$ & $\alpha=1+X\left(T_{r}-1\right)+Y\left(\sqrt{T_{r}}-1\right)$ & च & $\square$ & $\boldsymbol{x}$ & च & $\nabla$ & $\left\{\begin{array}{l}\mathrm{X} \geq 0 \\
-2 \mathrm{X}-2 \sqrt{\mathrm{X}} \leq \mathrm{Y} \leq \min (0 ;-2 \mathrm{X}+2 \sqrt{\mathrm{X}})\end{array}\right.$ \\
\hline $\begin{array}{c}\text { Stryjek-Vera } \\
{[11]}\end{array}$ & $\begin{array}{l}\alpha=\left[1+\kappa\left(1-\sqrt{T_{r}}\right)\right]^{2} \\
\kappa=\kappa_{0}+\kappa_{1}\left(1+\sqrt{T_{r}}\right)\left(0.7-T_{r}\right) \\
\kappa_{0}=0.378893+1.4897153 \omega-0.17131848 \omega^{2}+0.0196554 \omega^{3} \\
\left\{\begin{array}{l}\kappa_{1}\left(T \leq 0.7 T_{c}\right) \neq 0 \\
\kappa_{1}\left(T>0.7 T_{c}\right)=0\end{array}\right.\end{array}$ & 凶 & 甲 & 凶 & ఐ & $\square$ & $\kappa(1+\kappa) \geq 0$ \\
\hline $\begin{array}{l}\text { Mathias- } \\
\text { Copeman } \\
\text { [10] }\end{array}$ & $\begin{array}{l}\alpha_{\mathrm{SUB}}=\alpha\left(\mathrm{T}_{\mathrm{r}} \leq 1\right)=\left[1+\mathrm{c}_{1}\left(1-\sqrt{\mathrm{T}_{\mathrm{r}}}\right)+\mathrm{c}_{2}\left(1-\sqrt{\mathrm{T}_{\mathrm{r}}}\right)^{2}+\mathrm{c}_{3}\left(1-\sqrt{\mathrm{T}_{\mathrm{r}}}\right)^{3}\right. \\
\alpha_{\mathrm{SUP}}=\alpha\left(\mathrm{T}_{\mathrm{r}}>1\right)=\left[1+\mathrm{m}(\omega)\left(1-\sqrt{\mathrm{T}_{\mathrm{r}}}\right)\right]^{2}\end{array}$ & 冈 & $\nabla$ & 冈 & $\nabla$ & $\nabla$ & \\
\hline Mathias [28] & $\begin{array}{l}\alpha_{\text {SUB }}=\alpha\left(T_{\mathrm{r}} \leq 1\right)=\left[1+\mathrm{m}(\omega)\left(1-\sqrt{\mathrm{T}_{\mathrm{r}}}\right)-\mathrm{p}\left(1-\mathrm{T}_{\mathrm{r}}\right)\left(0.7-\mathrm{T}_{\mathrm{r}}\right)\right]^{2} \\
\left\{\begin{array}{l}\alpha_{\text {SUP }}=\alpha\left(\mathrm{T}_{\mathrm{r}}>1\right)=\left[\exp \left[\mathrm{L}\left(1-\mathrm{T}_{\mathrm{r}}^{\gamma}\right)\right]\right]^{2} \\
\mathrm{~L}=1+\frac{\mathrm{m}}{2}+0.3 \mathrm{p} \\
\gamma=\frac{\mathrm{L}-1}{\mathrm{~L}}\end{array}\right.\end{array}$ & 冈 & $\nabla$ & & & & \\
\hline
\end{tabular}




\begin{tabular}{|c|c|c|c|c|c|c|c|}
\hline & $\alpha$-function & $\begin{array}{l}\text { Class } \\
\mathrm{C}^{2}(*) \\
\end{array}$ & $\alpha \geq 0$ & $\frac{\mathrm{d} \alpha}{\mathrm{dT}_{\mathrm{r}}} \leq 0$ & $\frac{\mathrm{d}^{2} \alpha}{\mathrm{dT}_{\mathrm{r}}^{2}} \geq 0$ & $\frac{\mathrm{d}^{3} \alpha}{\mathrm{dT}_{\mathrm{r}}^{3}} \leq 0$ & Condition(s) \\
\hline $\begin{array}{c}\text { Twu }(1995) \\
{[16,17]}\end{array}$ & 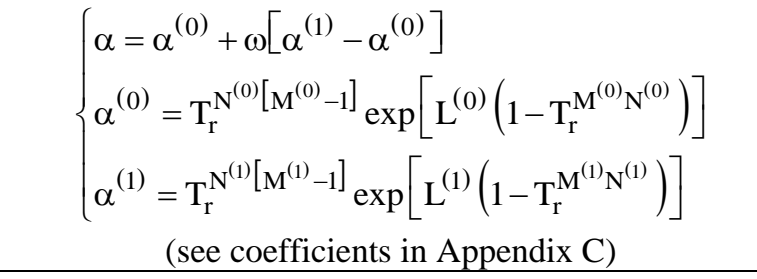 & $\nabla$ & $\square$ & $\square$ & $\square$ & 冈 & $\omega \in[0 ; 1]$ \\
\hline $\begin{array}{c}\text { Boston- } \\
\text { Mathias [19] }\end{array}$ & $\begin{array}{l}\alpha_{\mathrm{SUB}}=\alpha\left(\mathrm{T}_{\mathrm{r}} \leq 1\right)=\alpha_{\mathrm{SOAVE}}=\left[1+\mathrm{m}(\omega)\left(1-\sqrt{\mathrm{T}_{\mathrm{r}}}\right)\right]^{2} \\
\alpha_{\mathrm{SUP}}=\alpha\left(\mathrm{T}_{\mathrm{r}} \geq 1\right)=\exp \left[\mathrm{L}\left(1-\mathrm{T}_{\mathrm{r}}^{\gamma}\right)\right] \\
\left\{\begin{array}{l}\mathrm{L}=\frac{2 \mathrm{~m}}{1+\mathrm{m}} \\
\gamma=\frac{1+\mathrm{m}}{2}\end{array}\right.\end{array}$ & 叉 & $\square$ & & & & $0 \leq \mathrm{m} \leq 3$ \\
\hline $\begin{array}{c}\text { Trebble- } \\
\text { Bishnoi [26] } \\
\end{array}$ & $\alpha=\exp \left[L\left(1-T_{r}\right)\right]$ & $\nabla$ & $\square$ & $\square$ & 甲 & $\square$ & $\mathrm{L} \geq 0$ \\
\hline $\begin{array}{c}\text { Melhem- } \\
\text { Saini- } \\
\text { Goodwin } \\
{[27]}\end{array}$ & $\alpha=\exp \left[m\left(1-T_{r}\right)+n\left(1-\sqrt{T_{r}}\right)^{2}\right]$ & $\nabla$ & $\square$ & $\square$ & $\square$ & $\nabla$ & $\mathrm{m} \geq \mathrm{n} \geq 0$ \\
\hline $\begin{array}{c}\text { Twu (1988) } \\
{[14]}\end{array}$ & $\alpha=\mathrm{T}_{\mathrm{r}}^{2(\mathrm{M}-1)} \exp \left[\mathrm{L}\left(1-\mathrm{T}_{\mathrm{r}}^{2 \mathrm{M}}\right)\right]$ & 口 & $\square$ & $\square$ & $\nabla$ & $\square$ & $\left\{\begin{array}{l}\mathrm{LM} \geq 0 \\
\mathrm{M} \leq 0.8909\end{array}\right.$ \\
\hline
\end{tabular}




\begin{tabular}{|c|c|c|c|c|c|c|c|}
\hline & $\alpha$-function & $\begin{array}{l}\text { Class } \\
\mathrm{C}^{2}(*)\end{array}$ & $\alpha \geq 0$ & $\frac{\mathrm{d} \alpha}{\mathrm{d} \mathrm{T}_{\mathrm{r}}} \leq 0$ & $\frac{\mathrm{d}^{2} \alpha}{\mathrm{dT}_{\mathrm{r}}^{2}} \geq 0$ & $\frac{\mathrm{d}^{3} \alpha}{\mathrm{dT}_{\mathrm{r}}^{3}} \leq 0$ & Condition(s) \\
\hline $\begin{array}{c}\text { Twu (1991) } \\
{[15]}\end{array}$ & $\alpha=T_{r}^{\delta} \exp \left[L\left(1-T_{r}^{\gamma}\right)\right]$ & ఐ & ఐ & ఐ & च & $\nabla$ & $\begin{array}{l}\left\{\begin{array}{l}\delta \leq 0 \\
\mathrm{~L} \gamma \geq 0 \\
\gamma \leq 1-\delta\end{array}\right. \\
\text { or } \\
\left\{\begin{array}{l}\delta \leq 0 \\
\mathrm{~L} \gamma \geq 0 \\
\gamma \leq 1-2 \delta+2 \sqrt{\delta(\delta-1)} \\
4 \mathrm{Y}^{3}+4 \mathrm{ZX}+27 \mathrm{Z}^{2}-18 \mathrm{XYZ}-\mathrm{X}^{2} \mathrm{Y}^{2} \geq 0\end{array}\right. \\
\text { with } \\
\left\{\begin{array}{l}\mathrm{X}=-3(\gamma+\delta-1) \\
\mathrm{Y}=\gamma^{2}+3 \delta \gamma-3 \gamma+3 \delta^{2}-6 \delta+2 \\
\mathrm{Z}=-\delta\left(\delta^{2}-3 \delta+2\right)\end{array}\right.\end{array}$ \\
\hline
\end{tabular}

Table 7. Mathematical analysis of the mostly used $\alpha$-functions.

(*) $\alpha$ function is said to be of class $\mathrm{C}^{2}$ if the function, its first derivative and its second derivative are all continuous. 


\section{Appendices}

\section{Appendix A: mathematical study of the Twu91 $\alpha$-function [15]}

Although classically expressed by introducing 3 adjustable parameters denoted L, M and N (see Eq. (A.1)), the Twu91 $\alpha$-function can be alternatively written under a simpler form involving three different adjustable parameters denoted L, $\delta$ and $\gamma$ (this form appears more convenient to perform a mathematical analysis of the function and its derivatives):

$$
\begin{gathered}
\alpha\left(\mathrm{T}_{\mathrm{r}}\right)=\mathrm{T}_{\mathrm{r}}^{\mathrm{N}(\mathrm{M}-1)} \exp \left[\mathrm{L}\left(1-\mathrm{T}_{\mathrm{r}}^{\mathrm{MN}}\right)\right] \\
\alpha\left(\mathrm{T}_{\mathrm{r}}\right)=\mathrm{T}_{\mathrm{r}}^{\delta} \exp \left[\mathrm{L}\left(1-\mathrm{T}_{\mathrm{r}}^{\gamma}\right)\right]
\end{gathered}
$$

where $\delta$ and $\gamma$ are related to $\mathrm{M}$ and $\mathrm{N}$ following:

$$
\left\{\begin{array} { l } 
{ \delta = N ( M - 1 ) } \\
{ \gamma = N M }
\end{array} \Leftrightarrow \left\{\begin{array}{l}
\mathrm{N}=\gamma-\delta \\
M=\frac{\gamma}{\gamma-\delta}
\end{array}\right.\right.
$$

- Is the $\boldsymbol{\alpha}$-function of class $\mathbf{C}^{2}$ ? Yes.

It is recalled that a given function is said to be of class $C^{2}$ if its first and second derivatives exist and are continuous.

- Is the $\alpha$-function always positive? Yes.

- Is the first derivative of the $\alpha$-function always negative?

The first derivative of this $\alpha$-function is

$$
\left\{\begin{array}{l}
\frac{d \alpha}{\mathrm{dT}_{\mathrm{r}}}\left(\mathrm{T}_{\mathrm{r}}\right)=-\frac{\alpha\left(\mathrm{T}_{\mathrm{r}}\right)}{\mathrm{T}_{\mathrm{r}}} \mathrm{P}\left(\mathrm{T}_{\mathrm{r}}\right) \\
\mathrm{P}\left(\mathrm{T}_{\mathrm{r}}\right)=-\delta+\mathrm{L} \gamma \mathrm{T}_{\mathrm{r}}^{\gamma}
\end{array}\right.
$$

The quantity $\frac{d \alpha}{d T_{r}}\left(T_{r}\right)$ is positive provided $P\left(T_{r}\right)$ is positive itself.

Study of the sign of $\mathrm{P}\left(\mathrm{T}_{\mathrm{r}}\right)$ (reported in Table A.1): $\mathrm{T}_{\mathrm{r}}$ is positive so $\mathrm{P}$ is a monotonic function of $T_{r}$. Therefore, $P\left(T_{r}\right)$ is positive for any value of $T_{r}>0$ if the limits of $P$ are both positive when $\mathrm{T}_{\mathrm{r}}$ tends to 0 or to $+\infty$. 


\begin{tabular}{|c|c|c|c|c|}
\hline & \multicolumn{2}{|c|}{$\gamma>0 \Rightarrow\left\{\begin{array}{c}\lim _{\mathrm{T}_{\mathrm{r}} \rightarrow 0} \mathrm{~T}_{\mathrm{r}}^{\gamma}=0 \\
\lim _{\mathrm{T}_{\mathrm{r}} \rightarrow+\infty} \mathrm{T}_{\mathrm{r}}^{\gamma}=+\infty\end{array}\right.$} & \multicolumn{2}{|c|}{$\gamma<0 \Rightarrow\left\{\begin{array}{c}\lim _{\mathrm{T}_{\mathrm{r}} \rightarrow 0} \mathrm{~T}_{\mathrm{r}}^{\gamma}=+\infty \\
\lim _{\mathrm{T}_{\mathrm{r}} \rightarrow+\infty} \mathrm{T}_{\mathrm{r}}^{\gamma}=0\end{array}\right.$} \\
\hline $\lim _{\mathrm{T}_{\mathrm{r}} \rightarrow 0} \mathrm{P}\left(\mathrm{T}_{\mathrm{r}}\right)$ & $-\delta$ & $-\delta$ & $-\infty$ & $+\infty$ \\
\hline $\lim _{\mathrm{T}_{\mathrm{r}} \rightarrow+\infty} \mathrm{P}\left(\mathrm{T}_{\mathrm{r}}\right)$ & $+\infty$ & $-\infty$ & $-\delta$ & $-\delta$ \\
\hline $\begin{array}{c}\text { Acceptable } \\
\text { solution? }\end{array}$ & $\begin{array}{c}\mathrm{Yes}, \text { if } \\
\delta<0\end{array}$ & No & No & $\begin{array}{c}\mathrm{L}<0 \\
\delta<0\end{array}$ \\
\hline
\end{tabular}

Table A.1. Limit of $\mathrm{P}$ at the infinite temperature limit with respect to the signs of $\mathrm{L}$ and $\gamma$.

Summary: $P\left(T_{r}\right)$ is positive for any positive value of $T_{r}$ if:

$$
\left\{\begin{array}{l}
\mathrm{L} \gamma>0 \\
\delta<0
\end{array}\right.
$$

\section{- Is the second derivative of the $\alpha$-function always positive?}

Following Eq. (A.5), it is now assumed that $\mathrm{L} \gamma>0$ and $\delta<0$. The second derivative of the Twu91 $\alpha$-function writes

$$
\left\{\begin{array}{l}
\frac{\mathrm{d}^{2} \alpha}{\mathrm{dT}_{\mathrm{r}}^{2}}\left(\mathrm{~T}_{\mathrm{r}}\right)=\frac{\alpha\left(\mathrm{T}_{\mathrm{r}}\right)}{\mathrm{T}_{\mathrm{r}}^{2}} \mathrm{Q}(\theta) \\
\mathrm{Q}(\theta)=\theta^{2}-(2 \delta+\gamma-1) \theta+\delta(\delta-1) \\
\theta=\mathrm{L} \gamma \mathrm{T}_{\mathrm{r}}^{\gamma}
\end{array}\right.
$$

$\mathrm{T}_{\mathrm{r}}$ and $\mathrm{L} \gamma$ being positive, the variable $\theta$ is also positive. Polynomial $\mathrm{Q}(\theta)$ is positive if [41]:

$$
\left\{\begin{array}{l}
-(2 \delta+\gamma-1)>-2 \sqrt{\delta(\delta-1)} \\
\text { and } \\
\delta(\delta-1)>0
\end{array}\right.
$$

Since $\delta<0$, the second condition of Eq. (A.7) is already true and can be left aside. Finally, Eq. (A.7) leads to a single inequality:

$$
\gamma<1-2 \delta+2 \sqrt{\delta(\delta-1)}
$$

\section{- Is the third derivative of the $\alpha$-function always negative?}

Inequalities (A.5) and (A.8) are now assumed to be true. The third derivative of the Twu91 $\alpha$ function is:

A consistency test for $\alpha$-functions of cubic equations of state 


$$
\left\{\begin{array}{l}
\frac{\mathrm{d}^{3} \alpha}{\mathrm{dT}_{\mathrm{r}}^{3}}\left(\mathrm{~T}_{\mathrm{r}}\right)=-\frac{\alpha\left(\mathrm{T}_{\mathrm{r}}\right)}{\mathrm{T}_{\mathrm{r}}^{3}} \mathrm{R}(\theta) \\
\mathrm{R}(\theta)=\theta^{3}-3(\gamma+\delta-1) \theta^{2}+\left(\gamma^{2}+3 \delta \gamma-3 \gamma+3 \delta^{2}-6 \delta+2\right) \theta-\delta\left(\delta^{2}-3 \delta+2\right) \\
\theta=\mathrm{L} \gamma \mathrm{T}_{\mathrm{r}}^{\gamma}
\end{array}\right.
$$

with $\theta>0$. The quantities $\mathrm{X}, \mathrm{Y}$ and $\mathrm{Z}$ are defined as

$$
\left\{\begin{array}{l}
\mathrm{X}=-3(\gamma+\delta-1) \\
\mathrm{Y}=\gamma^{2}+3 \delta \gamma-3 \gamma+3 \delta^{2}-6 \delta+2 \\
\mathrm{Z}=-\delta\left(\delta^{2}-3 \delta+2\right)=-\delta(\delta-1)(\delta-2)
\end{array}\right.
$$

Polynomial $R(\theta)$ is positive if [41]:

$$
\left\{\begin{array} { l } 
{ \mathrm { X } > 0 } \\
{ \mathrm { Y } > 0 } \\
{ \mathrm { Z } > 0 }
\end{array} \text { or } \left\{\begin{array}{l}
\mathrm{Z}>0 \\
\mathrm{H}=4 \mathrm{Y}^{3}+4 \mathrm{ZX}^{3}+27 \mathrm{Z}^{2}-18 \mathrm{XYZ}-\mathrm{X}^{2} \mathrm{Y}^{2}>0
\end{array}\right.\right.
$$

Since $\delta<0$ (see Eq. (A.5)), the condition $Z>0$ (where $Z$ is defined by Eq. (A.10)) is always verified. According to Eqs. (A.9) and (A.11), it can be concluded that $\frac{\mathrm{d}^{3} \alpha}{\mathrm{dT}_{\mathrm{r}}^{3}}\left(\mathrm{~T}_{\mathrm{r}}\right)$ is negative provided:

$$
\left\{\begin{array}{l}
\mathrm{X}>0 \\
\mathrm{Y}>0
\end{array} \text { or } \mathrm{H}=4 \mathrm{Y}^{3}+4 \mathrm{ZX}^{3}+27 \mathrm{Z}^{2}-18 \mathrm{XYZ}-\mathrm{X}^{2} \mathrm{Y}^{2}>0\right.
$$

A graphical representation of the constraints $\mathrm{Y}<0$ (red area) and $\mathrm{X}<0$ (yellow area) is proposed in Figure A.1. Colored areas are forbidden to parameters $\gamma$ and $\delta$, only the white area is permitted. The concavity constraint of the $\alpha$-function is also represented (the blue area is an area wherein the condition $\frac{\mathrm{d}^{2} \alpha}{\mathrm{dT}_{\mathrm{r}}^{2}}\left(\mathrm{~T}_{\mathrm{r}}\right) \geq 0$ is not satisfied). An analysis of the graphic shows that if the constraint $\mathrm{X}>0$ is satisfied then the convexity constraint and the $\mathrm{Y}>0$ constraint are automatically satisfied. 


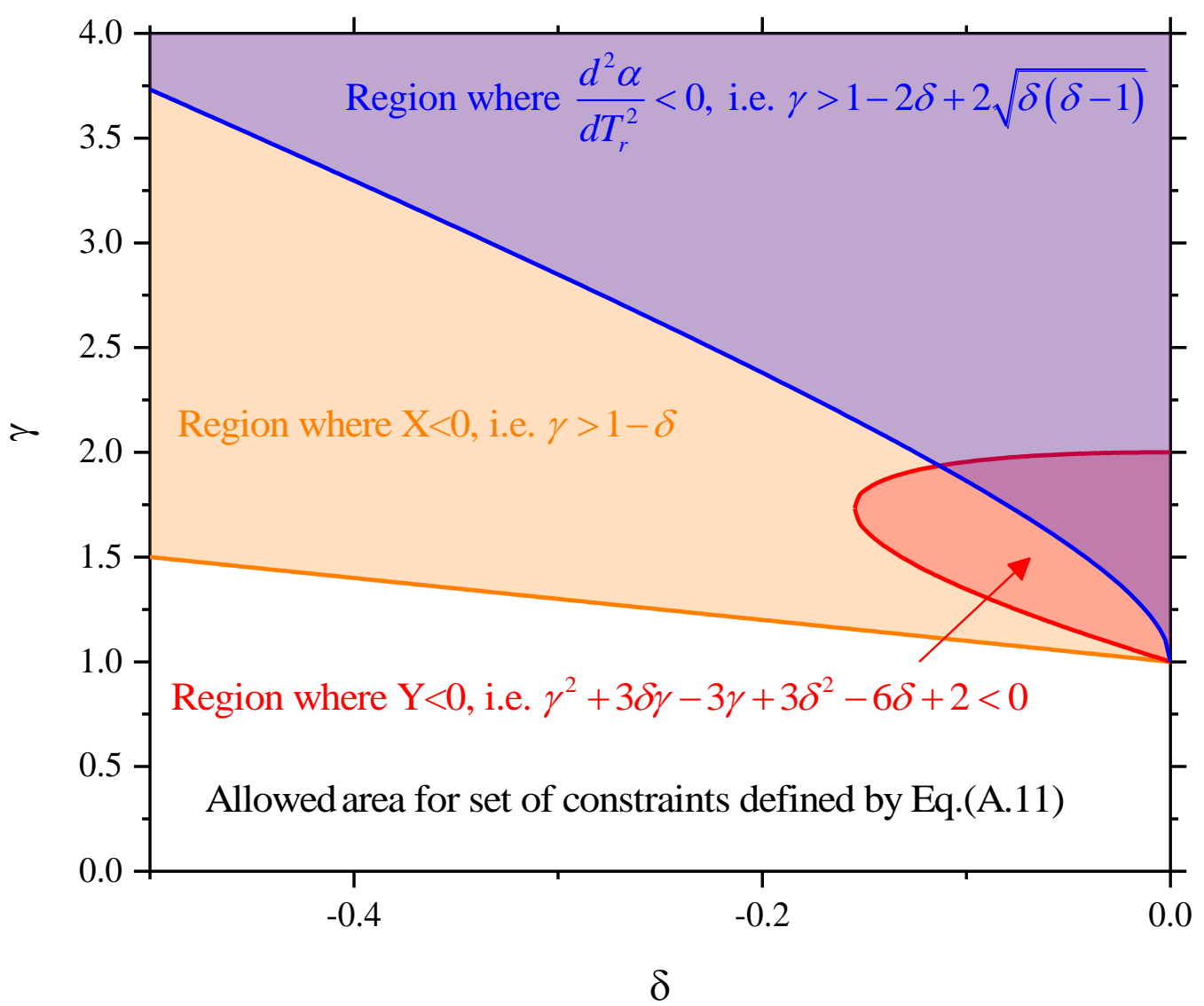

Figure A.1. Representation of the set of constraints defined by Eq. (A.11).

\section{- Conclusion:}

Therefore, the Twu91 $\alpha$-function is a positive decreasing convex function of temperature with a negative third derivative if one of the two following sets of constraints is verified

$$
\left\{\begin{array} { l } 
{ \delta < 0 } \\
{ \mathrm { L } \gamma > 0 } \\
{ \gamma < 1 - \delta }
\end{array} \text { or } \left\{\begin{array}{l}
\delta<0 \\
\mathrm{~L} \gamma>0 \\
\gamma<1-2 \delta+2 \sqrt{\delta(\delta-1)} \\
4 \mathrm{Y}^{3}+4 \mathrm{ZX}^{3}+27 \mathrm{Z}^{2}-18 \mathrm{XYZ}-\mathrm{X}^{2} \mathrm{Y}^{2}>0
\end{array}\right.\right.
$$

Where the quantities $\mathrm{X}, \mathrm{Y}$ and $\mathrm{Z}$ are defined by Eq. (A.10). 


\section{Appendix B: mathematical study of the Twu88 $\alpha$-function [14]}

This $\alpha$-function writes

$$
\alpha\left(\mathrm{T}_{\mathrm{r}}\right)=\mathrm{T}_{\mathrm{r}}^{2(\mathrm{M}-1)} \exp \left[\mathrm{L}\left(1-\mathrm{T}_{\mathrm{r}}^{2 \mathrm{M}}\right)\right]
$$

This $\alpha$-function is a particular case of the Twu91 $\alpha$-function with $\mathrm{N}$ set to 2 . Therefore, results derived in Appendix A for the Twu91 $\alpha$-function can be used to determine the conditions on the $\mathrm{L}$ and $\mathrm{M}$ parameters that lead to a consistent Twu88 $\alpha$-function.

For this $\alpha$-function, the relations between parameters $M, N$ and $\delta, \gamma$ are

$$
\left\{\begin{array}{l}
\delta=2(M-1) \\
\gamma=2 M \\
N=2
\end{array}\right.
$$

- Is the $\alpha$-function of class $\mathbf{C}^{2}$ ? Yes.

- Is the $\alpha$-function always positive? Yes.

- Is the first derivative of the $\alpha$-function always negative?

By combining Eqs. (A.5) and (B.2), one obtains:

$$
\left\{\begin{array} { l } 
{ \mathrm { L } \gamma > 0 } \\
{ \delta < 0 }
\end{array} \Leftrightarrow \left\{\begin{array}{l}
\mathrm{M}<1 \\
\mathrm{LM}>0
\end{array}\right.\right.
$$

\section{- Is the second derivative of the $\alpha$-function always positive?}

It is now assumed that $\mathrm{M}<1$ and $\mathrm{LM}>0$. By combining Eqs. (A.8) and (B.2), one obtains:

$$
\gamma<1-2 \delta+2 \sqrt{\delta(\delta-1)} \Leftrightarrow 6 \mathrm{M}-5<2 \sqrt{2(\mathrm{M}-1)(2 \mathrm{M}-3)}
$$

A mathematical study of inequality (B.4) makes it possible to demonstrate that the only acceptable values of $\mathrm{M}$ are such that:

$$
\mathrm{M} \leq \frac{1}{2}+\frac{1}{\sqrt{5}} \approx 0.947
$$

Note that the combination of inequalities $\mathbf{M}<1$ and (B.5) results in the single inequality (B.5)

\section{- Is the third derivative of the $\alpha$-function always negative?}

One assumes that $\mathrm{LM}>0$ and $\mathrm{M} \leq \frac{1}{2}+\frac{1}{\sqrt{5}}$. According to Eqs. (A.10), (A.12) and (B.2), two possible sets of conditions ensure the negativity of $\frac{d^{3} \alpha}{{d T_{r}^{3}}^{3}}\left(T_{r}\right)$ :

1. Either $\mathrm{X}>0$ and $\mathrm{Y}>0$ :

As for the Twu91 $\alpha$-function, the constraint $X>0$ entails the convexity of the Twu88 $\alpha$-function and the inequality $\mathrm{Y}>0$.

A consistency test for $\alpha$-functions of cubic equations of state 


$$
\mathrm{X}>0 \Leftrightarrow \gamma<1-\delta \Leftrightarrow \mathrm{M}<0.75
$$

2. Or $\mathrm{H}=4 \mathrm{Y}^{3}+4 Z \mathrm{X}^{3}+27 \mathrm{Z}^{2}-18 \mathrm{XYZ}-\mathrm{X}^{2} \mathrm{Y}^{2}>0$ :

In the case of the Twu $88 \alpha$-function, this inequality writes:

$$
-16448 \mathrm{M}^{6}+55296 \mathrm{M}^{5}-64416 \mathrm{M}^{4}-29376 \mathrm{M}^{3}-4020 \mathrm{M}^{2}+216 \mathrm{M}-4 \geq 0
$$

By solving numerically this inequality, one obtains:

$$
\mathrm{M} \in[0.0448,0.8909] \cup[1,1.2902]
$$

Combining inequalities (B.5) and (B.8) leads to:

$$
M \in[0.0448,0.8909]
$$

As previous, it can be proved that choosing the $\mathrm{M}$ parameter in this range ensures also the convexity of the Twu $88 \alpha$-function.

Finally, according to Eqs. (B.6) and (B.9), one deduces that the third derivative of the Twu88 $\alpha$-function is negative provided:

$$
\mathrm{M}<0.8909
$$

\section{- Conclusion:}

To summarize, the Twu $88 \alpha$-function is a positive decreasing convex function of temperature with a negative third derivative if the following set of constraints is verified (resulting from the combination of Eqs. (B.3) and (B.10)):

$$
\left\{\begin{array}{l}
\mathrm{LM}>0 \\
\mathrm{M}<0.8909
\end{array}\right.
$$




\section{Appendix C: mathematical analysis of the Twu95 $\alpha$-function $[16,17]$}

This $\alpha$-function is said generalized since it does not involve adjustable parameters. The sole knowledge of an experimental value of the acentric factor ( $\omega$ ) makes it possible to evaluate $\alpha\left(\mathrm{T}_{\mathrm{r}}\right)$.

$$
\left\{\begin{array}{l}
\alpha\left(\mathrm{T}_{\mathrm{r}}\right)=\alpha^{(0)}\left(\mathrm{T}_{\mathrm{r}}\right)+\omega\left[\alpha^{(1)}\left(\mathrm{T}_{\mathrm{r}}\right)-\alpha^{(0)}\left(\mathrm{T}_{\mathrm{r}}\right)\right] \\
\alpha^{(0)}\left(\mathrm{T}_{\mathrm{r}}\right)=\mathrm{T}_{\mathrm{r}}^{\mathrm{N}^{(0)}\left[\mathrm{M}^{(0)}-1\right]} \exp \left[\mathrm { L } ^ { ( 0 ) } \left(1-\mathrm{T}_{\mathrm{r}}^{\left.\left.\mathrm{M}^{(0)} \mathrm{N}^{(0)}\right)\right]}\right.\right. \\
\alpha^{(1)}\left(\mathrm{T}_{\mathrm{r}}\right)=\mathrm{T}_{\mathrm{r}}^{\mathrm{N}^{(1)}\left[\mathrm{M}^{(1)}-1\right]} \exp \left[\mathrm { L } ^ { ( 1 ) } \left(1-\mathrm{T}_{\mathrm{r}}^{\left.\left.\mathrm{M}^{(1)} \mathrm{N}^{(1)}\right)\right]}\right.\right.
\end{array}\right.
$$

The universal parameters $\left(\mathrm{L}^{(\mathrm{k})}, \mathrm{M}^{(\mathrm{k})}, \mathrm{N}^{(\mathrm{k})}\right.$ for $\mathrm{k}=0$ and $\left.\mathrm{k}=1\right)$ involved in this $\alpha$-function are reported in Table C.1.

\begin{tabular}{|c|c|c|c|c|c|}
\hline & & \multicolumn{2}{|c|}{$\mathrm{T}_{\mathrm{r}} \leq 1$} & \multicolumn{2}{c|}{$\mathrm{T}_{\mathrm{r}}>1$} \\
\hline \multirow{4}{*}{ Redlich-Kwong } & & $\alpha^{(0)}$ & $\alpha^{(1)}$ & $\alpha^{(0)}$ & $\alpha^{(1)}$ \\
\hline \multirow{3}{*}{ Peng-Robinson } & $\mathrm{L}$ & 0.141599 & 0.500315 & 0.441411 & 0.032580 \\
\cline { 2 - 6 } & $\mathrm{M}$ & 0.919422 & 0.799457 & 6.500018 & 1.289098 \\
\cline { 2 - 6 } & $\mathrm{N}$ & 2.496441 & 3.291790 & -0.200000 & -8.000000 \\
\cline { 2 - 6 } & $\mathrm{L}$ & 0.125283 & 0.511614 & 0.401219 & 0.024955 \\
\cline { 2 - 6 } & $\mathrm{M}$ & 0.911807 & 0.784054 & 4.963070 & 1.248089 \\
\hline
\end{tabular}

Table C.1. Universal parameters regressed for the Twu95 $\alpha$-function.

Different sets of parameters are used in the subcritical and supercritical domains. These parameters were regressed to obtain an $\alpha$-function of class $\mathrm{C}^{2}$.

- Is the $\boldsymbol{\alpha}$-function of class $\mathbf{C}^{2}$ ? Yes, due to the addition of this constraint during the regression procedure of the universal parameters (see Figure $\mathrm{C} .1$ )

The presence of salient points on the second derivative curves of this $\alpha$-function can however be noticed (which is the consequence of a non-continuous third derivative of the $\alpha$-function).

- Is the $\alpha$-function always positive? No (see $\alpha$-function curves plotted for negative or high positive values of $\omega$ in Figure C.1(a)).

- Is the first derivative of the $\alpha$-function always negative? No (see Figure C.1(b)).

- Is the second derivative of the $\alpha$-function always positive? No (see Figure C.1(c)).

- Is the third derivative of the $\alpha$-function always negative? No (see Figure C.1(d)). 


\section{- Conclusion:}

To conclude, Figure C.1 shows that the consistency test proposed in this article (see Eq.(19)) is passed by molecules having an acentric factor ranging between 0 and 1 . For molecules having a higher acentric factor, the first and second derivatives of the Twu95 $\alpha$-function fail the proposed consistency test (this is for instance the case of n-alkanes heavier than $n-C_{22}$ ).

Let us note also that regardless of the $\omega$-value, the sign of the third derivative of the Twu95 $\alpha$ function is not constant on the whole temperature range (see Figure C.1(d)). Inevitably, poor predictions of heat capacities are obtained in the temperature domain where the third derivative of the $\alpha$-function is positive. For all molecules, this temperature domain is located in the vicinity of the critical temperature, i.e., it can be reached in many practical cases. Predictions of heat capacities with the Twu95 $\alpha$-function could thus be less accurate than those calculated with other simpler $\alpha$-functions. 

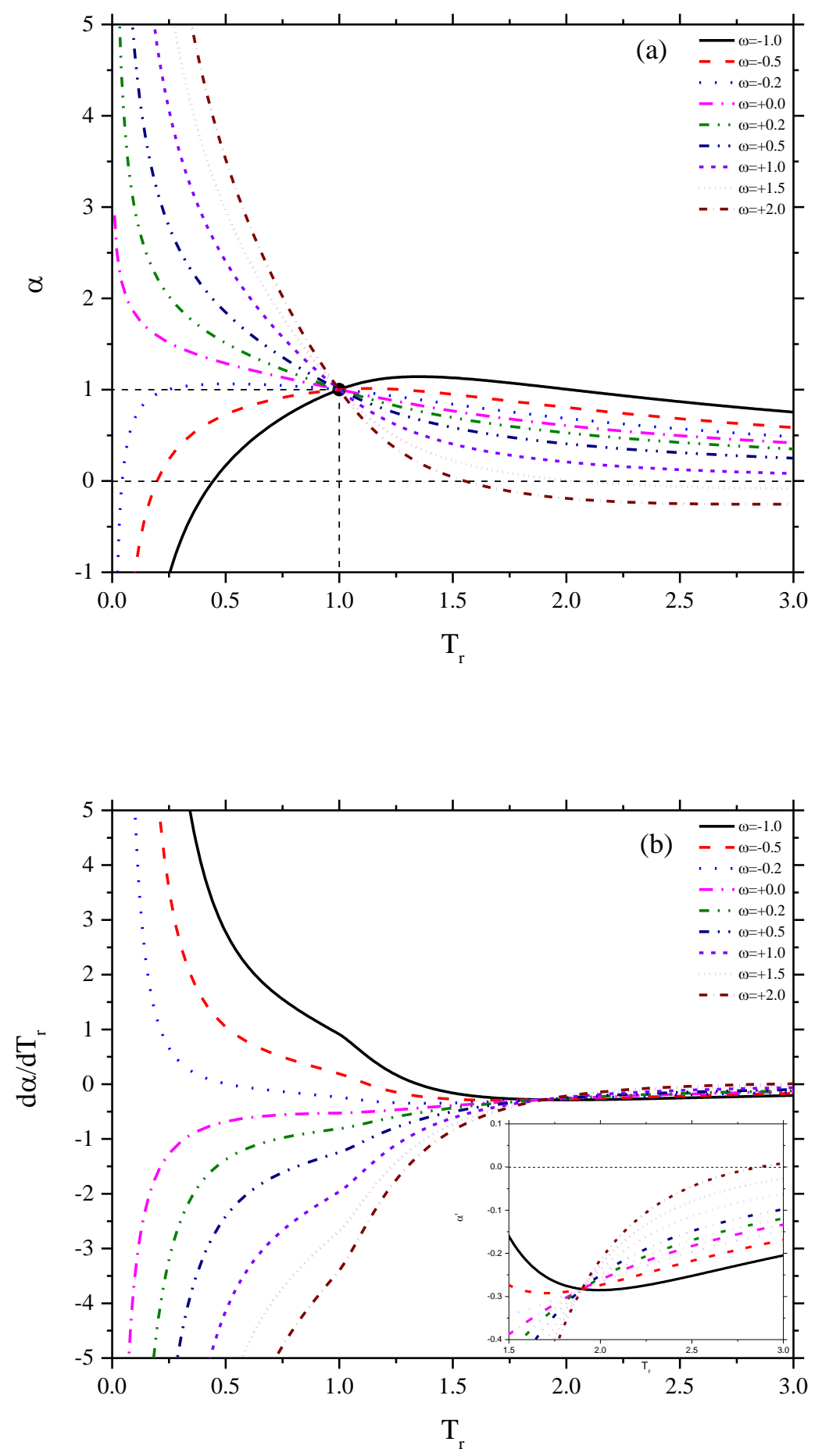

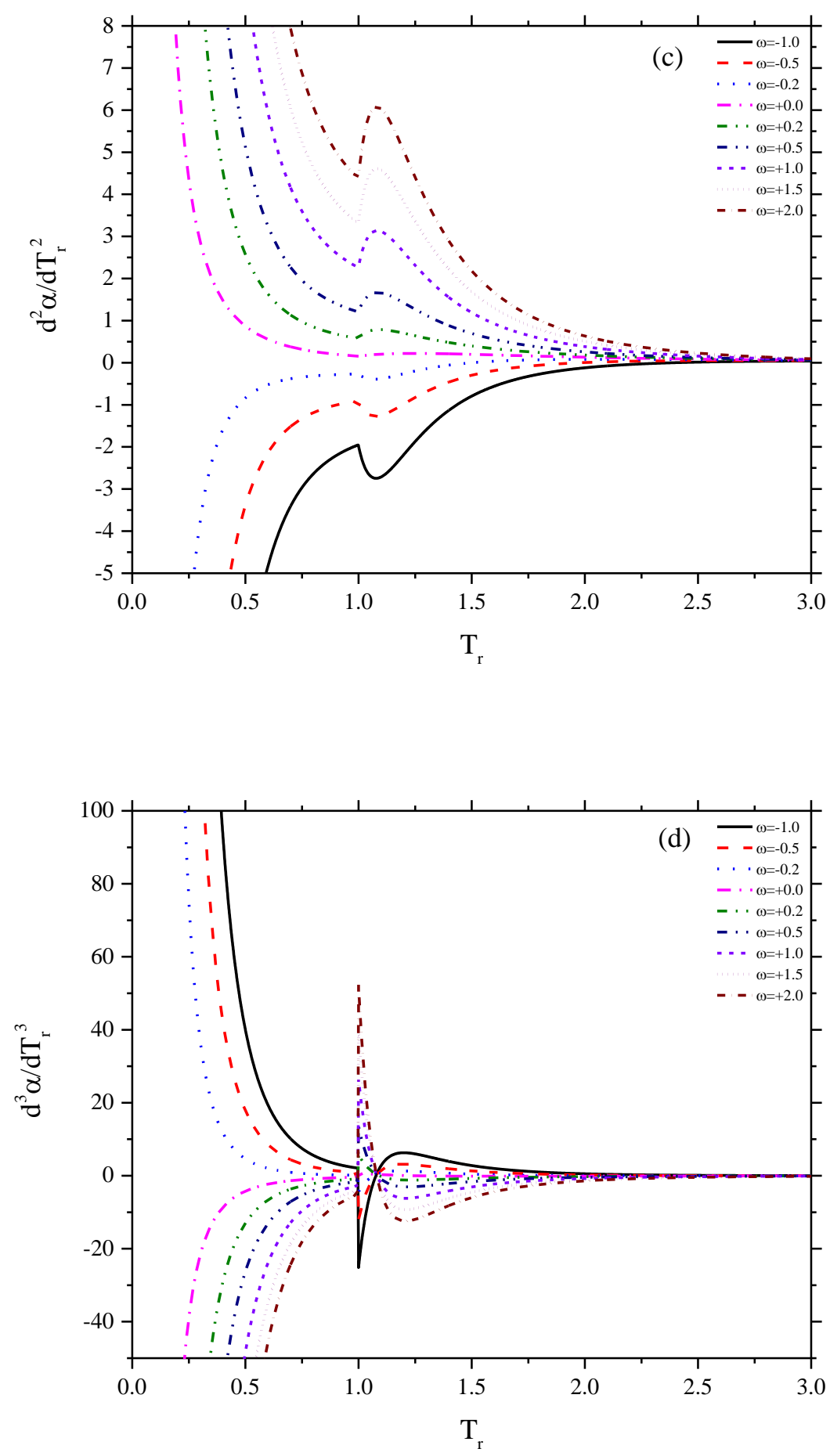

Figure C.1. The Twu95 $\alpha$-function (a) and its first (b), second (c) and third derivatives (d) (case of the RK EoS). 


\section{Appendix D: mathematical study of the Trebble and Bishnoi $\alpha$-function [26]}

This $\alpha$-function contains only one adjustable parameter $(\mathrm{L})$ :

$$
\alpha\left(\mathrm{T}_{\mathrm{r}}\right)=\exp \left[\mathrm{L}\left(1-\mathrm{T}_{\mathrm{r}}\right)\right]
$$

This $\alpha$-function can be seen as a particular case of the Twu91 $\alpha$-function with $\mathrm{N}$ set to 1 and $\mathrm{M}$ set to 1 .

- Is the $\boldsymbol{\alpha}$-function of class $\mathbf{C}^{2}$ ? Yes.

- Is the $\alpha$-function always positive? Yes.

- Is the first derivative of the $\alpha$-function always negative?

The first derivative of this $\alpha$-function writes

$$
\frac{\mathrm{d} \alpha}{\mathrm{dT}_{\mathrm{r}}}\left(\mathrm{T}_{\mathrm{r}}\right)=-\mathrm{L} \cdot \alpha\left(\mathrm{T}_{\mathrm{r}}\right)
$$

As a consequence, $\mathrm{d} \alpha / \mathrm{dT}_{\mathrm{r}}$ is negative provided $\mathrm{L}$ is positive.

- Is the second derivative of the $\alpha$-function always positive? Yes.

The second derivative of this $\alpha$-function indeed writes

$$
\frac{\mathrm{d}^{2} \alpha}{\mathrm{dT}_{\mathrm{r}}^{2}}\left(\mathrm{~T}_{\mathrm{r}}\right)=\mathrm{L}^{2} \cdot \alpha\left(\mathrm{T}_{\mathrm{r}}\right)
$$

- Is the third derivative of the $\alpha$-function always negative?

The third derivative of the Trebble-Bishnoi $\alpha$-function is:

$$
\frac{\mathrm{d}^{3} \alpha}{\mathrm{dT}_{\mathrm{r}}^{3}}\left(\mathrm{~T}_{\mathrm{r}}\right)=-\mathrm{L}^{3} \cdot \alpha\left(\mathrm{T}_{\mathrm{r}}\right)
$$

It is assumed that $\mathrm{L}>0$. Doing so, $\alpha>0$ and $\frac{\mathrm{d}^{3} \alpha}{\mathrm{dT}_{\mathrm{r}}^{3}}\left(\mathrm{~T}_{\mathrm{r}}\right)<0$.

\section{- Conclusion:}

To conclude, the Trebble and Bishnoi $\alpha$-function passes the proposed consistency test provided $\mathrm{L}>0$. 


\section{Appendix E: mathematical study of the Melhem-Saini-Goodwin $\alpha$-function [27]}

This $\alpha$-function involves 2 adjustable parameters ( $m$ and $n$ ):

$$
\alpha\left(\mathrm{T}_{\mathrm{r}}\right)=\exp \left[\mathrm{m}\left(1-\mathrm{T}_{\mathrm{r}}\right)+\mathrm{n}\left(1-\sqrt{\mathrm{T}_{\mathrm{r}}}\right)^{2}\right]
$$

- Is the $\alpha$-function of class $\mathbf{C}^{2}$ ? Yes.

- Is the $\alpha$-function always positive? Yes.

- Is the first derivative of the $\alpha$-function always negative?

The first derivative of the $\alpha$-function is:

$$
\left\{\begin{array}{l}
\frac{d \alpha}{d T_{r}}\left(T_{r}\right)=-\frac{\alpha\left(T_{r}\right)}{\sqrt{T_{r}}} P\left(T_{r}\right) \\
P\left(T_{r}\right)=(m-n) \sqrt{T_{r}}+n
\end{array}\right.
$$

The quantity $\mathrm{P}\left(\mathrm{T}_{\mathrm{r}}\right)$ is positive if:

$$
\left\{\begin{array}{l}
\mathrm{m}-\mathrm{n} \geq 0 \\
\mathrm{n} \geq 0
\end{array} \Leftrightarrow \mathrm{m} \geq \mathrm{n} \geq 0\right.
$$

- Is the second derivative of the $\alpha$-function always positive? Yes.

The second derivative of the Melhem-Saini-Goodwin $\alpha$-function is:

$$
\left\{\begin{array}{l}
\frac{\mathrm{d}^{2} \alpha}{\mathrm{dT}_{\mathrm{r}}^{2}}\left(\mathrm{~T}_{\mathrm{r}}\right)=\frac{\alpha\left(\mathrm{T}_{\mathrm{r}}\right)}{2 \mathrm{~T}_{\mathrm{r}}^{3 / 2} \mathrm{Q}\left(\sqrt{\mathrm{T}_{\mathrm{r}}}\right)} \\
\mathrm{Q}\left(\sqrt{\mathrm{T}_{\mathrm{r}}}\right)=\underbrace{2(\mathrm{~m}-\mathrm{n})^{2}}_{>0}\left(\sqrt{\mathrm{T}_{\mathrm{r}}}\right)^{3}+\underbrace{4 \mathrm{n}(\mathrm{m}-\mathrm{n})}_{>0}\left(\sqrt{\mathrm{T}_{\mathrm{r}}}\right)^{2}+\underset{>0}{2 \mathrm{n}^{2}}\left(\sqrt{\mathrm{T}_{\mathrm{r}}}\right)+\underset{>0}{\mathrm{n}}
\end{array}\right.
$$

Under assumption (E.3), all the coefficients of the polynomial Q are positive, therefore, Q is always positive.

- Is the third derivative of the $\alpha$-function always negative?

The third derivative of this $\alpha$-function is:

$$
\left\{\begin{array}{rl}
\frac{\mathrm{d}^{3} \alpha}{\mathrm{dT}_{\mathrm{r}}^{3}}\left(\mathrm{~T}_{\mathrm{r}}\right) & =-\frac{\alpha\left(\mathrm{T}_{\mathrm{r}}\right)}{4 \mathrm{~T}_{\mathrm{r}}^{5 / 2}} \mathrm{R}\left(\sqrt{\mathrm{T}_{\mathrm{r}}}\right) \\
\mathrm{R}\left(\sqrt{\mathrm{T}_{\mathrm{r}}}\right) & =\underbrace{4(\mathrm{~m}-\mathrm{n})^{3}}_{>0}\left(\sqrt{\mathrm{T}_{\mathrm{r}}}\right)^{5}+\underbrace{12 \mathrm{n}(\mathrm{m}-\mathrm{n})^{2}}_{>0}\left(\sqrt{\mathrm{T}_{\mathrm{r}}}\right)^{4}+\underbrace{12 \mathrm{n}^{2}(\mathrm{~m}-\mathrm{n})}_{>0}\left(\sqrt{\mathrm{T}_{\mathrm{r}}}\right)^{3} \\
& +\left(4 \mathrm{n}^{3}+6 \mathrm{mn}-6 \mathrm{n}^{2}\right)\left(\sqrt{\mathrm{T}_{\mathrm{r}}}\right)^{2}+\underset{>0}{6 n^{2}}\left(\sqrt{\mathrm{T}_{\mathrm{r}}}\right)+3 \mathrm{n} \\
>0 & 3 \mathrm{n}
\end{array}\right.
$$

By noting that:

$$
\mathrm{m}>\mathrm{n}>0 \Rightarrow 6 \mathrm{mn}>6 \mathrm{n}^{2} \Rightarrow 4 \mathrm{n}^{3}+\left(6 \mathrm{mn}-6 \mathrm{n}^{2}\right)>0
$$


it can be claimed that under assumption (E.3), all the coefficients of the polynomial R are positive and thus $R\left(\sqrt{T_{r}}\right) \geq 0$. Consequently, the third derivative of the Melhem-SainiGoodwin $\alpha$-function is always negative.

\section{- Conclusion:}

The Melhem-Saini-Goodwin $\alpha$-function is consistent (i.e., positive, decreasing, convex with a negative third derivative) provided $\mathrm{m} \geq \mathrm{n} \geq 0$. 


\section{Appendix F: mathematical study of the Soave72 $\alpha$-function [24]}

The Soave72 $\alpha$-function involved a generalized parameter $(\mathrm{m})$ correlated to the acentric factor $(\omega)$ :

$$
\begin{cases}\alpha\left(T_{r}\right)=\left[1+m(\omega)\left(1-\sqrt{T_{r}}\right)\right]^{2} & \\ m(\omega)=0.480+1.574 \omega-0.176 \omega^{2} & \text { for the RK EoS } \\ m(\omega)=0.37464+1.54226 \omega-0.26992 \omega^{2} & \text { for the PR EoS }\end{cases}
$$

The Soave72 function is certainly the most employed $\alpha$-function in the oil and gas industries. It is in particular used in the PPR78 [42-44] and PR2SRK predictive models [45].

- Is the $\alpha$-function of class $\mathbf{C}^{2}$ ? Yes.

- Is the $\alpha$-function always positive? Yes.

- Is the first derivative of the $\alpha$-function always negative?

The first derivative of the Soave $72 \alpha$-function is:

$$
\frac{\mathrm{d} \alpha}{\mathrm{dT}_{\mathrm{r}}}\left(\mathrm{T}_{\mathrm{r}}\right)=-\frac{\mathrm{m}(\omega)}{\sqrt{\mathrm{T}_{\mathrm{r}}}}\left[1+\mathrm{m}(\omega)\left(1-\sqrt{\mathrm{T}_{\mathrm{r}}}\right)\right]=-\mathrm{m}(\omega) \sqrt{\frac{\alpha\left(\mathrm{T}_{\mathrm{r}}\right)}{\mathrm{T}_{\mathrm{r}}}}
$$

The limit of the first derivative of the $\alpha$-function when the temperature tends to $+\infty$ is:

$$
\lim _{\mathrm{T}_{\mathrm{r}} \rightarrow+\infty} \frac{\mathrm{d} \alpha}{\mathrm{dT}_{\mathrm{r}}}\left(\mathrm{T}_{\mathrm{r}}\right)=[\mathrm{m}(\omega)]^{2}>0
$$

It appears that the first derivative of the Soave $72 \alpha$-function is not always negative.

Due to its polynomial expression in $\sqrt{\mathrm{T}_{\mathrm{r}}}$, the Soave72 $\alpha$-function can only exhibit two types of behavior, depending on the $\omega$-value:

- $\quad$ either the function is decreasing then increasing for increasing values of $T_{r}$,

- or, the function is monotonically increasing.

To discriminate between these two scenarios, the limit of the first derivative of the $\alpha$-function when the temperature tends to 0 is now studied:

$$
\lim _{T_{r} \rightarrow 0} \frac{d \alpha}{d T_{r}}\left(T_{r}\right)=-\operatorname{sign}[m(1+m)]_{\infty}
$$

Case 1: $\mathrm{m}(1+\mathrm{m})>0$

If $\mathrm{m}(1+\mathrm{m})$ is positive (what is the case for more than $99 \%$ of the compounds), one has $\lim _{T_{r} \rightarrow 0} \frac{d \alpha}{d T_{r}}\left(T_{r}\right)=-\infty$ and the Soave72 $\alpha$-function exhibits a minimum at a reduced temperature denoted $\mathrm{T}_{\mathrm{r}, \text { min }}$. For $\mathrm{T}_{\mathrm{r}} \in\left[0 ; \mathrm{T}_{\mathrm{r}, \mathrm{min}}\right], \alpha$ is a decreasing function while it is an increasing 
function for $T_{r}>T_{r, \text { min }}$. Such a behavior is observed for the following values of the acentric factor:

$$
\begin{array}{ll}
\omega \in]-1 ;-0.8580] \cup]-0.2952 ; 9.2384[\cup[9.8012 ;+\infty[ & \text { for the RK EoS } \\
\omega \in]-1 ;-0.7838] \cup]-0.2334 ; 5.9472[\cup[6.4976 ;+\infty[ & \text { for the PR EoS }
\end{array}
$$

To understand whether the irregular behavior of the Soave72 $\alpha$-function (i.e., increasing of $\alpha$ for $T_{r}>T_{r, \text { min }}$ ) may affect practical applications, the relation between $T_{r, \text { min }}$ and $\omega$ is now investigated. $\mathrm{T}_{\mathrm{r}, \mathrm{min}}$ is obtained by solving:

$$
\begin{gathered}
\frac{d \alpha}{d T_{r}}\left(T_{r, \text { min }}\right)=0 \\
\Leftrightarrow m(\omega)\left[1+\mathrm{m}(\omega)\left(1-\sqrt{T_{r, \text { min }}}\right)\right]=0 \\
\Leftrightarrow \mathrm{T}_{\mathrm{r}, \min }=\left[\frac{1+\mathrm{m}(\omega)}{\mathrm{m}(\omega)}\right]^{2}
\end{gathered}
$$

Note that at $T_{r, \min }$, the Soave72 $\alpha$-function cancels: $\alpha\left(T_{r, \min }\right)=0$.

The evolution of $T_{r, \text { min }}$ with respect to the acentric factor is reported in Figure F.1.

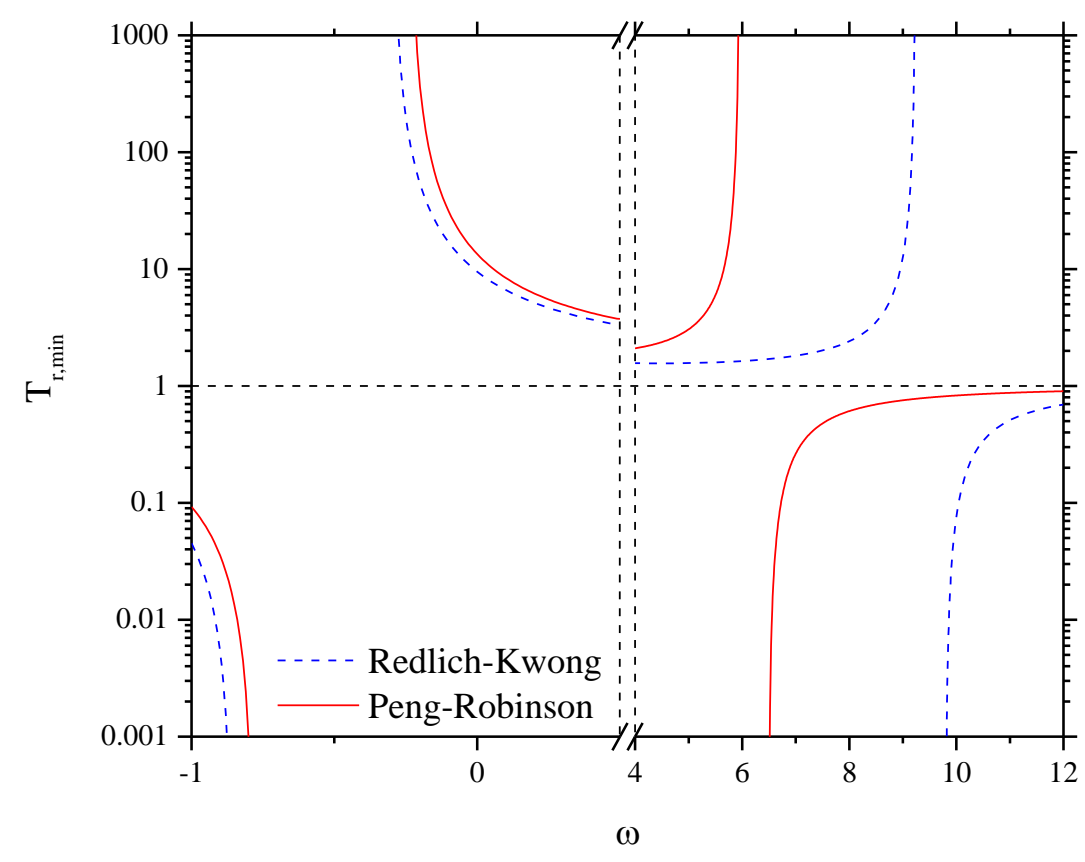

Figure F.1. $T_{r, \min }$ as a function of $\omega$.

To complete the analysis, some values of $T_{r, \text { min }}$ and $T_{\min }$ are reported in Table $F_{0} 1$ for a series of real compounds of various sizes (i.e., a large range of acentric-factor values is covered). It is 
observed that in practice, $\mathrm{T}_{\min }$ is often higher than $1500 \mathrm{~K}$, largely above common temperatures encountered in practical applications.

\begin{tabular}{|c|c|c|c|c|c|c|}
\hline \multirow{2}{*}{ Component } & \multirow{2}{*}{$\begin{array}{c}\text { Acentric } \\
\text { factor } \omega\end{array}$} & \multirow{2}{*}{$\mathrm{T}_{\mathrm{c}} / \mathrm{K}$} & \multicolumn{2}{|c|}{$\mathrm{RK} \mathrm{CEOS}$} & \multicolumn{2}{c|}{ PR CEoS } \\
\cline { 4 - 7 } & & $\mathrm{T}_{\mathrm{r}, \min }$ & $\mathrm{T}_{\min } / \mathrm{K}$ & $\mathrm{T}_{\mathrm{r}, \min }$ & $\mathrm{T}_{\min } / \mathrm{K}$ \\
\hline Methane & 0.012 & 190.564 & 9.045 & 1723.566 & 12.591 & 2399.325 \\
\hline n-decane & 0.492 & 617.700 & 3.330 & 2057.108 & 3.748 & 2314.913 \\
\hline n-eicosane & 0.907 & 768.000 & 2.456 & 1886.582 & 2.705 & 2077.277 \\
\hline n-triacontane & 1.307 & 844.000 & 2.094 & 1767.355 & 2.305 & 1945.584 \\
\hline Water & 0.345 & 647.096 & 3.992 & 2583.530 & 4.595 & 2973.520 \\
\hline CO 2 & 0.224 & 304.21 & 4.905 & 1492.258 & 5.839 & 1776.253 \\
\hline Argon & 0.000 & 150.860 & 9.507 & 1434.218 & 13.463 & 2031.065 \\
\hline Ethanol & 0.644 & 514.000 & 2.904 & 1492.795 & 3.228 & 1659.020 \\
\hline Ammonia & 0.253 & 405.650 & 4.641 & 1882.512 & 5.469 & 2218.676 \\
\hline
\end{tabular}

Table F.1. Values of $\mathrm{T}_{\min }$ for some chemical compounds using either the PR or RK CEoS

Case 2: $\mathrm{m}(1+\mathrm{m})<0$

This case is observed for the following values of the acentric factor:

$$
\begin{array}{ll}
\omega \in]-0.8580 ;-0.2952] \cup] 9.2384 ; 9.8012[ & \text { for the RK EoS } \\
\omega \in]-0.7838 ;-0.2334] \cup] 5.9472 ; 6.4976[ & \text { for the PR EoS }
\end{array}
$$

In practice, this instance arises for molecules having negative acentric factors (e.g., helium, aluminum and arsenic). In such a case: $\lim _{T_{r} \rightarrow 0} \frac{d \alpha}{d T_{r}}\left(T_{r}\right)=+\infty$ and the Soave72 $\alpha$-function is an increasing function of temperature for any positive value of $\mathrm{T}_{\mathrm{r}}$. This behavior is not desirable and therefore, the Soave72 $\alpha$-function should be used only for molecules having an acentric factor $\omega$ in the ranges defined by Eq.(F.5) or Eq.(F.6).

\section{- Is the second derivative of the $\alpha$-function always positive?}

It is now assumed that $\mathrm{m}(1+\mathrm{m})>0$ (which is obtained for acentric factor values lying in the ranges defined by Eq.(F.5) or Eq.(F.6)). The second derivative of the Soave72 $\alpha$-function is:

$$
\frac{\mathrm{d}^{2} \alpha}{\mathrm{dT}_{\mathrm{r}}^{2}}\left(\mathrm{~T}_{\mathrm{r}}\right)=\frac{\mathrm{m}(\omega)[\mathrm{m}(\omega)+1]}{2 \mathrm{~T}_{\mathrm{r}}^{3 / 2}}
$$

Since $m(1+m)>0$, the convexity constraint is verified. 
- Is the third derivative of the $\alpha$-function always negative?

The third derivative of the Soave72 $\alpha$-function is:

$$
\frac{\mathrm{d}^{3} \alpha}{\mathrm{dT}_{\mathrm{r}}^{3}}\left(\mathrm{~T}_{\mathrm{r}}\right)=-\frac{3}{4} \frac{\mathrm{m}(\omega)[\mathrm{m}(\omega)+1]}{\mathrm{T}_{\mathrm{r}}^{5 / 2}}
$$

As previous, assuming $\mathrm{m}(1+\mathrm{m})>0$, the negativity of the third derivative is ensured.

\section{- Conclusion:}

When the quantity $\mathrm{m}(1+\mathrm{m})$ is positive (i.e., for acentric-factor values lying in the ranges defined by Eq.(F.5) or Eq.(F.6), which is verified in practice for more than $99 \%$ of real components), the Soave $\alpha$-function is consistent up to the temperature defined by Eq.(F.7), which is generally higher than $1500 \mathrm{~K}$ (it can thus be claimed that the Soave $72 \alpha$-function is consistent on temperature ranges of practical interest).

Such an $\alpha$-function can thus be considered as fully consistent in most cases explaining why it has achieved great success in the industry. 


\section{Appendix G: mathematical study of the Soave84 $\alpha$-function [24]}

This $\alpha$-function involves two adjustable parameters a and $b$ :

$$
\alpha\left(T_{r}\right)=1+\left(1-T_{r}\right)\left(a+\frac{b}{T_{r}}\right)
$$

- Is the $\alpha$-function of class $\mathbf{C}^{2}$ ? Yes.

- Is the $\alpha$-function always positive? Yes.

The Soave84 $\alpha$-function can be written as a second order polynomial of the reduced temperature

$$
\left\{\begin{array}{l}
\alpha\left(T_{r}\right)=\frac{1}{T_{r}} F\left(T_{r}\right) \\
F\left(T_{r}\right)=-a T_{r}^{2}+T_{r}(1+a-b)+b
\end{array}\right.
$$

Polynomial $F\left(T_{r}\right)$ is positive provided [41]:

$$
\left\{\begin{array}{l}
a \leq 0 \\
b \geq 0 \\
1+a-b \geq-2 \sqrt{-a b}
\end{array}\right.
$$

- Is the first derivative of the $\alpha$-function always negative?

The first derivative of the Soave $84 \alpha$-function is:

$$
\left\{\begin{array}{l}
\frac{d \alpha}{d T_{r}}\left(T_{r}\right)=-\frac{P\left(T_{r}\right)}{T_{r}^{2}} \\
P\left(T_{r}\right)=a T_{r}^{2}+b
\end{array}\right.
$$

Polynomial $\mathrm{P}\left(\mathrm{T}_{\mathrm{r}}\right)$ is positive provided:

$$
\left\{\begin{array}{l}
a \geq 0 \\
b \geq 0 \\
0 \geq-2 \sqrt{a b}
\end{array}\right.
$$

Note that the last condition is automatically satisfied. It appears that constraints (G.3) and (G.5) are contradictory and cannot be satisfied simultaneously.

Therefore, if a is positive:

- $\alpha\left(T_{r}\right)$ is negative, at least, on a certain temperature range

- $\frac{\mathrm{d} \alpha}{\mathrm{dT}_{\mathrm{r}}}\left(\mathrm{T}_{\mathrm{r}}\right)$ is negative for any (positive) temperature value

On the other hand, if a is negative:

- $\alpha\left(T_{r}\right)$ is positive for any (positive) temperature value 
- $\frac{d \alpha}{d_{\mathrm{r}}}\left(\mathrm{T}_{\mathrm{r}}\right)$ is positive, at least, on a certain temperature range

- Is the second derivative of the $\alpha$-function always positive?

The second derivative of the Soave $84 \alpha$-function is:

$$
\frac{\mathrm{d}^{2} \alpha}{\mathrm{dT}_{\mathrm{r}}^{2}}\left(\mathrm{~T}_{\mathrm{r}}\right)=\frac{2 \mathrm{~b}}{\mathrm{~T}_{\mathrm{r}}^{3}}
$$

It appears that $\frac{d^{2} \alpha}{d_{r}^{2}}\left(T_{r}\right)$ is positive provided $b$ is positive.

- Is the third derivative of the $\alpha$-function always negative?

The third derivative of the $\alpha$-function writes

$$
\frac{\mathrm{d}^{3} \alpha}{\mathrm{dT}_{\mathrm{r}}^{3}}\left(\mathrm{~T}_{\mathrm{r}}\right)=-\frac{6 \mathrm{~b}}{\mathrm{~T}_{\mathrm{r}}^{4}}
$$

It appears that $\frac{\mathrm{d}^{3} \alpha}{\mathrm{dT}_{\mathrm{r}}^{3}}\left(\mathrm{~T}_{\mathrm{r}}\right)$ is negative provided $\mathrm{b}$ is positive.

\section{- Conclusion:}

The only possibility for satisfying both the positivity condition for the Soave $84 \alpha$-function and the negativity condition for its first derivative would be to set:

$$
\mathrm{a}=0
$$

This would lead to modify the mathematical expression of the Soave84 $\alpha$-function. As a conclusion, the Soave84 $\alpha$-function cannot pass the proposed consistency test. 


\section{Appendix H: mathematical analysis of the Stryjek-Vera $\alpha$-function [11]}

The Stryjek-Vera $\alpha$-function involves one adjustable parameter $\left(\kappa_{1}\right)$ and one universal parameter $\left(\kappa_{0}(\omega)\right)$ :

$$
\begin{aligned}
& \alpha\left(T_{r}\right)=\left[1+\kappa\left(T_{r}\right) \cdot\left(1-\sqrt{T_{r}}\right)\right]^{2} \\
& \kappa\left(T_{r}\right)=\kappa_{0}(\omega)+\kappa_{1}\left(1+\sqrt{T_{r}}\right)\left(0.7-T_{r}\right) \\
& \kappa_{0}(\omega)=0.378893+1.4897153 \omega-0.17131848 \omega^{2}+0.0196554 \omega^{3} \\
& \left\{\begin{array}{l}
\kappa_{1}\left(T_{r} \leq 0.7\right) \neq 0 \\
\kappa_{1}\left(T_{r}>0.7\right)=0
\end{array}\right.
\end{aligned}
$$

The Stryjek-Vera $\alpha$-function is identical to the Soave $\alpha$-function for reduced temperatures above 0.7. Therefore, it suffers from all the identified defects of the Soave $\alpha$-function described in Appendix F. In addition, the Stryjek-Vera $\alpha$-function exhibits a discontinuous behavior in $\mathrm{T}_{\mathrm{r}}=0.7$ which is prejudicial to all derived EoS-properties (enthalpy, entropy, heat capacity etc.). 


\section{Appendix I: mathematical study of the Mathias-Copeman $\alpha$-function [10]}

This $\alpha$-function uses two different expressions depending on the temperature domain considered (sub- or super-critical) and involves three adjustable parameters $\left(c_{1}, c_{2}, c_{3}\right)$

$$
\alpha\left(T_{\mathrm{r}}\right)= \begin{cases}\text { if } \mathrm{T}_{\mathrm{r}} \leq 1: & \alpha_{\mathrm{SUB}}\left(\mathrm{T}_{\mathrm{r}}\right)=\left[\begin{array}{l}
1+\mathrm{c}_{1}\left(1-\sqrt{\mathrm{T}_{\mathrm{r}}}\right)+\mathrm{c}_{2}\left(1-\sqrt{\mathrm{T}_{\mathrm{r}}}\right)^{2} \\
+c_{3}\left(1-\sqrt{\mathrm{T}_{\mathrm{r}}}\right)^{3}
\end{array}\right]^{2} \\
\text { if } \mathrm{T}_{\mathrm{r}}>1: & \alpha_{\mathrm{SUP}}\left(\mathrm{T}_{\mathrm{r}}\right)=\left[1+\mathrm{c}_{1}\left(1-\sqrt{\mathrm{T}_{\mathrm{r}}}\right)\right]^{2}\end{cases}
$$

\section{- Is the $\alpha$-function of class $\mathbf{C}^{2}$ ?}

The first derivatives of the Mathias-Copeman $\alpha$-function are:

$$
\frac{d \alpha}{d T_{r}}\left(T_{r}\right)= \begin{cases}\text { if } T_{r} \leq 1: & \frac{d \alpha_{S U B}}{d T_{r}}\left(T_{r}\right)=-\sqrt{\frac{\alpha_{S U B}\left(T_{r}\right)}{T_{r}}}\left[\begin{array}{l}
c_{1}+2 c_{2}\left(1-\sqrt{T_{r}}\right) \\
+3 c_{3}\left(1+T_{r}-2 \sqrt{T_{r}}\right)
\end{array}\right] \\
\text { if } T_{r}>1: & \frac{d \alpha_{S U P}}{d T_{r}}\left(T_{r}\right)=-c_{1} \sqrt{\frac{\alpha_{S U P}\left(T_{r}\right)}{T_{r}}}\end{cases}
$$

It appears that:

$$
\frac{\mathrm{d} \alpha_{\text {SUB }}}{d T_{\mathrm{r}}}\left(\mathrm{T}_{\mathrm{r}}=1\right)=\frac{\mathrm{d} \alpha_{\mathrm{SUP}}}{\mathrm{dT}_{\mathrm{r}}}\left(\mathrm{T}_{\mathrm{r}}=1\right)=-\mathrm{c}_{1}
$$

The Mathias-Copeman $\alpha$-function is thus at least of class $C^{1}$.

The second derivatives of the Mathias-Copeman $\alpha$-function are:

$$
\frac{\mathrm{d}^{2} \alpha}{\mathrm{dT}_{\mathrm{r}}^{2}}\left(\mathrm{~T}_{\mathrm{r}}\right)=\left\{\begin{aligned}
& \text { if } \mathrm{T}_{\mathrm{r}} \leq 1: \quad \frac{\mathrm{d}^{2} \alpha_{\mathrm{SUB}}}{\mathrm{dT} \mathrm{T}_{\mathrm{r}}^{2}}\left(\mathrm{~T}_{\mathrm{r}}\right)=\frac{\mathrm{P}\left(\mathrm{T}_{\mathrm{r}}\right)}{2 \mathrm{~T}_{\mathrm{r}}^{3 / 2}} \\
& \mathrm{P}\left(\mathrm{T}_{\mathrm{r}}\right)= 12 \mathrm{c}_{3}^{2} \mathrm{~T}_{\mathrm{r}}^{5 / 2}-15 \mathrm{c}_{3}\left(\mathrm{c}_{2}+3 \mathrm{c}_{3}\right) \mathrm{T}_{\mathrm{r}}^{2} \\
&+4 \mathrm{~T}_{\mathrm{r}}^{3 / 2}\left(2 \mathrm{c}_{1} \mathrm{c}_{3}+10 \mathrm{c}_{2} \mathrm{c}_{3}+\mathrm{c}_{2}^{2}+15 \mathrm{c}_{3}^{2}\right) \\
&-3 \mathrm{~T}_{\mathrm{r}}\left(4 \mathrm{c}_{1} \mathrm{c}_{3}+\mathrm{c}_{1} \mathrm{c}_{2}+\mathrm{c}_{3}+2 \mathrm{c}_{2}^{2}+10 \mathrm{c}_{3}^{2}+10 \mathrm{c}_{2} \mathrm{c}_{3}\right) \\
&+3 \mathrm{c}_{3}^{2}+2 \mathrm{c}_{2}^{2}+\mathrm{c}_{1}^{2}+3 \mathrm{c}_{3}+\mathrm{c}_{1}+3 \mathrm{c}_{1} \mathrm{c}_{2}+5 \mathrm{c}_{2} \mathrm{c}_{3} \\
&+4 \mathrm{c}_{1} \mathrm{c}_{3}+2 \mathrm{c}_{2} \\
& \text { if } \mathrm{T}_{\mathrm{r}}>1: \quad \frac{\mathrm{d}^{2} \alpha_{\mathrm{SUP}}}{\mathrm{dT} \mathrm{T}_{\mathrm{r}}^{2}}\left(\mathrm{~T}_{\mathrm{r}}\right)=\frac{\mathrm{c}_{1}\left(1+\mathrm{c}_{1}\right)}{2 \mathrm{~T}_{\mathrm{r}}^{3 / 2}}
\end{aligned}\right.
$$

Therefore, one has: 


$$
\left\{\begin{array}{l}
\frac{\mathrm{d}^{2} \alpha_{\mathrm{SUB}}}{\mathrm{dT}_{\mathrm{r}}^{2}}\left(\mathrm{~T}_{\mathrm{r}}=1\right)=\frac{\mathrm{c}_{1}\left(1+\mathrm{c}_{1}\right)}{2} \\
\frac{\mathrm{d}^{2} \alpha_{\mathrm{SUP}}}{\mathrm{dT}_{\mathrm{r}}^{2}}\left(\mathrm{~T}_{\mathrm{r}}=1\right)=\frac{\mathrm{c}_{1}\left(1+\mathrm{c}_{1}\right)+2 \mathrm{c}_{2}}{2}
\end{array}\right.
$$

As a consequence, the Mathias-Copeman $\alpha$-function is of class $\mathrm{C}^{2}$ provided $\mathrm{c}_{2}$ is set equal to 0 . Doing so, this $\alpha$-function would loose one of its three adjustable parameters.

\section{- Conclusion:}

At this step, there is no need to pursue the study: it is obvious that the Mathias-Copeman $\alpha-$ function cannot pass the consistency test since the $\mathrm{C}^{2}$-class condition requires to annihilate coefficient $c_{2}$ and consequently to modify the $\alpha$-function expression.

In addition, it is remarkable that the Mathias-Copeman $\alpha$-function is similar to the Soave $72 \alpha$-function for $T_{r}>1$ except that the universal $m(\omega)$ parameter of the Soave function is replaced by an adjustable parameter $c_{1}$.

If, as often seen in practice, the parameter $c_{1}$ is set to $m(\omega)$, the Mathias-Copeman $\alpha$ function would loose a second adjustable parameter $\left(c_{1}\right)$. It would result that the MathiasCopeman $\alpha$-function would only contain one adjustable parameter $\left(c_{3}\right)$.

Furthermore, similarly to the Soave $72 \alpha$-function, the Mathias-Copeman $\alpha$-function exhibits an unphysical behavior at infinite temperature:

$$
\lim _{\mathrm{T}_{\mathrm{r}} \rightarrow+\infty} \alpha\left(\mathrm{T}_{\mathrm{r}}\right)=\lim _{\mathrm{T}_{\mathrm{r}} \rightarrow+\infty} \alpha_{\mathrm{SUP}}\left(\mathrm{T}_{\mathrm{r}}\right)=+\infty
$$




\section{Appendix J: mathematical study of the Boston-Mathias $\alpha$-function [19]}

The Boston-Mathias $\alpha$-function contains one universal parameter $\mathrm{m}(\omega)$ :

$$
\alpha\left(T_{r}\right)=\left\{\begin{array}{l}
\text { if } T_{r} \leq 1: \quad \alpha_{\text {SUB }}\left(T_{r}\right)=\alpha_{\text {SOAVE }}\left(T_{r}\right)=\left[1+m(\omega) \cdot\left(1-\sqrt{T_{r}}\right)\right]^{2} \\
\text { if } T_{r} 1: \quad \alpha_{S U P}\left(T_{r}\right)=\exp \left[L\left(1-T_{r}^{\gamma}\right)\right] \\
\text { with : } \quad L=\frac{m(\omega)}{\gamma} \text { and } \gamma=1+\frac{m(\omega)}{2}
\end{array}\right.
$$

The relations between parameters $\mathrm{L}, \gamma$ and $\mathrm{m}(\omega)$ were derived by Boston and Mathias assuming that

- The first derivatives of $\sqrt{\alpha_{\text {SUB }}}$ and $\sqrt{\alpha_{\text {SUP }}}$ are equal at the critical temperature,

- The second derivative of $\sqrt{\alpha_{\text {SUP }}}$ has to be equal to zero at the critical temperature.

A priori, these assumptions do not guaranty for the function to be of class $\mathrm{C}^{2}$ and more generally, to pass the proposed consistency test for $\alpha$-functions.

\section{- Is the $\alpha$-function of class $\mathbf{C}^{2}$ ?}

The first derivatives of the Boston-Mathias $\alpha$-function are:

$$
\frac{d \alpha}{\mathrm{dT}_{\mathrm{r}}}\left(\mathrm{T}_{\mathrm{r}}\right)= \begin{cases}\text { if } \mathrm{T}_{\mathrm{r}} \leq 1: & \frac{\mathrm{d} \alpha_{\mathrm{SUB}}}{\mathrm{dT}_{\mathrm{r}}}\left(\mathrm{T}_{\mathrm{r}}\right)=-\mathrm{m}(\omega) \sqrt{\frac{\alpha_{\mathrm{SUB}}\left(\mathrm{T}_{\mathrm{r}}\right)}{\mathrm{T}_{\mathrm{r}}}} \\ \text { if } \mathrm{T}_{\mathrm{r}}>1: & \frac{\mathrm{d} \alpha_{\mathrm{SUP}}}{\mathrm{dT}}\left(\mathrm{T}_{\mathrm{r}}\right)=-\mathrm{L} \gamma \mathrm{T}_{\mathrm{r}}^{\gamma-1} \alpha_{\mathrm{SUP}}\left(\mathrm{T}_{\mathrm{r}}\right)\end{cases}
$$

At $\mathrm{T}_{\mathrm{r}}=1$, one has:

$$
\left\{\begin{array}{l}
\frac{d \alpha_{S U B}}{d T_{r}}\left(T_{r}=1\right)=-m(\omega) \\
\frac{d \alpha_{S U P}}{d_{r}}\left(T_{r}=1\right)=-L \gamma=-\frac{m(\omega)}{\gamma} \gamma=-m(\omega)
\end{array}\right.
$$

This proves that the Boston-Mathias $\alpha$-function is at least of class $\mathrm{C}^{1}$.

The second derivatives of the Boston-Mathias $\alpha$-function are:

$$
\frac{\mathrm{d}^{2} \alpha}{\mathrm{dT}_{\mathrm{r}}^{2}}\left(\mathrm{~T}_{\mathrm{r}}\right)= \begin{cases}\text { if } \mathrm{T}_{\mathrm{r}} \leq 1: & \frac{\mathrm{d}^{2} \alpha_{\mathrm{SUB}}}{\mathrm{dT}_{\mathrm{r}}^{2}}\left(\mathrm{~T}_{\mathrm{r}}\right)=\frac{1}{2} \frac{\mathrm{m}(\omega)[\mathrm{m}(\omega)+1]}{\mathrm{T}_{\mathrm{r}}^{3 / 2}} \\ \text { if } \mathrm{T}_{\mathrm{r}}>1: & \frac{\mathrm{d}^{2} \alpha_{\mathrm{SUP}}}{\mathrm{dT}_{\mathrm{r}}^{2}}\left(\mathrm{~T}_{\mathrm{r}}\right)=\mathrm{L} \gamma \mathrm{T}_{\mathrm{r}}^{\gamma-2}\left[\mathrm{~L} \gamma \mathrm{T}_{\mathrm{r}}^{\gamma}-\gamma+1\right] \alpha_{\mathrm{SUP}}\left(\mathrm{T}_{\mathrm{r}}\right)\end{cases}
$$

At $\mathrm{T}_{\mathrm{r}}=1$, one has: 


$$
\left\{\begin{array}{l}
\frac{\mathrm{d}^{2} \alpha_{\mathrm{SUB}}}{\mathrm{dT}_{\mathrm{r}}^{2}}\left(\mathrm{~T}_{\mathrm{r}}=1\right)=\frac{\mathrm{m}(\omega)[\mathrm{m}(\omega)+1]}{2} \\
\frac{\mathrm{d}^{2} \alpha_{\mathrm{SUP}}}{\mathrm{dT}_{\mathrm{r}}^{2}}\left(\mathrm{~T}_{\mathrm{r}}=1\right)=\mathrm{L} \gamma[\mathrm{L} \gamma-\gamma+1]=\mathrm{m}(\omega)\left[\mathrm{m}(\omega)-1-\frac{\mathrm{m}(\omega)}{2}+1\right]=\frac{[\mathrm{m}(\omega)]^{2}}{2}
\end{array}\right.
$$

Since $\frac{\mathrm{d}^{2} \alpha_{\mathrm{SUB}}}{\mathrm{dT}_{\mathrm{r}}^{2}}\left(\mathrm{~T}_{\mathrm{r}}=1\right) \neq \frac{\mathrm{d}^{2} \alpha_{\mathrm{SUP}}}{\mathrm{dT}_{\mathrm{r}}^{2}}\left(\mathrm{~T}_{\mathrm{r}}=1\right)$, the Boston-Mathias $\alpha$-function is thus not of class $\mathrm{C}^{2}$

\section{- Conclusion:}

At this step, there is no need to pursue the study. Not being of class $C^{2}$, the Boston-Mathias $\alpha-$ function does not pass the proposed consistency test. 


\section{Appendix K: mathematical study of the Mathias $\alpha$-function [28]}

The Mathias $\alpha$-function contains one universal parameter $(m(\omega))$ and one (componentdependent) adjustable parameter (p).

$$
\alpha\left(\mathrm{T}_{\mathrm{r}}\right)= \begin{cases}\text { if } \mathrm{T}_{\mathrm{r}} \leq 1: & \alpha_{\mathrm{SUB}}\left(\mathrm{T}_{\mathrm{r}}\right)=\left[1+\mathrm{m}(\omega)\left(1-\sqrt{\mathrm{T}_{\mathrm{r}}}\right)-\mathrm{p}\left(1-\mathrm{T}_{\mathrm{r}}\right)\left(0.7-\mathrm{T}_{\mathrm{r}}\right)\right]^{2} \\ \text { if } \mathrm{T}_{\mathrm{r}}>1: & \alpha_{\mathrm{SUP}}\left(\mathrm{T}_{\mathrm{r}}\right)=\left[\exp \left[\mathrm{L}\left(1-\mathrm{T}_{\mathrm{r}}^{\gamma}\right)\right]\right]^{2} \\ \text { with : } \mathrm{L}=1+\frac{\mathrm{m}(\omega)}{2}+0.3 \mathrm{p} \quad \text { and } \quad \gamma=\frac{\mathrm{L}-1}{\mathrm{~L}}\end{cases}
$$

The expressions of parameters $\mathrm{L}$ and $\gamma$ were derived by Mathias by assuming that:

- The first derivatives of $\sqrt{\alpha_{\text {SUB }}}$ and $\sqrt{\alpha_{\text {SUP }}}$ are equal at the critical temperature,

- The second derivative of $\sqrt{\alpha_{\text {SUP }}}$ is equal to zero at the critical temperature.

A priori, these assumptions do not guaranty for the function to be of class $\mathrm{C}^{2}$ and more generally, to pass the proposed consistency test for $\alpha$-functions.

\section{- Is the $\alpha$-function of class $\mathbf{C}^{2}$ ?}

The first derivatives of the Mathias $\alpha$-function are:

$$
\frac{d \alpha}{d T_{r}}\left(T_{r}\right)= \begin{cases}\text { if } T_{r} \leq 1: & \frac{d \alpha_{S U B}}{d T_{r}}\left(T_{r}\right)=-2 \sqrt{\alpha_{S U B}\left(T_{r}\right)}\left[\frac{m(\omega)}{2 \sqrt{T_{r}}}+p\left(2 T_{r}-1.7\right)\right] \\ \text { if } T_{r}>1: & \frac{d \alpha_{S U P}}{d T_{r}}\left(T_{r}\right)=-2 L \gamma T_{r}^{\gamma-1} \alpha_{S U P}\left(T_{r}\right)\end{cases}
$$

At $\mathrm{T}_{\mathrm{r}}=1$ :

$$
\left\{\begin{array}{l}
\frac{\mathrm{d} \alpha_{\mathrm{SUB}}}{\mathrm{dT}_{\mathrm{r}}}\left(\mathrm{T}_{\mathrm{r}}=1\right)=-2\left[\frac{\mathrm{m}(\omega)}{2}+\mathrm{p}(1.7-2)\right]=-2\left[\frac{\mathrm{m}(\omega)}{2}+0.3 \mathrm{p}\right] \\
\frac{\mathrm{d} \alpha_{\mathrm{SUP}}}{\mathrm{dT}_{\mathrm{r}}}\left(\mathrm{T}_{\mathrm{r}}=1\right)=-2 \mathrm{~L} \gamma=-2\left[\frac{\mathrm{m}(\omega)}{2}+0.3 \mathrm{p}\right]
\end{array}\right.
$$

This proves that the Mathias $\alpha$-function is at least of class $C^{1}$.

The second derivatives of the Mathias $\alpha$-function are:

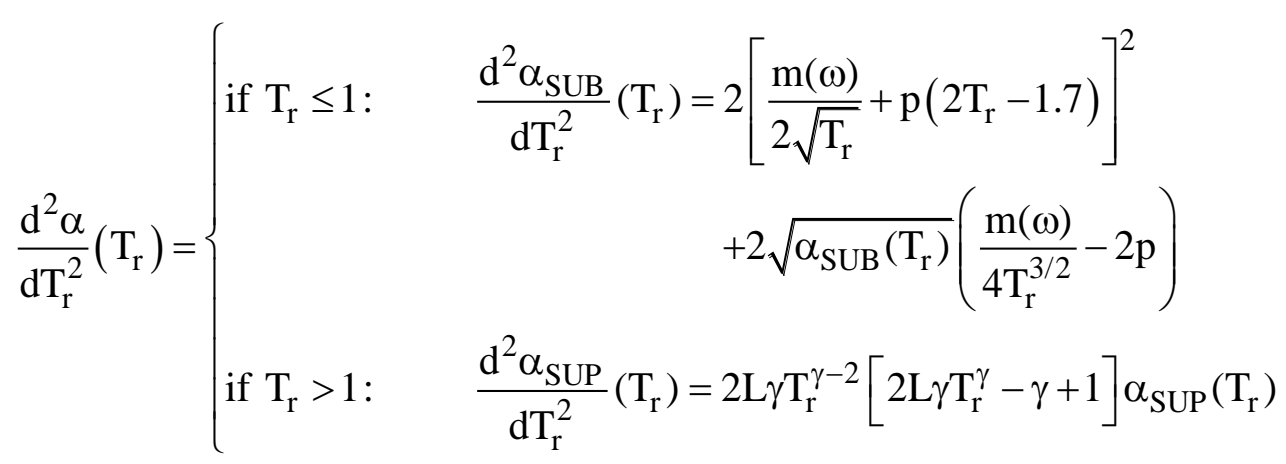


At $\mathrm{T}_{\mathrm{r}}=1$, one has:

$$
\left\{\begin{aligned}
\frac{\mathrm{d}^{2} \alpha_{\mathrm{SUB}}}{\mathrm{dT_{ \textrm {r } } ^ { 2 }}}\left(\mathrm{T}_{\mathrm{r}}=1\right) & =0.5 \mathrm{~m}^{2}+0.6 \mathrm{mp}++0.18 \mathrm{p}^{2}+0.5 \mathrm{~m}-4 \mathrm{p} \\
\frac{\mathrm{d}^{2} \alpha_{\mathrm{SUP}}}{\mathrm{dT}_{\mathrm{r}}^{2}}\left(\mathrm{~T}_{\mathrm{r}}=1\right) & =2 \mathrm{~L} \gamma[2 \mathrm{~L} \gamma-\gamma+1] \\
& =\frac{10 \mathrm{~m}^{2}+12 \mathrm{mp}+5 \mathrm{~m}^{3}+9 \mathrm{~m}^{2} \mathrm{p}+5.4 \mathrm{mp}^{2}+10 \mathrm{~m}+3.6 \mathrm{p}^{2}+1.08 \mathrm{p}^{3}+6 \mathrm{p}}{10+5 \mathrm{~m}+3 \mathrm{p}}
\end{aligned}\right.
$$

Since $\frac{\mathrm{d}^{2} \alpha_{\mathrm{SUB}}}{\mathrm{dT}_{\mathrm{r}}^{2}}\left(\mathrm{~T}_{\mathrm{r}}=1\right) \neq \frac{\mathrm{d}^{2} \alpha_{\mathrm{SUP}}}{\mathrm{dT}_{\mathrm{r}}^{2}}\left(\mathrm{~T}_{\mathrm{r}}=1\right)$, the Boston-Mathias $\alpha$-function is thus not of class $\mathrm{C}^{2}$.

\section{- Conclusion:}

At this step, there is no need to pursue the study. Not being of class $\mathrm{C}^{2}$, the Mathias $\alpha$-function does not pass the proposed consistency test. 


\section{Appendix L: mathematical study of the Gibbons and Laughton $\alpha$-function [25]}

The $\alpha$-function involved two adjustable parameters denoted $\mathrm{X}$ and $\mathrm{Y}$ :

$$
\alpha\left(\mathrm{T}_{\mathrm{r}}\right)=1+\mathrm{X}\left(\mathrm{T}_{\mathrm{r}}-1\right)+\mathrm{Y}\left(\sqrt{\mathrm{T}_{\mathrm{r}}}-1\right)
$$

- Is the $\alpha$-function of class $\mathbf{C}^{2}$ ? Yes.

- Is the $\alpha$-function always positive?

Eq.(L.1) can be alternatively written :

$$
\alpha\left(T_{r}\right)=X\left(\sqrt{T_{r}}\right)^{2}+Y \sqrt{T_{r}}+(1-X-Y)
$$

Which is a second-order polynomial of the square root of the reduced temperature. Therefore, this polynomial is positive if [41]

$$
\left\{\begin{array}{l}
X \geq 0 \\
Y \leq 1-X \\
Y \geq-2 \sqrt{X(1-X-Y)}
\end{array}\right.
$$

As will be shown below, the parameter $\mathrm{Y}$ is necessarily negative to ensure that the $\alpha$-function is decreasing at low temperature. The third inequality of Eq. (L.3) can be squared, both sides of the equation being negative, in order to solve this inequality with respect to Y. The resolution of the inequality provides the following existence interval for parameter $\mathrm{Y}$

$$
-2 \mathrm{X}-2 \sqrt{\mathrm{X}} \leq \mathrm{Y} \leq-2 \mathrm{X}+2 \sqrt{\mathrm{X}}
$$

One can demonstrate that $-2 X+2 \sqrt{X} \leq 1-X$. Therefore, positivity condition of the $\alpha$-function is, reminding that $\mathrm{Y}$ has to be negative:

$$
\left\{\begin{array}{l}
X \geq 0 \\
-2 X-2 \sqrt{X} \leq Y \leq \min (0 ;-2 X+2 \sqrt{X})
\end{array}\right.
$$

\section{- Is the first derivative of the $\alpha$-function always negative?}

The first derivative of the Gibbons and Laughton $\alpha$-function is:

$$
\frac{\mathrm{d} \alpha}{\mathrm{dT}_{\mathrm{r}}}\left(\mathrm{T}_{\mathrm{r}}\right)=\mathrm{X}+\frac{\mathrm{Y}}{2 \sqrt{\mathrm{T}_{\mathrm{r}}}}
$$

When $\mathrm{T}_{\mathrm{r}}$ tends to 0 , the limit of Eq.(L.6) is:

$$
\lim _{T_{r} \rightarrow 0} \frac{d \alpha}{d T_{r}}\left(T_{r}\right)= \begin{cases}-\infty & \text { if } Y<0 \\ +\infty & \text { if } Y>0\end{cases}
$$

Therefore, Y has to be negative

When $\mathrm{T}_{\mathrm{r}}$ tends to $+\infty$, the limit of Eq.(L.6) is: 


$$
\lim _{\mathrm{T}_{\mathrm{r}} \rightarrow+\infty} \frac{\mathrm{d} \alpha}{\mathrm{dT}_{\mathrm{r}}}\left(\mathrm{T}_{\mathrm{r}}\right)=\mathrm{X}
$$

Therefore, $\mathrm{X}$ has to be negative. This condition is contradictory with condition (L.3). The reason of this contradiction is that the Gibbons and Laughton $\alpha$-function exhibits a minimum when $\left\{\begin{array}{l}X \geq 0 \\ Y \leq 0\end{array}\right.$ (this behavior is similar to the one of the Soave $72 \alpha$-function). As a conclusion, the Gibbons and Laughton $\alpha$-function can only be decreasing on a limited temperature range $\left[0 ; \mathrm{T}_{\mathrm{r}, \mathrm{min}}\right]$. As illustrated in Figure L.1, the minimum of the $\alpha$-function is found at

$$
\sqrt{T_{r, \min }}=\frac{-Y}{2 X}
$$

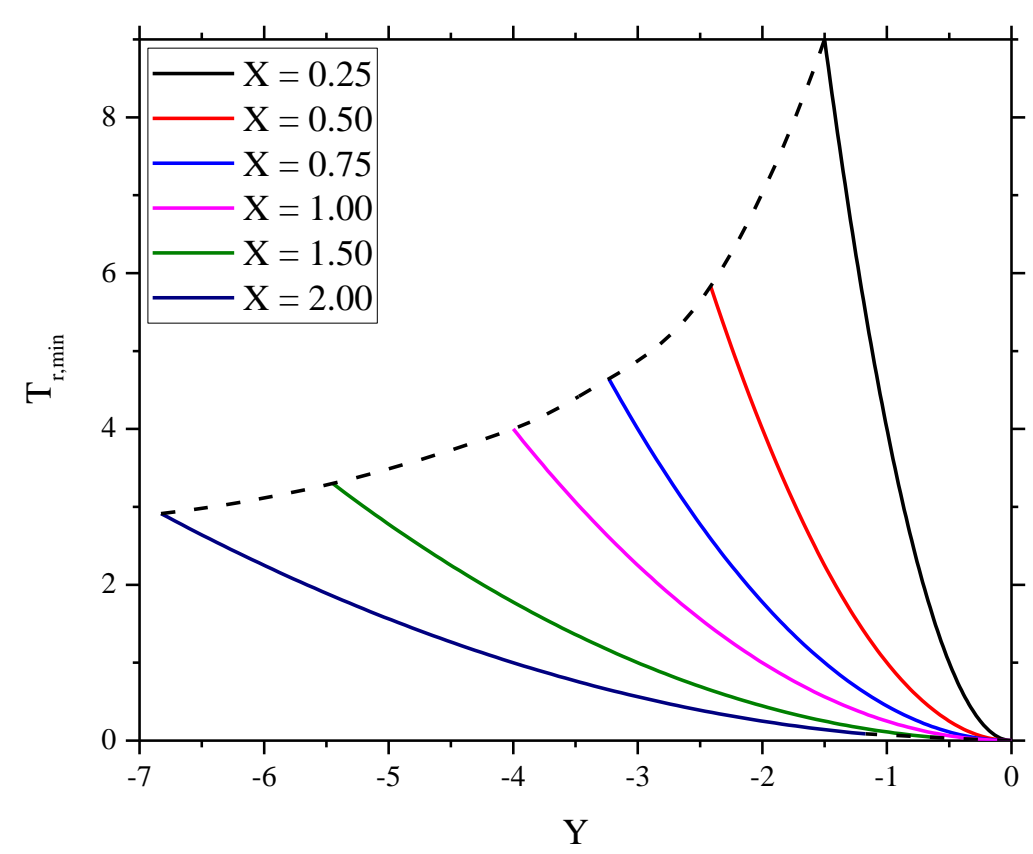

Figure L.1. Changes of $T_{r}$,min with respect to the change of $Y$ for different values of $X$.

Note that the value of the $\alpha$-function at $T_{r, m i n}$ is not equal to zero.

$$
\alpha\left(\mathrm{T}_{\mathrm{r}, \min }\right)=\frac{-\mathrm{Y}^{2}}{4 \mathrm{X}}+1-\mathrm{X}-\mathrm{Y}
$$

- Is the second derivative of the $\alpha$-function always positive?

The second derivative of the Gibbons and Laughton $\alpha$-function is:

$$
\frac{\mathrm{d}^{2} \alpha}{\mathrm{dT}_{\mathrm{r}}^{2}}\left(\mathrm{~T}_{\mathrm{r}}\right)=-\frac{1}{4} \frac{\mathrm{Y}}{\mathrm{T}_{\mathrm{r}}^{3 / 2}}
$$


As a consequence, $\frac{\mathrm{d}^{2} \alpha}{\mathrm{dT}_{\mathrm{r}}^{2}}\left(\mathrm{~T}_{\mathrm{r}}\right)$ is positive provided $\mathrm{Y}$ is negative.

- Is the third derivative of the $\alpha$-function always negative?

The third derivative of the Gibbons and Laughton $\alpha$-function is:

$$
\frac{\mathrm{d}^{3} \alpha}{\mathrm{dT}_{\mathrm{r}}^{3}}\left(\mathrm{~T}_{\mathrm{r}}\right)=\frac{3}{8} \frac{\mathrm{Y}}{\mathrm{T}_{\mathrm{r}}^{5 / 2}}
$$

As a consequence, $\frac{\mathrm{d}^{3} \alpha}{\mathrm{dT}_{\mathrm{r}}^{3}}\left(\mathrm{~T}_{\mathrm{r}}\right)$ is negative provided $\mathrm{Y}$ is negative.

- Conclusion:

The Gibbons and Laughton $\alpha$-function behaves as a consistent $\alpha$-function, up to a certain reduced temperature $\mathrm{T}_{\mathrm{r}, \mathrm{min}}$ defined by Eq.(L.9) if

$$
\left\{\begin{array}{l}
X \geq 0 \\
-2 X-2 \sqrt{X} \leq Y \leq \min (0 ;-2 X+2 \sqrt{X})
\end{array}\right.
$$




\section{Bibliography}

[1] J.O. Valderrama, The State of the Cubic Equations of State, Ind. Eng. Chem. Res. 42 (2003) 1603-1618. doi:10.1021/ie020447b.

[2] G.M. Kontogeorgis, E.C. Voutsas, I.V. Yakoumis, D.P. Tassios, An equation of state for associating fluids, Ind. Eng. Chem. Res. 35 (1996) 4310-4318.

[3] G. Soave, Equilibrium constants from a modified Redlich-Kwong equation of state, Chem. Eng. Sci. 27 (1972) 1197-1203.

[4] M.S. Wertheim, Fluids with highly directional attractive forces. I. Statistical thermodynamics, J. Stat. Phys. 35 (1984) 19-34.

[5] J.D. Van der Waals, Over de continuiteit van den gas- en vloeistoftoestand, 1873.

[6] J.V. Sengers, R.F. Kayser, C.J. Peters, H.J. White, Equations of state for fluids and fluid mixtures, 1st ed, Elsevier, Amsterdam ; New York, 2000.

[7] R. Clausius, Über das Verhalten der Kohlensäure in Bezug auf Druck, Volumen und Temperatur, Ann. Phys. 245 (1880) 337-357.

[8] O. Redlich, J.N.S. Kwong, On the thermodynamics of solutions; an equation of state; fugacities of gaseous solutions, Chem. Rev. 44 (1949) 233-244.

[9] V. Kalikhman, D. Kost, I. Polishuk, About the physical validity of attaching the repulsive terms of analytical EOS models by temperature dependencies, Fluid Phase Equilibria. 293 (2010) 164-167. doi:10.1016/j.fluid.2010.03.003.

[10] P.M. Mathias, T.W. Copeman, Extension of the Peng-Robinson equation of state to complex mixtures: Evaluation of the various forms of the local composition concept, Fluid Phase Equilibria. 13 (1983) 91-108. doi:10.1016/0378-3812(83)80084-3.

[11] R. Stryjek, J.H. Vera, PRSV: An improved Peng-Robinson equation of state for pure compounds and mixtures, Can. J. Chem. Eng. 64 (1986) 323-333. doi:10.1002/cjce.5450640224.

[12] B.E. Poling, J.M. Prausnitz, J.P. O'Connell, The properties of gases and liquids, McGrawHill, New York, 2001. http://accessengineeringlibrary.com/browse/properties-of-gasesand-liquids-fifth-edition (accessed July 22, 2015).

[13] G. Heyen, A cubic equation of state with extended range of application, in: Chem. Eng. Thermodyn., SA Newman, 1981.

[14] C.H. Twu, A Modified Redlich-Kwong Equation of State for Highly Polar, supercritical Systems, in: Proc. Int. Symp. Thermodyn. Chem. Eng. Ind., 1988: p. 148. 
[15] C.H. Twu, D. Bluck, J.R. Cunningham, J.E. Coon, A cubic equation of state with a new alpha function and a new mixing rule, Fluid Phase Equilibria. 69 (1991) 33-50. doi:10.1016/0378-3812(91)90024-2.

[16] C.H. Twu, J.E. Coon, J.R. Cunningham, A new generalized alpha function for a cubic equation of state Part 1. Peng-Robinson equation, Fluid Phase Equilibria. 105 (1995) 4959. doi:10.1016/0378-3812(94)02601-V.

[17] C.H. Twu, J.E. Coon, J.R. Cunningham, A new generalized alpha function for a cubic equation of state Part 2. Redlich-Kwong equation, Fluid Phase Equilibria. 105 (1995) 6169. doi:10.1016/0378-3812(94)02602-W.

[18] C. Coquelet, A. Chapoy, D. Richon, Development of a new alpha function for the PengRobinson equation of state: comparative study of alpha function models for pure gases (natural gas components) and water-gas systems, Int. J. Thermophys. 25 (2004) 133-158. doi:10.1023/B:IJOT.0000022331.46865.2f.

[19] J.F. Boston, P.M. Mathias, Phase equilibria in a third-generation process simulator, in: Proc. 2nd Int. Conf. Phase Equilibria Fluid Prop. Chem. Process Ind., West Berlin, 1980: pp. 17-21.

[20] E. Neau, O. Hernández-Garduza, J. Escandell, C. Nicolas, I. Raspo, The Soave, Twu and Boston-Mathias alpha functions in cubic equations of state, Fluid Phase Equilibria. 276 (2009) 87-93. doi:10.1016/j.fluid.2008.09.023.

[21] E. Neau, I. Raspo, J. Escandell, C. Nicolas, O. Hernández-Garduza, The Soave, Twu and Boston-Mathias alpha functions in cubic equations of state. Part II. Modeling of thermodynamic properties of pure compounds, Fluid Phase Equilibria. 276 (2009) 156164. doi:10.1016/j.fluid.2008.10.010.

[22] P. Mahmoodi, M. Sedigh, Soave alpha function at supercritical temperatures, J. Supercrit. Fluids. (2016). doi:10.1016/j.supflu.2016.01.004.

[23] P. Mahmoodi, M. Sedigh, Second derivative of alpha functions in cubic equations of state, J. Supercrit. Fluids. (2016). doi:10.1016/j.supflu.2016.05.012.

[24] G. Soave, Improvement of the Van Der Waals equation of state, Chem. Eng. Sci. 39 (1984) 357-369. doi:10.1016/0009-2509(84)80034-2.

[25] R.M. Gibbons, A.P. Laughton, An equation of state for polar and non-polar substances and mixtures, J. Chem. Soc. Faraday Trans. 2. $80 \quad$ (1984) 1019. doi:10.1039/f29848001019.

[26] M.A. Trebble, P.R. Bishnoi, Development of a new four-parameter cubic equation of state, Fluid Phase Equilibria. 35 (1987) 1-18. doi:10.1016/0378-3812(87)80001-8. 
[27] G.A. Melhem, R. Saini, B.M. Goodwin, A modified Peng-Robinson equation of state, Fluid Phase Equilibria. 47 (1989) 189-237. doi:10.1016/0378-3812(89)80176-1.

[28] P.M. Mathias, A versatile phase equilibrium equation of state, Ind. Eng. Chem. Process Des. Dev. 22 (1983) 385-391. doi:10.1021/i200022a008.

[29] J.L. Daridon, B. Lagourette, H. Saint-Guirons, P. Xans, A cubic equation of state model for phase equilibrium calculation of alkane + carbon dioxide + water using a group contribution kij, Fluid Phase Equilibria. 91 (1993) 31-54. doi:10.1016/03783812(93)85077-Y.

[30] U.K. Deiters, Comments on the modeling of hydrogen and hydrogen-containing mixtures with cubic equations of state, Fluid Phase Equilibria. 352 (2013) 93-96. doi:10.1016/j.fluid.2013.05.032.

[31] C. Colina, J. Santos, C. Olivera-Fuentes, High-temperature behaviour of the cohesion parameter of cubic equations of state, High Temp.-High Press. 29 (1997) 525-532. doi:10.1068/htec462.

[32] M.M. Abbott, J.M. Prausnitz, Generalized van der waals theory: a classical perspective, Fluid Phase Equilibria. 37 (1987) 29-62. doi:10.1016/0378-3812(87)80042-0.

[33] S.I. Sandler, The generalized van der Waals partition function as a basis for excess free energy models, J. Supercrit. Fluids. 55 (2010) 496-502. doi:10.1016/j.supflu.2010.10.014.

[34] R. Privat, J.-N. Jaubert, Classification of global fluid-phase equilibrium behaviours in binary systems, Chem. Eng. Res. Des. 91 (2013) 1807-1839. doi:10.1016/j.cherd.2013.06.026.

[35] S. Lasala, P. Chiesa, R. Privat, J.-N. Jaubert, VLE properties of CO2 - Based binary systems containing N2, O2 and Ar: Experimental measurements and modelling results with advanced cubic equations of state, Fluid Phase Equilibria. (2016). doi:10.1016/j.fluid.2016.05.015.

[36] M.-J. Huron, J. Vidal, New mixing rules in simple equations of state for representing vapour-liquid equilibria of strongly non-ideal mixtures, Fluid Phase Equilibria. 3 (1979) 255-271. doi:10.1016/0378-3812(79)80001-1.

[37] G.M. Wilson, Vapor-Liquid Equilibrium. XI. A New Expression for the Excess Free Energy of Mixing, J. Am. Chem. Soc. 86 (1964) 127-130. doi:10.1021/ja01056a002.

[38] R. Span, W. Wagner, A New Equation of State for Carbon Dioxide Covering the Fluid Region from the Triple-Point Temperature to $1100 \mathrm{~K}$ at Pressures up to $800 \mathrm{MPa}$, J. Phys. Chem. Ref. Data. 25 (1996) 1509. doi:10.1063/1.555991. 
[39] C. Tegeler, R. Span, W. Wagner, A New Equation of State for Argon Covering the Fluid Region for Temperatures From the Melting Line to $700 \mathrm{~K}$ at Pressures up to $1000 \mathrm{MPa}$, Phys. Chem. Ref. Data. 28 (1999) 779. doi:10.1063/1.556037.

[40] Y. Chen, F. Mutelet, J.-N. Jaubert, Modeling the Solubility of Carbon Dioxide in Imidazolium-Based Ionic Liquids with the PC-SAFT Equation of State, J. Phys. Chem. B. 116 (2012) 14375-14388. doi:10.1021/jp309944t.

[41] J.W. Schmidt, W. Heß, Positivity of cubic polynomials on intervals and positive spline interpolation, BIT. 28 (1988) 340-352. doi:10.1007/BF01934097.

[42] J.-N. Jaubert, F. Mutelet, VLE predictions with the Peng-Robinson equation of state and temperature dependent kij calculated through a group contribution method, Fluid Phase Equilibria. 224 (2004) 285-304. doi:10.1016/j.fluid.2004.06.059.

[43] S. Vitu, R. Privat, J.-N. Jaubert, F. Mutelet, Predicting the phase equilibria of CO2+hydrocarbon systems with the PPR78 model (PR EOS and kij calculated through a group contribution method), J. Supercrit. Fluids. 45 (2008) 1-26. doi:10.1016/j.supflu.2007.11.015.

[44] J.-N. Jaubert, R. Privat, F. Mutelet, Predicting the phase equilibria of synthetic petroleum fluids with the PPR78 approach, AIChE J. 56 (2010) 3225-3235. doi:10.1002/aic.12232.

[45] J.-N. Jaubert, R. Privat, Relationship between the binary interaction parameters (kij) of the Peng-Robinson and those of the Soave-Redlich-Kwong equations of state: Application to the definition of the PR2SRK model, Fluid Phase Equilibria. 295 (2010) 26-37. doi:10.1016/j.fluid.2010.03.037. 